\title{
Cazadores de las punas de Junín y Cerro de Pasco, Perú
}

Luis Hurtado de Mendoza ${ }^{1}$

\section{Introducción}

Las punas de la Sierra Central de Perú aparecen a los ojos del viajero como una región hostil y poco adecuada para la vida. Ubicadas en una zona altitudinal extrema, entre 3800 y $4600 \mathrm{~m}$, se caracterizan por una eficiencia térmica muy baja, inadecuada para la formación de suelos, por lo que su flora casi se limita a un sistema de pastizal propio de ecosistemas clasificables como "páramo húmedo" o "páramo muy húmedo" (Holdridge 1947; Tosi 1960).

Desde la invasión europea que introdujo una serie de modificaciones en la distribución y tipos de fauna, la Puna sostiene una variedad bastante monótona de especies animales indígenas que incluye cérvidos, camélidos andinos, algunos roedores, aves, un tipo peculiar de rana y algunos otros mamíferos pequeños.

A pesar de un escenario aparentemente magro, las punas han mostrado evidencias de una ocupación humana muy prolongada, continua y relativamente densa en tiempos prehistóricos. Fechas de radiocarbón obtenidas de sitios arqueológicos indican que grupos humanos dedicados a un modo de vida basado en la caza y recolección habitaron las cuevas de Lauricocha desde 7500 AC (Cardich 1960) y cuevas al suroeste del lago Junín desde el 9850 AC (Rick 1977). Al parecer, estos sitios no disminuyeron en su importancia hasta el advenimiento del pastoralismo y la agricultura, como actividades económicas predominantes, durante el Formativo Medio, entre 1000 y 500 años AC.

La densidad ocupacional de las punas, en tiempos precerámicos, parece estar comprobada objetivamente. En la región de Junín y Cerro de Pasco se han registrado 70 sitios, los que incluyen más de

1 Informe sobre trabajos arqueológicos realizados en la Sierra Central de Perú, presentado al Departamento de Antropología de Smithsonian Institution, Washington D.C. en marzo de 1980.
200 cuevas, abrigos rocosos y localidades abiertas (Hurtado de Mendoza 1977). En cinco regiones más al sur, incluyendo las punas al oeste de Huancayo, se han registrado otras 189 cuevas y abrigos rocosos, y unos 50 sitios abiertos, cuyo reconocimiento superficial ha provisto indicios muy claros de ocupaciones precerámicas (Hurtado de Mendoza 1979a).

Esta abundancia de sitios precerámicos adquiere dimensiones significativas cuando se tiene en cuenta la escasez de sitios comparables en los valles interandinos de la Sierra Central, donde se acumulan las poblaciones humanas actuales. Con la sola excepción registrada del valle seco de Ayacucho (McNeish et al. 1970), esta aparente incongruencia, unida a la aparente pobreza de recursos de la Puna, ha atraído la atención de diversos especialistas durante la última década, de manera que la información arqueológica, etnográfica y medioambiental se está incrementando muy rápidamente.

Mi interés particular en la arqueología del Precerámico, en las punas andinas, se inició cuando aún era estudiante en la Universidad del Centro del Perú, Huancayo. Entonces se reportaron los resultados de una exploración en Palcamayo, Junín (Hurtado de Mendoza y Ramírez 1971). Entre la serie de sitios que fueron registrados se incluyó la cueva de Cuchimachay, cerca del pueblo de San Pedro de Cajas. El material cultural que se recolectó de su superficie mostraba características que se habían establecido como propias de los complejos Lauricocha I y II, en Huánuco (Cardich 1964), y Puente, Jaywa y Piki, en Ayacucho (McNeish 1969).

Si bien las apreciaciones morfológicas del material lítico de Cuchimachay proveían un criterio comparativo que parecía ayudar en la tarea de establecer fechas relativas de ocupación del sitio y sus relaciones culturales con otras regiones de los Andes Centrales, sin embargo, no era mucho más lo que se podía inferir de estos datos. Preocupado por la necesidad de obtener información detallada sobre los modos de vida de los habitantes de las punas, 
durante el Precerámico, reinicié en 1975 y 1976 mis exploraciones en Junín y Cerro de Pasco.

La intención básica de este trabajo fue la de realizar un extenso registro de sitios con evidencias de ocupación precerámica, como etapa preliminar de un proyecto de investigación a largo plazo, tendiente a conseguir información sobre diversos aspectos del proceso de desarrollo sociocultural, a nivel de sistema regional.

Una tarea de estas dimensiones no podía ser cumplida a base de excavaciones de prueba en un número limitado de sitios aislados, escogidos con criterios subjetivos. Lo más adecuado pareció ser una selección de éstos, previo apercibimiento de los patrones regionales de asentamiento, configuraciones culturales y consideraciones medioambientales que debía ser posible detectar. Por ejemplo, podía intuirse que los patrones de selección y uso de cuevas y abrigos rocosos en el pasado debían responder a algún conjunto de criterios discriminatorios, de parte de los grupos humanos, puesto que resultaba observable que en áreas reducidas, donde se agrupaban varios abrigos rocosos, no todos fueron ocupados. Similarmente, en áreas más extensas, se repetía la tendencia ocupacional discriminatoria de sitios disponibles.

Por lo tanto, se impuso la tarea de identificar los factores culturales y medioambientales que podrían haber condicionado la selección de sitios en el pasado. La altitud, la exposición a vientos e insolación, la disponibilidad de agua y la distribución de pastos se incluyeron en una lista preliminar a ser tenida en cuenta durante el progreso de las investigaciones.

La necesidad de realizar una selección de sitios representativos para su eventual excavación fue confrontada con una estrategia de investigación tendiente a generar una caracterización objetiva de sitios registrados. Esta tarea fue cumplida, teniendo dos aspectos de las colecciones de material lítico cultural recolectado en la superficie de los sitios. En primer lugar, se consideró que las características funcionales de cada sitio podían ser deducibles de la observación cuantitativa de los tipos de artefactos líticos que se habían recuperado. En segundo lugar, se consideró posible obtener indicios de interacción y/o asociación entre sitios, observando la popularidad relativa de ciertos tipos de piedra utilizados como materia prima en la manufactura de artefactos.
Cuando se cruzaron estos dos aspectos caracterizadores de sitios, se pudo construir una tipología regional (Hurtado de Mendoza 1977) que sirvió de base, junto con las otras consideraciones mencionadas, para obtener una muestra estratificada de sitios representativos de los patrones de asentamiento en las punas de Junín y Cerro de Pasco, en tiempos precerámicos.

Hasta 1980 se han realizado excavaciones de prueba en dos de los sitios seleccionados mediante el procedimiento descrito: Piedras Gordas, al norte del lago de Junín, y Vizcas, al sur de Marcapomacocha. En esta ocasión se reportan los resultados de las exploraciones regionales y algunos datos sobre el proceso ocupacional del abrigo PG-1 de Piedras Gordas.

\section{Las punas de Junín y Cerro de Pasco}

La región en estudio está localizada en el altiplano de la Sierra Central de Perú, inmediatamente al sur de la ciudad de Cerro de Pasco. Se extiende por el sur, flanqueada por dos cadenas de la cordillera andina, y cortada longitudinalmente por el naciente río Mantaro. La gran planicie que forma esta fisiografía tiene en su centro el lago de Junín (Figura 1). En líneas generales, la región corresponde a lo que Matos Mendieta (1976) denomina "Región Mantaro Puna", ubicada entre 3800 y $4600 \mathrm{~m}$ de altitud. El límite sur de la región puede ser ubicado cerca de la ciudad de La Oroya.

En la actualidad la región es dedicada a dos tipos principales de actividad económica: la minería y el pastoreo. La población humana está distribuida en pequeñas ciudades, campamentos mineros, pueblos, aldeas y estancias. Las necesidades generadas por estas actividades han determinado la apertura de un número apreciable de carreteras y caminos secundarios que facilitan el acceso con vehículos a la mayor parte del área de investigación.

Geológicamente, la región ha sido descrita ampliamente por especialistas, debido principalmente a intereses de explotación minera. La columna geológica se remonta al Silúrico según McLaughlin (1924), pero más recientemente se han ubicado formaciones de posible origen Precámbrico (Jenks 1961). Sin embargo, la planicie central y los sistemas de colinas que la flanquean están formados predominantemente de calizas y areniscas del Triásico y el Jurásico, las que constituyen el denominado Grupo Pucara 


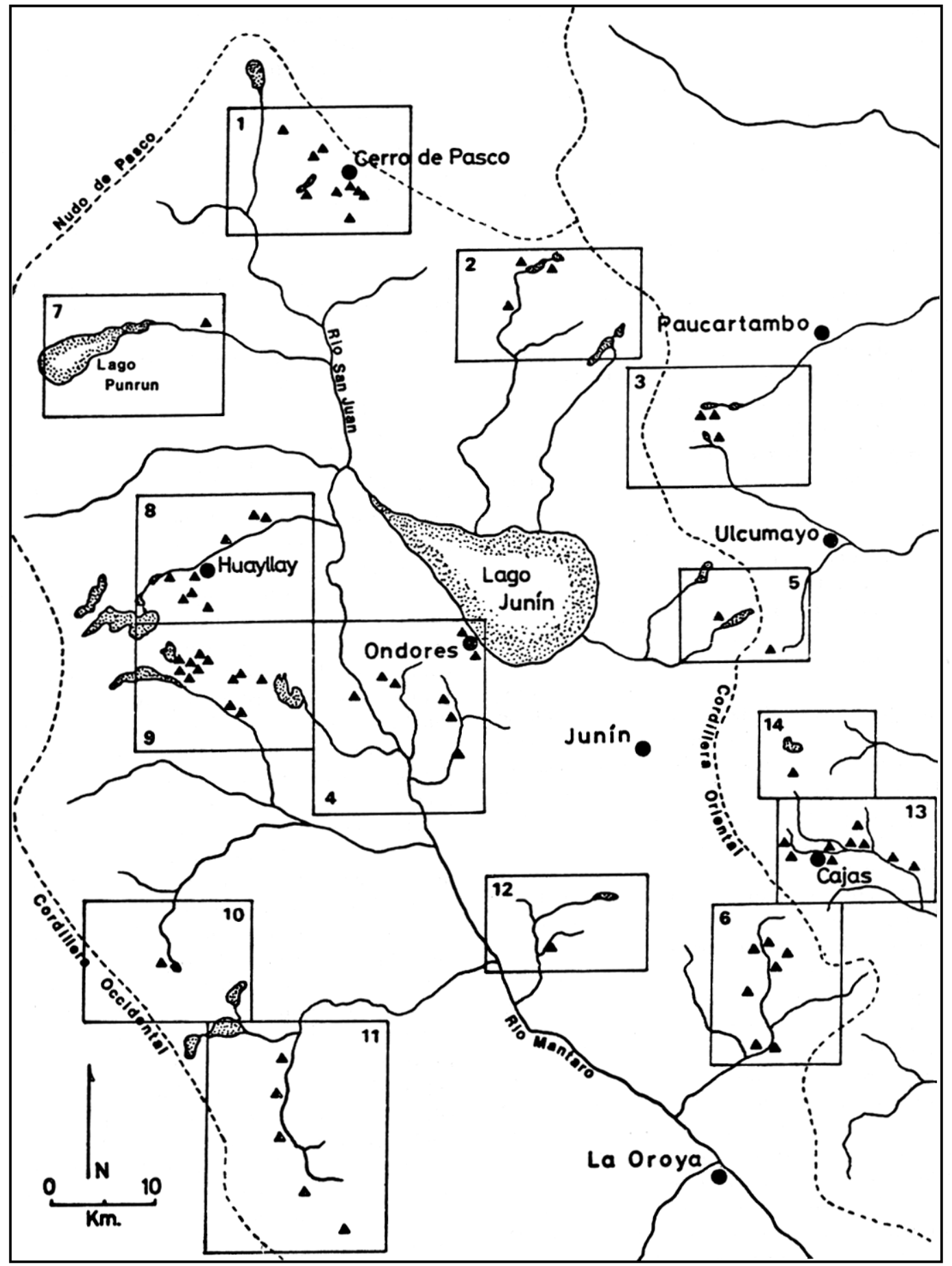

Figura 1. La región de Junín y Cerro de Pasco. Los cuadrángulos numerados 1 a 12 delimitan las subregiones definidas en la exploración. Las líneas discontinuas marcan las principales cadenas de picos. En el caso de la cordillera Occidental, ésta es, a la vez, la divisoria continental de aguas. Los círculos negros representan poblaciones importantes modernas, mientras los triángulos negros indican la presencia de sitios arqueológicos con evidencia de ocupación precerámica. 
(Harrison 1944; Mégard 1968; Szekely y Grose 1972). Sedimentos y morrenas más recientes, del Cuaternario, llenan extensamente los valles, dándole a la región su peculiar aspecto de "pampa".

El extremo norte de la región acusa presencia de grandes mantos de un conglomerado denominado shuco, cuya matriz es una caliza rojiza. Aun cuando el origen de esta formación corresponde al Terciario, su mayor componente es un conglomerado muy metamorfoseado de origen Pérmico. Al oeste y noroeste del lago Junín, y dispuesta longitudinalmente de norte a sur, se observa una extensa exposición de tufo dacítico, cuya silicificación parcial en fisuras ha provocado una forma peculiar de erosión que ha dejado formas columnares y figuras caprichosas a lo largo de unos $25 \mathrm{~km}$ hacia el sur, pasando por el pueblo de Huayllay. Esta zona, conocida como el "bosque de piedra", posee numerosos abrigos rocosos, muchos de los cuales fueron ocupados en tiempos precerámicos, según lo evidencian restos líticos y pictografías.

Las exposiciones de tufo del "bosque de piedra" se apoyan confortablemente sobre mantos rojos de fines del Terciario (McLaughlin 1924), haciendo posible ubicarlas en la transición al Cuaternario, cuando se habría producido alguna actividad volcánica en la región (Jenks 1961), que produjo un gran levantamiento que marcó el inicio del Pleistoceno.

Ni el conglomerado shuco ni el tufo dacítico parecen haber provisto materia prima para la elaboración de artefactos líticos en el pasado. En cambio, las calizas del Grupo Pucara deben haber sido una fuente potencial, puesto que contienen concreciones silícicas de diversos tipos, predominando los horstenos (chert) que son los más populares en ensamblajes culturales de la región. Los lechos de las corrientes fluviales también poseen una relativa abundancia de materia prima, pero los guijarros de silicatos microcristalinos que se suelen encontrar son generalmente de tamaño reducido, inadecuados para el proceso "normal" de reducción propio de la elaboración de bifaces. Sin embargo, estos guijarros de calcedonias de calidad bastante pobre fueron utilizados en la producción de utensilios no muy sofisticados. De otro lado, parece factible la posibilidad de que algunos tipos de materia prima fueran introducidos desde fuera de la región, como veremos más adelante.

Ecológicamente, la Puna es un ecosistema que sólo muy recientemente está empezando a ser conocido.
Las bajas temperaturas reinantes, con promedios anuales de $5-7^{\circ} \mathrm{C}$, a altitudes de $3950 \mathrm{~m}$, y de $3-4^{\circ} \mathrm{C}$, a $4500 \mathrm{~m}$, deben contarse entre los factores que determinan su deficiente productividad primaria de energía. A una altitud de $4000 \mathrm{~m}$ se suelen registrar unos 240 días del año con temperaturas iguales o menores de $0^{\circ} \mathrm{C}$, lo que debe ilustrar una de las condiciones que impiden la descomposición de materia orgánica, y con ello la constitución de suelos adecuados para el desarrollo de plantas que no sean pastos forrajeros de consumo animal.

La agricultura es casi inexistente, y limitada a pisos ubicados por debajo de los $4000 \mathrm{~m}$, donde se siembran algunos tubérculos, siguiendo regímenes de rotación de campos con ciclos de 5-6 años.

A pesar de la impresión inicial de que se trata de una región homogénea en sus características ecológicas, la Puna acusa variaciones importantes. Sus límites superiores, cercanos a la línea de glaciares, poseen características más clasificables como tundra antes que páramo. Su humedad es una consecuencia no de la precipitación pluvial (menor que $1000 \mathrm{cc}$ por año), sino más bien del bajo índice de evapotranspiración provocado por las bajas temperaturas y la alta incidencia de nubosidad parcial o total. No más de 100 días por año suelen ser completamente claros, caracterizándose el resto por cubiertas parciales o totales de nubes, por lo menos durante un medio día. El exceso de humedad suele depositarse en depresiones con drenaje ineficiente, produciendo áreas pantanosas y semipantanosas que los lugareños llaman occonales, alrededor de los cuales se concentran los animales de pastoreo durante los meses de invierno, cuando el pajonal de pisos inferiores tiende a secarse.

La cubierta vegetal tampoco es homogénea en su distribución, ni difiere únicamente en su tamaño y frecuencia, de acuerdo a la humedad relativa, como sugiere Custred (1977: 62). Esto suele ser correcto si comparamos solamente las comunidades de plantas del pajonal y del occonal, donde prevalecen los pastos conocidos como ichu (Festuca sp., Stipa sp., Poa; Calamagrostis sp., etc.), pero la Puna posee extensas áreas donde progresan otras especies.

Estas otras formaciones vegetales son: la champa, de pastos muy densos y almohadillados o muy pegados al suelo; el garbanzal de arbustos, principalmente Astragalus, y el queñual, compuesto por árboles, como Polylepis sp. A pesar de su relativa escasez 
y dispersión (Tosi 1960: 135), estas áreas deben tenerse en cuenta en estudios sobre la capacidad de sostenimiento del ecosistema Puna, puesto que su utilidad, en términos de producción primaria de energía, no está tan relacionada con la alimentación de animales forrajeros, sino más bien con su uso directo por el hombre.

La champa, extraída del suelo con todo y raíces y puesta a secar en bloques, es un combustible doméstico muy eficiente. El garbanzal, propio de terrenos pedregosos, es considerado localmente como inadecuado y hasta dañino para los animales, pero suele también proporcionar combustible. Los queñuales, ubicados en áreas protegidas, de buena irrigación, en vallecillos formados por riachuelos en pisos intermedios e inferiores de la Puna, proporcionan madera para construcción y combustible. De otro lado, cuando los queñuales son más o menos planos y extensos, es posible su uso para el cultivo de tubérculos adaptados a la altura.

Desde tiempos coloniales, la fauna domesticada más común en la región está compuesta por especies introducidas desde el Viejo Mundo: ovinos, vacunos, caballos, asnos y algunas aves de corral. Estas especies han reemplazado en gran medida a las especies herbívoras indígenas como la alpaca (Lama pacos), la vicuña (Vicugna vicugna) y el guanaco (Lama guanicoe). En cambio, la llama (Lama glama) aún se utiliza extensamente como bestia de carga, especialmente en viajes anuales de intercambio a grandes distancias.

Al parecer, sólo una especie de cérvido (Odocoileus sp.) se preserva en las partes menos transitadas de las punas de Junín y Cerro de Pasco, aunque periódicamente los lugareños reportan la visualización de alguna taruca (Hippocamelus antisensis), especie de venado muy cotizada en el pasado por sus astas cortas y fuertes, de doble ramal, que se usaban hasta en tiempos históricos como artefactos en minería.

De importancia por su consumo por el hombre, son una especie domesticada de cavidae, el cuy (Cavia porcellus); y otra especie, silvestre de chinchillidae, la vizcacha (Lagidium peruanum). Las lagunas y pantanos ofrecen algunos peces, pero mayor tradición de consumo humano la posee un tipo de rana muy apreciada (Batrachophrynus sp.). Finalmente, hay una extensa variedad de aves silvestres que habitan las orillas pantanosas de lagos y lagunas.
Aun cuando en la actualidad su explotación por el hombre es casi nula, no fue tal el caso en tiempos precerámicos, cuando su consumo fue más generalizado. Algo similar deber haber ocurrido con el perro doméstico. De aparición relativamente tardía en depósitos arqueológicos, los huesos de perro presentan las mismas características de desarticulación y fragmentación que se observan en los restos de otros animales, sugiriendo su consumo como alimento, por parte de humanos, los cuales no continúan tal práctica en el presente.

En conclusión, puede decirse que a medida que se observa la Puna con cierta minuciosidad, se hace evidente que no se trata de un ecosistema tan desprovisto de recursos como se podría suponer. Aun cuando su capacidad de sostenimiento no parece suficiente para una densidad poblacional humana significativa, resulta tan variada, que ha dado lugar a la emisión de hipótesis en el sentido de que en tiempos prehistóricos se habría desarrollado en la región una sociedad de cazadores sedentarios (Rick 1977, 1977a). Sin embargo, informaciones etnohistóricas y etnográficas (Murra 1972; Mayer 1971; Fonseca 1976; Landeo 1979) sugieren en forma consistente la imposibilidad de completar una dieta humana equilibrada a base de los recursos de un solo ecosistema andino, no importa cuál. En cambio, resulta bastante evidente que patrones tradicionales de adaptación a una multiplicidad de pisos altitudinales en los Andes han enfatizado en el acceso a un máximo de éstos, a fin de asegurar la consecución de recursos propios de cada uno.

El mecanismo cultural moderno se basa en el intercambio de productos mediante trueque y/o comercio (Landeo 1979). En el pasado histórico se manifestó en términos del modelo de verticalidad (Murra 1972); y no parecen existir razones para descartar la trashumancia (Lynch 1971) como el modelo adaptativo cultural del Precerámico.

\section{Cambios climáticos en el pasado}

Las características del paleoclima en las regiones de altitud extrema en los Andes tropicales permanecen como un área todavía abierta para la investigación científica. Nuestro conocimiento de las condiciones medioambientales del Pleistoceno Final y del Holoceno es aún escaso y superficial. Con la sola excepción de la versión de procesos glaciares en correlación invertida, respecto del hemisferio norte, propuesta por McNeish (1971), parece haber un 
consenso general en favor de una correspondencia de la secuencia de glaciaciones en los Andes con las observadas en Norteamérica y el Viejo Mundo.

Es ahora evidente que estos avances glaciares fueron de una magnitud considerable. La línea actual de los hielos está por encima de los $5000 \mathrm{~m}$, pero es clara la presencia de morrenas terminales a menos de 4000 m. Por ejemplo, el pueblo de San Pedro de Cajas, en el sureste de la región de Junín, está ubicado en un gran circo glaciar, desecado gracias al drenaje producido por dos ríos, el Yanayacu y el Shaca, que cortan una morrena a una altitud de 3900 m. Más al sur de la región, cerca de la ciudad de La Oroya, se pueden notar morrenas terminales y laterales a altitudes de $3600 \mathrm{~m}$.

Obviamente, la mayor gradiente de algunos valles debe haber facilitado el desplazamiento de glaciares hasta menores altitudes aún. Estos procesos fueron más marcados en el caso de la cordillera Oriental, debido a regímenes de precipitación más intensos. Así, los glaciares de San Antonio y Huaytapallana, al este de Huancayo, unos $150 \mathrm{~km}$ al sur de Junín, han dejado morrenas en el piso del valle a $3400 \mathrm{~m}$ de altitud, esto es, más de 1000 m más abajo que la actual línea de nieves perpetuas en Huaytapallana.

Los intentos de determinación del inicio del Holoceno presentan también problemas. De acuerdo a las informaciones de Cardich (1964), el estadio glaciar "Antarragá" sería contemporáneo con la fase climática Janca 4, fechada entre 9000 y 8000 AC, marcando el final del Pleistoceno. Datos más recientes (Wright y Bradbury 1975; Matos 1976) indican que la región circundante del lago de Junín habría estado libre de hielos desde hace 16500 años. Si consideramos que el espejo del lago de Junín está a casi 200 m más de altitud que el lago Lauricocha, entonces las ocupaciones en las cuevas de Lauricocha, reconocidas como el Horizonte Cultural Lauricocha I, no son pleistocénicas sino primordialmente del Holoceno.

Las condiciones climáticas del Holoceno se conocen en términos generales sólo gracias a los esfuerzos de investigación de Cardich (1964). Su esquema considera una serie de fases a partir de 8000 AC, cuando una franca desglaciación que habría durado unos 1000 años se habría interrumpido por un recrudecimiento del frío, al cual llama "estadio Sheguel-Huaman". Hacia 6000 AC, un nuevo retraimiento de los hielos habría iniciado una etapa de eficiencia térmica excepcionalmente alta, coincidente con el optimum climaticum, que se ha registrado en otras áreas del mundo. Esta situación habría prevalecido hasta $2000 \mathrm{AC}$, cuando el clima se habría estabilizado en niveles comparables a los regímenes de temperatura moderada que se observan en el presente, pero con etapas alternas de mayor humedad.

Las peculiaridades climáticas del Holoceno, sin embargo, aún están por ser determinadas con mayor exactitud. Esfuerzos en esta dirección están siendo realizados por Wright, a base de estudios de sedimentos en lagos de las punas de Junín, y por Cardich, utilizando criterios arqueológicos (Cardich 1975).

De otro lado, aquí reportamos algunos resultados de los análisis de suelos realizados a base de muestras obtenidas de los diversos niveles de Piedras Gordas, en Cerro de Pasco. Parte de esta información es utilizada en la deducción de una curva de temperatura a lo largo del lapso ocupacional del sitio. Correlaciones culturales y paleoclimáticas con otros sitios, así como algunas fechas radiocarbónicas, permiten fechar tentativamente ciertos eventos importantes del proceso climático en Cerro de Pasco durante unos ocho milenios del Holoceno.

\section{Arqueología precerámica en Junín y Cerro de Pasco}

Las investigaciones arqueológicas del Precerámico en las punas de Junín y Cerro de Pasco tienen ya una historia de más de una década. A los trabajos iniciales de fines de la década del 60 (Matos 1970; Hurtado de Mendoza y Ramírez 1971), pronto se sumaron los esfuerzos de otros especialistas, quienes no sólo incidieron en problemas arqueológicos (Matos 1970, 1976; Lavallée y Julien 1975; Hurtado de Mendoza 1976, 1975, 1977; Rick 1976, 1977, 1977a), sino también del paleoclima (Wright y Bradbury 1975) y de Paleofauna (Wheeler 1975; Wing 1975, 1977; Wheeler et al. 1976).

Más específicamente, el trabajo realizado en Junín y Cerro de Pasco desde 1975, que aquí se reporta en mayor detalle e integración, ha dado lugar a una serie de informes previos sobre temas fragmentarios, incidiendo en aspectos metodológicos y de organización de labores de campo (Hurtado de Mendoza 1975, 1977, 1978, 1978a, 1979; Hurtado de Mendoza y Chahud 1978; Ríos 1978). 
Estas investigaciones se han venido realizando en dos etapas principales: una, de exploración, ubicación y registro de sitios, y, la otra, de excavaciones de prueba en sitios seleccionados. Ni una ni otra etapa han sido cumplidas en su totalidad prevista. Sólo dos sitios, de una muestra mínima de ocho, han sido excavados hasta la fecha; y cada nueva incursión en la región estudiada suele ampliar el registro de sitios. Por ejemplo, después de la estación de campo de 1976, se han ubidado nueve abrigos rocosos en tres nuevos sitios, los que han sido agregados al inventario arqueológico regional.

Paralelamente con el trabajo de campo, se han estado realizando algunos trabajos de análisis, los que se han complementado con labores de laboratorio y procesamiento de la información en años más recientes. Esta parte del trabajo tampoco puede considerarse terminada. Gran parte del material cultural recuperado de Piedras Gordas y la totalidad de la colección de Vizcas, aún se encuentran en proceso de análisis.

\section{Patrones de asentamiento}

Cada uno de los 70 sitios registrados suele estar compuesto por más de un abrigo rocoso y/o localidades abiertas, de manera que el inventario regional incluye un total de 203 abrigos rocosos y siete sitios abiertos. El arreglo espacial de los 70 sitios no corresponde a una distribución de puntos al azar en toda la región, sino que presenta un patrón discernible. Hay grupos de sitios que se aglutinan dentro de 14 subregiones, cuya delimitación es bastante definible (ver Figura 1). Además de este agrupamiento de sitios en subregiones relativamente discretas, el patrón regional de asentamientos posee una serie de características comprobadas. En primer lugar, se ha notado una tendencia ocupacional que es correlacionable con el tiempo. A mayores altitudes relativas dentro del ecosistema Puna, menor es la antigüedad de las ocupaciones. La altitud promedio de ensamblaje asociable con el Horizonte Lauricocha I (antes de $6000 \mathrm{AC}$ ) es de $4252 \pm 79 \mathrm{~m}$; los del Horizonte Lauricocha II (6000$3000 \mathrm{AC})$ es de $4328 \pm 127 \mathrm{~m}$; y los del Horizonte Lauricocha III (3000-1800 AC) es de 4355 $\pm 165 \mathrm{~m}$. Aun cuando estos valores no incluyen sitios de las subregiones 13 y 14 (Hurtado de Mendoza 1977: 3), el incremento notable en la magnitud de las desviaciones estándar se ha interpretado en el sentido de expresar claramente una tendencia a que con el transcurrir del tiempo se fueran ocupando pisos altitudinales más altos, pero sin dejar de controlar los pisos más bajos cuya ocupación tenía mayor antigüedad. Si dicha tendencia es real, entonces puede pensarse en términos de una gradual expansión poblacional en las punas, con la consiguiente presión creciente en sus recursos naturales.

Otro aspecto de los patrones ocupacionales de la Puna en el Precerámico es que no todos los 203 abrigos rocosos registrados como constituyentes de sitios determinados presentan evidencia comparable de ocupación humana. Dentro de un sitio específico, se suele observar una gran variabilidad en la densidad de material recolectable de superficie. Lo mismo suele suceder a nivel regional y subregional, sugiriendo una tendencia selectiva de parte de los grupos humanos en el pasado. No es posible adelantar una lista de factores que habrían servido de criterios de selección, pero sí que la orientación de los abrigos rocosos fue uno de éstos. La región está involucrada dentro de un régimen meteorológico en el que predominan vientos del suroeste que trasfieren el frío de los picos glaciares de la cordillera Occidental o de La Viuda; mayor insolación en las mañanas y la ocurrencia de tormentas con lluvia, granizo y nieve en las tardes. Estas condiciones, aunadas a la deflección hacia el norte de la línea de paso del sol en el firmamento, hacen que los abrigos ubicados en las laderas sur y oeste de colinas mantengan un mayor grado de humedad y exposición, haciéndolos menos adecuados para su utilización por grupos humanos. Por el contrario, los sitios orientados hacia el norte y el este, susceptibles de mayor insolación y menor exposición, fueron utilizados con mayor énfasis, a menos que no hubiera alternativa.

Una tercera característica de los patrones ocupacionales se ha deducido de la observación de las colecciones de material lítico cultural recogido de la superficie de los sitios visitados en la región de Junín y Cerro de Pasco. Dentro de cada subregión suele haber una categorización de sitios en términos de función económica. Al realizar una clasificación multivariable de sitios, a base de las proporciones de tipos de artefactos en ensamblajes culturales, se logró definir cuatro clases de sitios distinguibles en sus posibles actividades sostenidas (Hurtado de Mendoza 1975, 1978a). La primera clase de sitios parecen ser campamentos-base con alta complejidad ocupacional, donde se habría realizado una amplia diversidad de actividades, incluyendo vivienda, preparación y consumo de alimentos, procesamiento de pieles, elaboración de artefactos de piedra y hueso, entre otros. 
Una segunda clase de sitios, de menor complejidad, habría enfatizado menos en el aspecto habitacional, calificando dentro de una categoría que se está denominando campamento secundario. Las actividades de manufactura de artefactos y de beneficio de animales parecen haber estado presentes, pero en escala bastante reducida. La tercera categoría incluye aquellos campamentos secundarios, en donde se puede notar una mayor incidencia de actividades propias de un taller lítico, antes que de beneficio y consumo de animales. Finalmente, la cuarta clase corresponde a sitios en donde es percibible un mayor énfasis en la manufactura de artefactos de piedra, estando conspicuamente ausentes otras actividades.

La tendencia regional es que cada subregión cuente con combinaciones de todos o la mayoría de estos tipos o clases de sitios, sugiriendo tal vez que cada subregión habría sostenido grupos humanos relativamente independientes, tal vez como el ámbito de utilización de territorio de bandas específicas. $\mathrm{Si}$ a estas observaciones, sin embargo, se agregan las obtenidas durante las excavaciones en Piedras Gordas, surge la posibilidad muy fuerte de que cada subregión o sectores de éstas hayan servido como áreas de convergencia de diversos grupos humanos con tradiciones culturales distinguibles, a pesar de compartir un mismo modo de vida basado en la caza y la recolección.

Los patrones de asentamiento en las punas de Junín y Cerro de Pasco ofrecen otra peculiaridad, detectada por el análisis comparativo del uso de diversos tipos de piedra como materia prima para la elaboración de artefactos líticos. Hay una clara correspondencia entre la popularidad relativa de tipos de piedra en los emsamblajes culturales de superficie de sitios y la distribución geográfica de los mismos. Esta correspondencia distribucional ha permitido delimitar tres grandes territorios según predominen significativamente: 1) El cuarzo y la calcedonia; 2) Las lavas; y 3) Los horstenos (chert). El territorio del cuarzo y la calcedonia se extiende en las partes norte y oeste de la región, mientras que el territorio de las lavas se ubica en el sector oriental de la región.

El territorio del horsteno es más restringido. Sólo la región ubicada al sur del lago de Junín acusa una marcada predominancia de horstenos en sus ensamblajes culturales, pero las diferencias proporcionales son lo suficientemente obvias como para justificar su definición como un territorio más. Estas diferencias son percibibles al examinar la Tabla 1.

Se puede notar que hay tres tipos de materia prima, pedernal, areniscas y la categoría de "otros" tipos de piedra, que no experimentan mayor variabilidad, y consecuentemente no ofrecen criterios informativos para la definición de los tres territorios propuestos. Por el contrario, son notorias las desproporciones en el caso de los horstenos (chert), cuarzo, lavas y calcedonia. El cuarzo y la calcedonia son los más abundantes en el primer caso, respecto de los otros dos casos. En cambio son las lavas las que aumentan apreciablemente en su popularidad en el segundo caso. Finalmente, resulta obvia la mayor abundancia de horstenos en el tercer caso, cuando se la compara con sus niveles de popularidad en los dos primeros territorios propuestos.

Estas observaciones pueden interpretarse un tanto en términos de diferenciación cultural, puesto que las mismas formas artefactuales no aparecen en todos los territorios en proporciones similares, pero también es posible tenerlas en cuenta cuando se trate de dilucidar sistemas de abastecimiento de materia prima peculiar a segmentos de las poblaciones humanas prehistóricas, cuyos ámbitos de actividad y trashumancia deben haber sido diferentes. Es muy posible que los habitantes del territorio del cuarzo y la calcedonia hayan tenido mayor interacción con los valles que bajan hacia la costa, mientras que los habitantes del territorio de la lava se habrían desplazado hacia el este, esto es, por los valles que bajan hacia la Amazonia.

\begin{tabular}{|l|l|ccccccc|c|}
\hline \multirow{2}{*}{ Territorio } & \multirow{2}{*}{ Subregiones } & \multicolumn{7}{|c|}{ Tipos de Piedra } & \multirow{2}{*}{ N } \\
\cline { 3 - 10 }$n$ & Cuarzo & Pedernal & Horsteno & Calcedonia & Lavas & Areniscas & Otros & \\
\hline Cuarzo y & $1,2,4,7$ & 27.8 & 5.8 & 36.0 & 17.9 & 0.6 & 2.7 & 9.2 & 1154 \\
calcedonia & $8,9,10,11$ & & & & & & & & \\
Lavas & $3,5,6,13,14$ & 9.9 & 6.1 & 44.9 & 2.0 & 25.7 & 2.6 & 8.7 & 951 \\
Horstenos & 12 & 20.5 & 7.7 & 62.4 & 3.4 & 3.4 & 0.0 & 2.5 & 118 \\
\hline
\end{tabular}

Tabla 1. Frecuencias relativas de tipos de materia prima lítica en Junín y Cerro de Pasco, por territorios. 
La subregión de Atocsayco (12) no puede ser incluida en ninguno de los dos territorios ya descritos, puesto que los diversos tipos de materia prima lítica ocurren en combinaciones peculiares. Mientras la popularidad de cuarzos es comparable a la del territorio del cuarzo, en cambio difiere por una ocurrencia muy baja de calcedonias, lo cual resulta más acorde con el caso del territorio de las lavas. Sin embargo, no puede identificarse con este otro territorio, puesto que la incidencia de lavas es reducida y más cercana a niveles propios del territorio del cuarzo.

Esta situación ambivalente es interpretada aquí en parte como resultado de la posición "fronteriza" de la subregión 12, respecto de los otros dos territorios, pudiendo ser que sitios complejos, como el de la cueva de Panaulauca, hayan sido puntos de contacto y convergencia de grupos humanos procedentes de diversas esferas de interacción y trashumancia. Los horstenos no son geológicamente tan abundantes en la región de Junín y Cerro de Pasco, como lo son las calcedonias y los cuarzos, constituyendo éste un aspecto de disponibilidad de materia prima que hay que tener en cuenta a medida que progresen las investigaciones.

Habíamos definido el norte y el oeste de la región, como el territorio del cuarzo y la calcedonia. Este territorio, por otro lado, es el que posee los pisos altitudinales más altos de la región. La mayoría de sus subregiones tienen una alta proporción de sitios cuyos ensamblajes son identificables como más tardíos. De otro lado, estos ensamblajes cuentan con las proporciones más altas de calcedonia y cuarzos, respecto del resto de la región de Junín y Cerro de Pasco. En resumen, es posible percibir cierta correlación positiva entre el uso de la calcedonia y el cuarzo, la mayor altitud de sitios, y las filiaciones cronológicas más recientes del Precerámico. Pero la conclusión casi lógica que debía seguir, en el sentido de que la calcedonia y el cuarzo sean materias primas asociables con ensamblajes tardíos, no es viable realmente.

La información secuencial en el uso de diversos tipos de piedra en el sitio de Piedras Gordas ofrece una respuesta diferente, al mismo tiempo que abre nuevas áreas de investigación. Según se puede ver más adelante, las calcedonias se utilizaban en proporciones abrumadoras en los tiempos más tempranos de ocupación del sitio, disminuyendo gradualmente con el paso del tiempo, hasta ser reemplazadas casi totalmente por los horstenos. De otro lado, ha sido posible observar cierta correlación entre el uso de la calcedonia como materia prima y algunas tradiciones tipológicas de artefactos, siendo significativo que se trate precisamente de aquellas que tienen mayor antigüedad. Sin embargo, esto no parece significar que tales tradiciones tipológicas se hayan limitado en su ocurrencia a sólo fases tempranas de ocupación, sino que, por el contrario, acusan una larga persistencia hasta fases más recientes.

La interpretación que aquí se adelanta a modo de hipótesis de trabajo, digna de ser comprobada en el futuro, es que la colonización de los pisos altitudinales más altos fue realizada por aquellos grupos más primitivos que utilizaban sitios en menores altitudes, desde el principio, pero que fueron siendo desplazados a áreas marginales del ecosistema por la creciente presión de nuevos grupos humanos premunidos de equipos culturales más eficientes y mejor elaborados. En otras palabras, el proceso de expansión poblacional que se describió más arriba habría sido una consecuencia del desplazamiento de los pobladores de tradiciones más antiguas hacia el oeste y norte de la región. En todo caso, este proceso significó una creciente presión sobre los recursos del ecosistema, lo que a la larga tendría consecuencias detrimentales para la estabilidad del modo de vida de los cazadores de las punas de Junín y Cerro de Pasco.

\section{Excavaciones en Piedras Gordas}

Una serie de ocho sitios en la región han sido seleccionados para excavar mediante un proceso previo de clasificación de sitios a base de su función económica (Hurtado de Mendoza 1977). Dos de estos sitios, Piedras Gordas en la subregión de Cerro de Pasco (1) y Vizcas en la subregión de Chancayo (11), fueron sometidos a excavaciones de prueba durante la estación de campo de 1978. La evaluación del material cultural y osteológico recuperado de estos sitios ha sido completada sólo parcialmente. Los análisis aún están en proceso, de manera que aquí se reportarán solamente algunas observaciones parciales acerca de los patrones de utilización de Piedras Gordas a lo largo de unos 8000 años de ocupación.

\section{Descripción del sitio}

Piedras Gordas es un sitio multicomponente del Precerámico postglacial y del Cerámico Inicial, ubicado en Champamarca, un suburbio al sur de la ciudad de Cerro de Pasco (Figuras 2 y 3 a). El sitio está compuesto por una serie de abrigos rocosos 


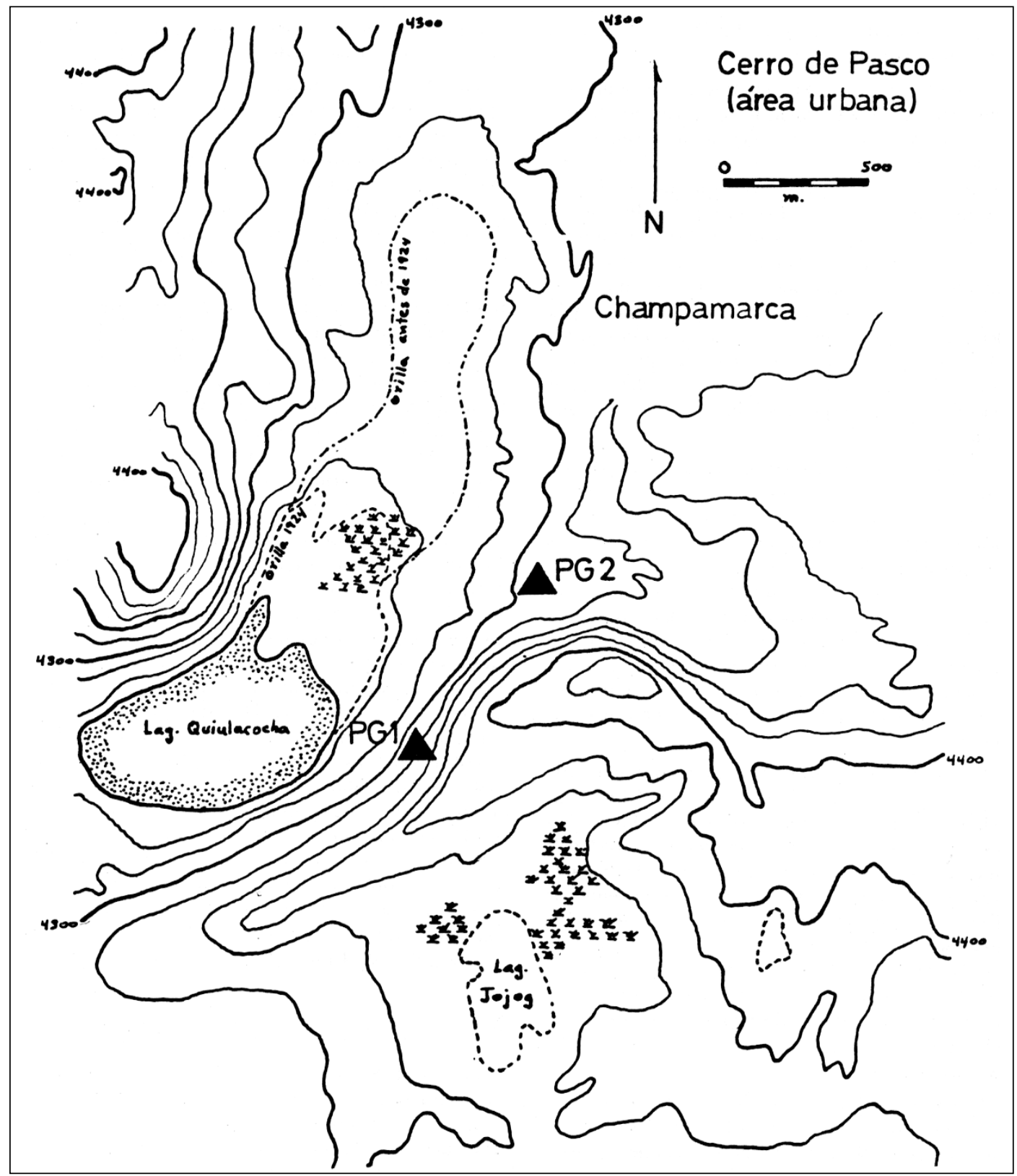

Figura 2. Ubicación de los abrigos rocosos PG-I y PG-2 de Piedras Gordas, en Champamarca, cerca de la ciudad de Cerro de Pasco. La laguna Quiulacocha tiene actualmente menos de un tercio de la extensión registrada en mapas de principios del siglo.

distribuidos a lo largo de unos $700 \mathrm{~m}$, en una extensa exposición de un conglomerado grueso, cementado en una caliza rojiza. Esta formación, de origen Terciario, es identificada en la literatura geológica por el nombre de shuco.

Piedras Gordas fue hallado y registrado en 1975, durante una estación de exploraciones arqueológicas realizadas por el autor, bajo un contrato de investigación con el Smithsonian Institution de Washington. En esa ocasión, sólo uno de los abrigos rocosos (PG-1) produjo evidencias de ocupación humana en tiempos precerámicos, pero, más recientemente labores de mantenimiento de una carretera vecina precisaron de material de relleno que se extrajo de la parte baja del talud de otro de los abrigos rocosos (PG-2), exponiendo artefactos líticos, tiestos y huesos de animales en cantidades apreciables. 


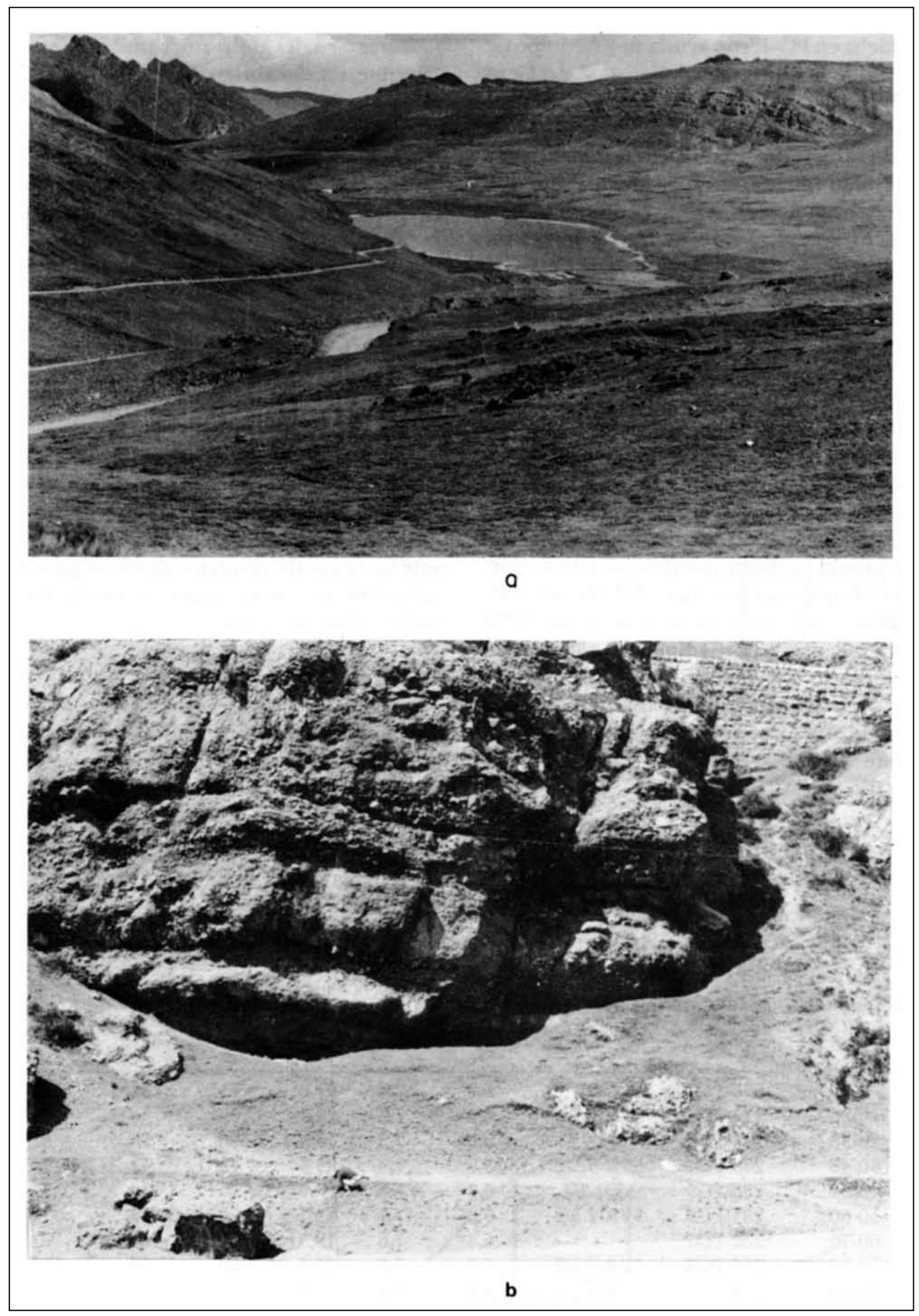

Figura 3. a) La región de Puna, cerca de la ciudad de Cerro de Pasco; b) El abrigo rocoso de Piedras Gordas (PG-1).

A mediados de junio de 1978 se iniciaron excavaciones de prueba en PG-1, con ayuda de un equipo de investigadores de la Universidad Nacional del Centro, el que incluyó a Rómulo Ríos Sánchez y Carlos Chaud Gutiérrez.
PG-1 es un abrigo rocoso de escasas dimensiones pero con un talud muy extenso, inclinado, pero que contiene un depósito cultural muy profundo (Figura 3b). $\mathrm{El}$ acceso al sitio es fácil y se realiza utilizando la carretera que une la ciudad de Cerro de Pasco con 
la aldea de Quiulacocha y otras poblaciones más al sur. La laguna Quiulacocha está ubicada cerca del sitio, existiendo evidencia objetiva de que ha sufrido reducciones drásticas en su tamaño durante las últimas décadas, debido a la constante deposición de desechos mineros en sus aguas.

El sitio mismo se encuentra en el límite entre una formación basal de sedimentos del Siluriano, conocidos como la Serie Excelsior, y el conglomerado grueso de matriz caliza llamado shuco. Su filiación Terciaria hace evidente el hecho de que descansa disconformemente en las rocas metamórficas de la Serie Excelsior. Las áreas más niveladas al oeste y sur de la laguna están rellenadas por sedimentos glaciares de origen Cuaternario. Su cubierta actual de pastos les provee la apariencia típica de las "pampas" del altiplano.

Cuando se hizo el primer reconocimiento del sitio, en 1975, éste lucía bastante bien preservado, sin mayores señales de disturbamiento, excepto en el piso interior del abrigo. Más tarde, en 1978, se supo que en la década de 1910 el sitio había sido utilizado como campamento por los trabajadores que tendieron la línea del ferrocarril entre Cerro de Pasco y La Oroya. También se pudo determinar que una faja nivelada, de unos $2 \mathrm{~m}$ de ancho, que se podía notar en la base del talud (ver Figura 3b), correspondía a una vieja carretera que fue abandonada aun antes de la construcción del ferrocarril.

Afortunadamente, la extensión de los daños al sitio no fue muy considerable, según se comprobó a medida que progresaban las excavaciones. El material extraído del interior del abrigo había sido transferido hacia fuera de éste y encima de la parte superior del talud, en donde formó una capa de material disturbado de entre 15 a $25 \mathrm{~cm}$ de espesor. El destino del material extraído del talud, al cortar el camino antiguo, no pudo determinarse. Es muy probable que las obras de construcción de la nueva carretera, unos $3 \mathrm{~m}$ más abajo, ocultaran las señales de todo trabajo anterior.

\section{Estratigrafía, suelos y paleoclima}

El depósito cultural de Piedras Gordas tiene un espesor que excede los $2 \mathrm{~m}$. Su formación gradual en el pasado, encima de un piso estéril de conglomerado shuco, ha sido el resultado de la aglomeración constante de desprendimientos de la roca matriz, deslizamientos de gravas y tierras desde los lados del acantilado donde está el abrigo, y la deposición humana de basura compuesta por artefactos y material de desecho de piedra, hueso y cerámica; restos de estructuras de piedra de campo; piedras quemadas utilizadas en hornos de suelo (pachamanca); huesos de animales y restos de plantas.

La observación de los perfiles de la trinchera excavada puso en evidencia una columna estratigráfica caracterizada principalmente por cambios en la coloración del relleno clástico (Figuras 4 y 5), mas no así en las características edafológicas del material. En otras palabras, los suelos de los diversos niveles del sitio acusan una alta homogeneidad estructural, según se ve en la Tabla 2, preparada a base de los análisis realizados por el Dr. Juan Bullón, del Laboratorio de Análisis de Suelos, de la Universidad Nacional del Centro. En esta tabla, sólo los porcentajes de materia orgánica y de arcilla acusan una variabilidad significativa. El porcentaje de materia orgánica tiende a reducirse regularmente a medida que aumenta la profundidad, como una consecuencia de procesos lentos de decaimiento. Por el contrario, la arcilla ofrece un cuadro mucho más irregular (Figura 6), atribuible a variaciones en las condiciones climáticas en el pasado. Su escasez relativa, respecto de los otros dos componentes estructurales, limo y arena, es típica de suelos dentro de regímenes de temperaturas bajas, como es el caso de las punas andinas tropicales.

De acuerdo a conceptos establecidos en teoría edafológica (Albareda y Hoyos 1961: 22), el contenido de arcilla en suelos aumenta con la humedad si la temperatura medioambiental permanece constante; $o$ si es la humedad la que permanece constante, entonces el aumento de la arcilla obedece a elevamientos de la temperatura. Lo más probable es que ambos factores hayan intervenido simultáneamente en el caso de las punas andinas. Pero es necesario, además, tener en cuenta la altitud, como factor interviniente.

Al examinar escalas de temperatura, precipitación y potencial de evapotranspiración en el sistema de clasificación de Holdridge, utilizado por Tosi en su mapa ecológico de Perú (Tosi 1960), se aprecia que en pisos altitudinales propios de la Puna basta una reducción de $3^{\circ} \mathrm{C}$ en la temperatura ambiental para que el potencial de evapotranspiración se restrinja en $50 \%$. Esta cifra adquiere mayor significación todavía al considerar que en los valles interandinos, unos $1000 \mathrm{~m}$ más abajo, se requiere de una diferencia de todavía $6^{\circ} \mathrm{C}$ para que se produzca un efecto similar. 


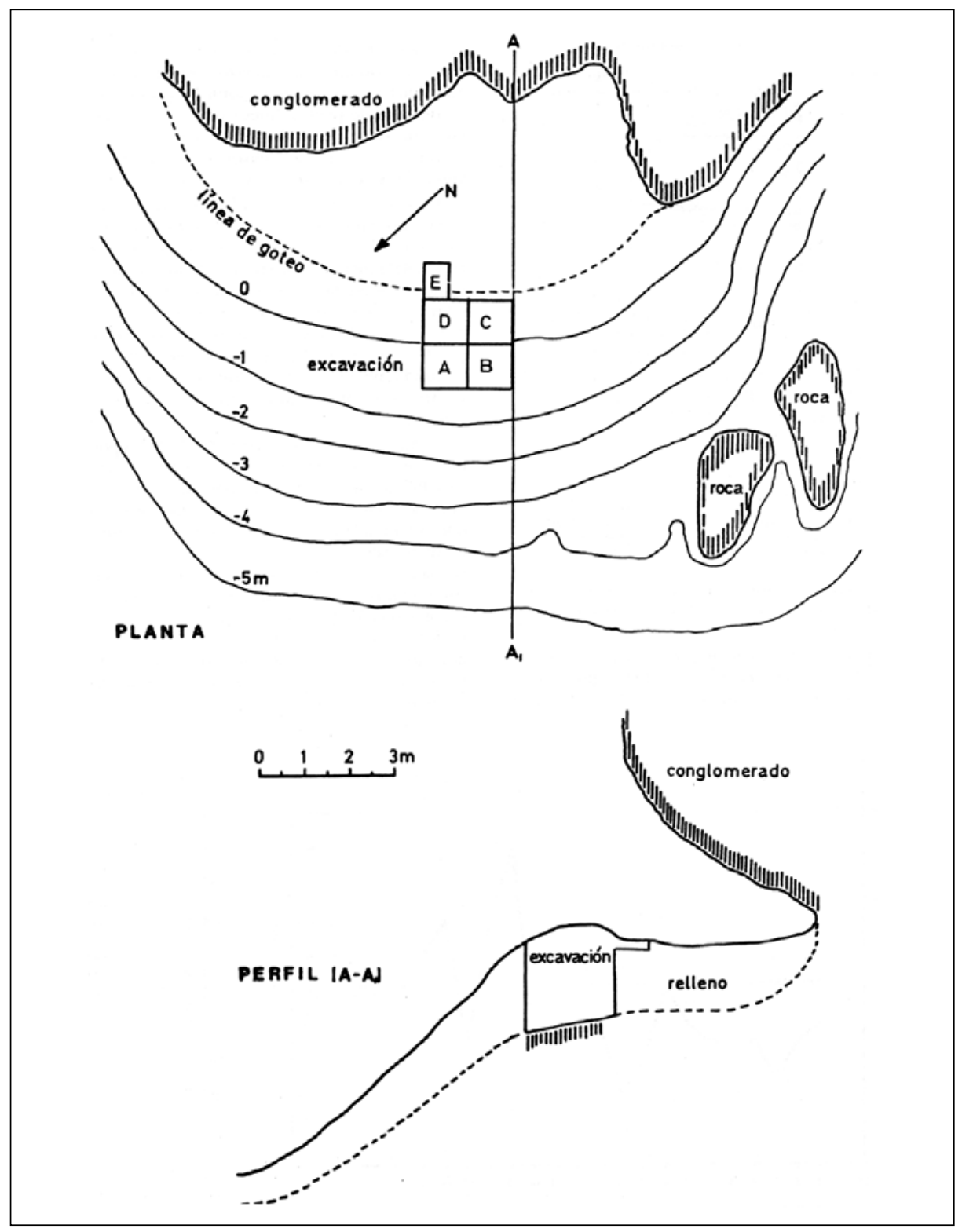

Figura 4. Croquis del abrigo rocoso PG-1 de Piedras Gordas, donde se realizaron excavaciones de prueba.

La sensibilidad de la Puna, como ecosistema, es pues, notable. Aparentemente, han bastado oscilaciones climáticas con diferencias de temperatura no mayores de $2-3^{\circ} \mathrm{C}$ para que los límites superiores de cultivo se hayan desplazado verticalmente hasta $400 \mathrm{~m}$ (Cardich 1975). El efecto de estos procesos en la estructura de los suelos también debe haber sido apreciable.

Si las oscilaciones de temperatura no han sido muy drásticas, pero sí sus efectos en la humedad disponible en suelos, entonces es posible suponer que el primer proceso relacional expuesto por Albareda y Hoyos (1961) debe haberse producido con mayor incidencia. Esto es, el aumento desproporcionado de la humedad, asociable a ligeras reducciones en la temperatura, podría haber alentado la formación de arcilla en el suelo, en cantidades suficientes como para hacer notorias las variaciones. Opuestamente, períodos de menor frío, cuando la humedad fue menor, podrían haber reducido la formación de arcillas. 


\begin{tabular}{|c|c|c|c|c|c|c|c|c|c|c|}
\hline \multirow[b]{2}{*}{ Nivel } & \multirow{2}{*}{$\begin{array}{c}\text { Profundidad } \\
\text { cm }\end{array}$} & \multirow{2}{*}{$\begin{array}{c}\text { Muestra } \\
\mathbf{N}^{\mathbf{0}}\end{array}$} & \multirow{2}{*}{$\begin{array}{l}\text { Color de } \\
\text { suelo }^{1}\end{array}$} & \multirow{2}{*}{$\begin{array}{c}\text { Materia } \\
\text { orgánica... } \\
\quad \%\end{array}$} & \multirow[b]{2}{*}{ pH } & \multirow{2}{*}{$\begin{array}{l}\mathrm{P}_{2} \mathrm{O}_{5} \\
\text { ppm }\end{array}$} & \multirow[b]{2}{*}{ C.I.C } & \multicolumn{3}{|c|}{ Estructura } \\
\hline & & & & & & & & $\begin{array}{c}\text { Arena } \\
\%\end{array}$ & $\begin{array}{c}\text { Arcilla } \\
\%\end{array}$ & $\begin{array}{c}\text { Limo } \\
\%\end{array}$ \\
\hline 1 & $0-10$ & 276-PG1 & - & 6.0 & 7.3 & 21.8 & 75 & 36 & 8 & 56 \\
\hline 1 & $10-20$ & 277-PG2 & $5 \mathrm{YR}-2.5 / 2$ & 5.9 & 7.8 & 23.3 & 80 & 30 & 7 & 63 \\
\hline 2 & $20-30$ & 278-PG3 & - & 6.0 & 7.5 & 18.5 & 90 & 33 & 5 & 62 \\
\hline 2 & $30-40$ & 279-PG4 & 5 YR-3.5/2 & 3.9 & 7.5 & 25.3 & 75 & 43 & 7 & 50 \\
\hline 3 & $40-50$ & 280-PG5 & $5 \mathrm{YR}-3 / 1$ & 6.3 & 7.6 & 18.5 & 75 & 30 & 7 & 63 \\
\hline 3 & $50-60$ & 281-PG6 & $5 \mathrm{YR}-2.5 / 2$ & 6.3 & 7.7 & 23.7 & 70 & 33 & 7 & 60 \\
\hline 4 & $60-70$ & 282-PG7 & - & 6.4 & 7.6 & 18.5 & 65 & 30 & 8 & 62 \\
\hline 4 & $70-80$ & 283-PG8 & $5 \mathrm{YR}-2.5 / 2$ & 6.2 & 7.6 & 25.3 & 60 & 30 & 10 & 60 \\
\hline 5 & $80-90$ & 284-PG9 & - & 6.1 & 7.4 & 26.4 & 65 & 32 & 6 & 62 \\
\hline 5 & $90-100$ & 285-PG10 & $5 \mathrm{YR}-3 / 3$ & 4.9 & 7.4 & 27.2 & 45 & 36 & 4 & 60 \\
\hline 6 & $100-110$ & 286-PG11 & $5 Y R-4 / 3$ & 4.6 & 7.7 & 27.9 & 50 & 36 & 8 & 56 \\
\hline 6 & $110-120$ & 287-PG12 & - & 4.6 & 7.8 & 28.2 & 55 & 36 & 8 & 56 \\
\hline 7 & $120-130$ & 288-PG13 & $5 \mathrm{YR}-3 / 3$ & 2.9 & 7.6 & 31.1 & 35 & 40 & 7 & 53 \\
\hline 7 & $130-140$ & 289-PG14 & - & 2.5 & 7.5 & 26.4 & 40 & 40 & 7 & 53 \\
\hline 8 & $140-150$ & 290-PG15 & $5 \mathrm{YR}-3 / 4$ & 3.2 & 7.6 & 27.5 & 40 & 36 & 18 & 46 \\
\hline 8 & $150-160$ & 291-PG16 & - & 3.8 & 7.8 & 27.1 & 40 & 36 & 14 & 50 \\
\hline 9 & $160-170$ & 292-PG17 & $5 \mathrm{YR}-6 / 3$ & 3.5 & 7.9 & 27.5 & 35 & 43 & 7 & 50 \\
\hline 9 & $170-180$ & 293-PG18 & - & 3.2 & 7.8 & 25.9 & 40 & 44 & 14 & 42 \\
\hline 10 & $180-190$ & 294-PG19 & $5 \mathrm{YR}-5 / 3$ & 2.3 & 7.5 & 24.6 & 30 & 45 & 12 & 43 \\
\hline
\end{tabular}

Tabla 2. Algunas características físicas y químicas de muestras de suelos de Piedras Gordas (PG-1), por niveles. ${ }^{1}=$ Código Munsell.

Si esta racionalización del proceso es correcta, entonces la curva de porcentajes de arcilla en el perfil de suelos de Piedras Gordas nos está proveyendo de un indicador de oscilaciones en la humedad y en la temperatura medioambiental de las punas de Cerro de Pasco, a lo largo del lapso ocupacional del sitio en el pasado.

La conclusión preliminar a que se llega en este estudio es que la humedad cumplió un rol mucho más importante que la temperatura en la formación de arcilla en los suelos de Piedras Gordas. Consecuentemente, las fases de incremento significativo en el contenido de arcilla deben corresponder a períodos de frío relativo, mientras que las de reducción del porcentaje de arcilla serían correlacionables con períodos de clima menos frío, relativamente.

Sin una serie consistente de fechas absolutas para los diversos niveles del relleno cultural de Piedras Gordas, no es posible definir cronologías irreprochables, pero si correlacionamos la muestra de suelos
278-PG3 del nivel 2, con fechas del Formativo Medio, dada la presencia de cerámica de estos tiempos en dicho nivel (Hurtado de Mendoza y Chahud 1978), obtenemos un punto cronológico adecuado para una fase de ligero mejoramiento del clima en la región. Por otro lado, el pico en la curva que se observa en el nivel 8 (Figura 6), dada su magnitud, puede asociarse con el período frío "Sheguel-Huaman", documentado anteriormente (Cardich 1964), proveyendo otro punto cronológico, que permite además correlacionar cómodamente el nivel 5, con tiempos de clima benigno identificables como "óptimo climático" del hemisferio meridional, o la Fase Yunga de los Andes Centrales (Cardich 1964). Dos fechas radiocarbónicas (SI-4071 y SI4072) ubican al nivel 5 en el cuarto milenio AC, lo que resulta consistente con la posición cronológica que se ha designado para la Fase Yunga 1 del Altitermal holocénico.

Estas correlaciones obtienen validación adicional, gracias a que los porcentajes de arcilla en las muestras 


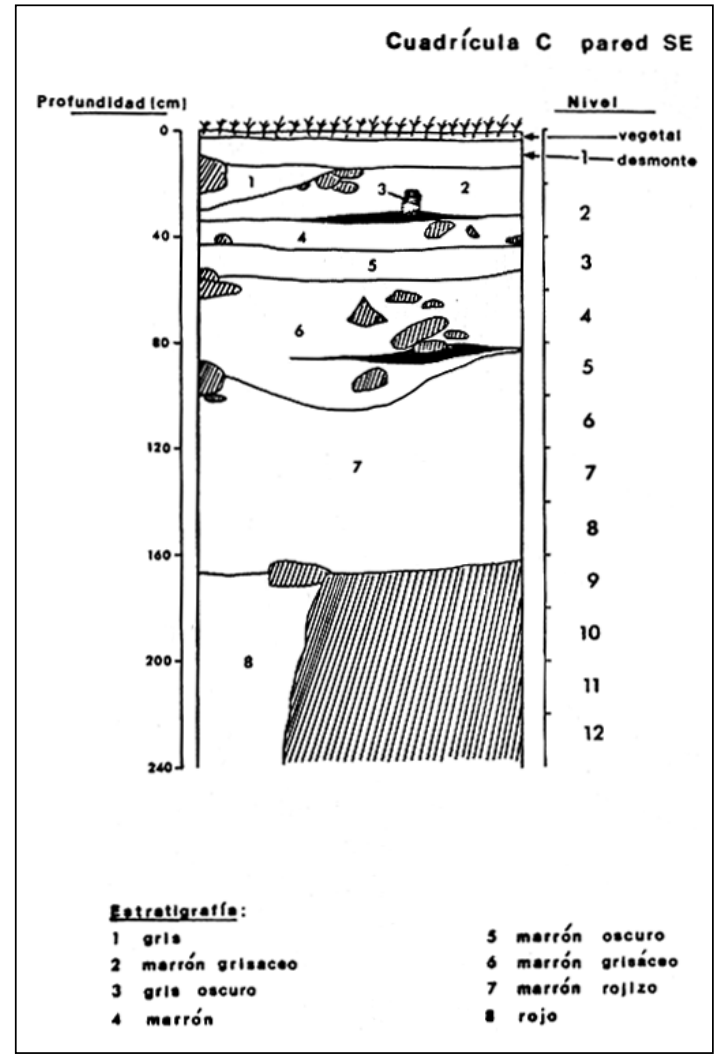

Figura 5. Estratigrafía natural del talud de PG-1, Piedras Gordas, basado en la coloración de suelos en la pared sureste de la cuadrícula C. de suelos pueden ayudar a deducir no sólo la humedad disponible en el medio ambiente (precipitación menos evapotranspiración), sino también pueden estimarse niveles de temperatura, pues existe una correlación estadística perfecta entre la evapotranspiración y la temperatura anual promedio del medio ambiente (Holdridge 1947; Tosi 1960).

La deducción de valores de humedad disponible en Piedras Gordas se ha realizado aplicando la ecuación que para el efecto ofrecen Albareda y Hoyos (1961: 22);

$$
\begin{aligned}
& \mathrm{A}=0.0114 \mathrm{~m} \mathrm{e}^{0,14 \mathrm{~T}} \\
& \mathrm{o}: \\
& \mathrm{m}=\frac{\mathrm{A}}{0.0114 \mathrm{e}^{0,14 T}}
\end{aligned}
$$

donde: A, es la cantidad de arcilla; $\mathrm{m}$, es el nivel de humedad disponible; y T, es la temperatura. Las cifras son factores constantes para el caso de suelos a una profundidad de $40 \mathrm{~cm}$.

A pesar de la relativa arbitrariedad con que se aplica esta expresión, los resultados son bastante razonables, como puede verse en la Figura 6. La primera

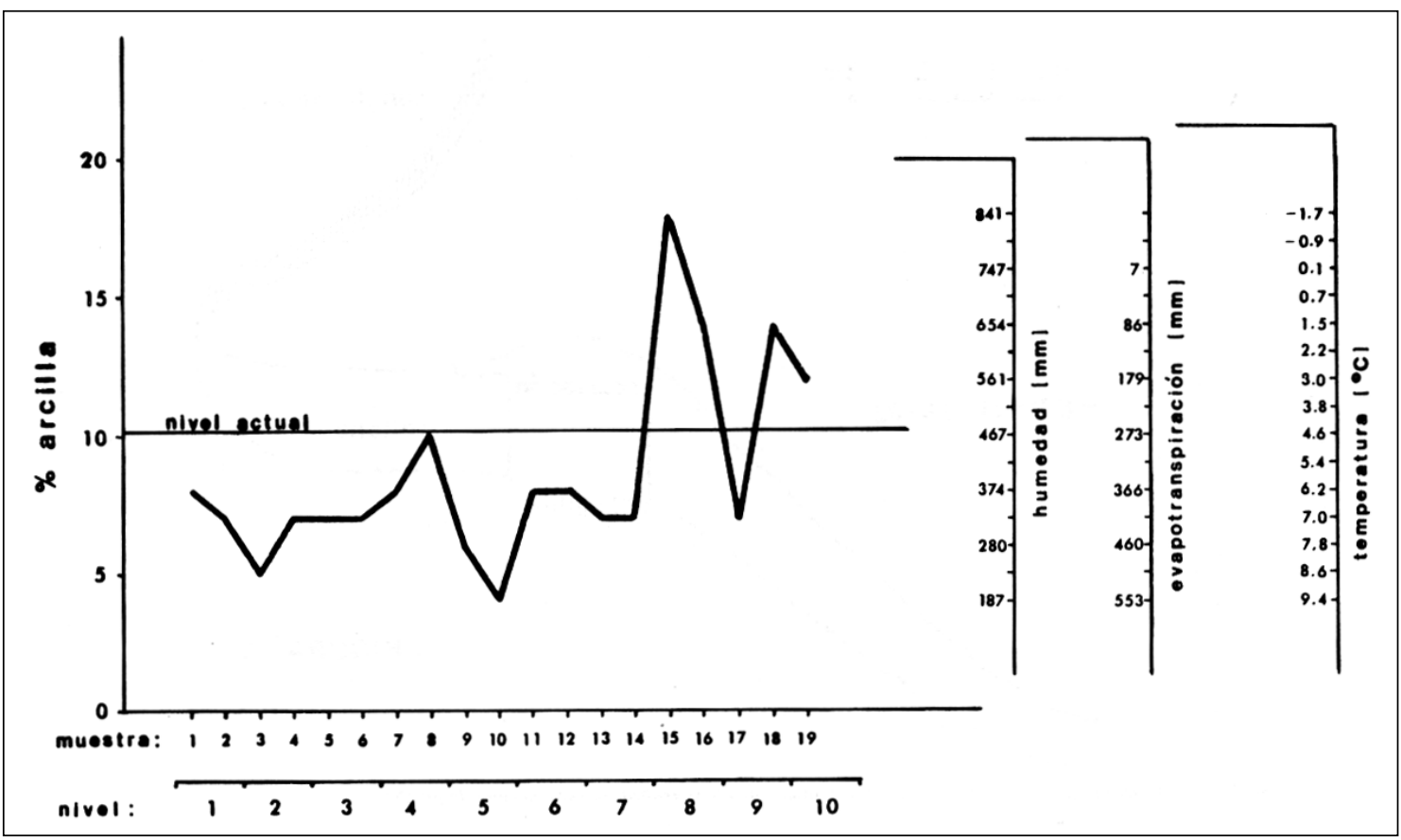

Figura 6. Fluctuaciones del porcentaje de arcilla en muestras de suelos en Piedras Gordas (PG-1). 
columna o escala, a la derecha del gráfico, representa los valores de la humedad disponible (m), correspondientes a cada punto porcentual del contenido de arcilla en los niveles culturales de la excavación. Si suponemos que el régimen de precipitación no habría variado mayormente durante el lapso ocupacional del sitio, manteniéndose alrededor del nivel actual de $740 \mathrm{~mm}$, entonces se puede intentar una estimación del potencial de evapotranspiración, mediante una simple operación de sustracción:

P.E. $=p-m$

donde: P.E., es el potencial de evapotranspiración; p, es la precipitación; y m, es la humedad disponible. Todos los valores se dan en milímetros. Los resultados de esta operación se muestran en la segunda columna a la derecha de la Figura 6.

Finalmente, el potencial de evapotranspiración se utiliza para estimar la temperatura medioambiental, en grados centígrados, mediante la aplicación de la ecuación predictiva obtenida a base de la correlación perfecta $(r=1.0)$ entre estas dos variables. $\mathrm{La}$ fórmula conocida, es

$y=b x+a$

donde: $\mathrm{y}=\mathrm{T}$, es la temperatura medioambiental; $\mathrm{b}=0.017 ; \mathrm{a}=0.0005 ; \mathrm{y} \mathrm{x}=$ P.E., es el potencial de evapotranspiración.

La tercera columna a la derecha en la Figura 6, muestra los resultados de esta transformación, pudiéndose ver que en Piedras Gordas, la temperatura medioambiental habría variado entre un mínimo de casi 2 grados centígrados bajo cero $\left(-2^{\circ} \mathrm{C}\right)$, durante la pulsación fría postpleistocénica "Sheguel-Huaman", y un máximo de $9.5^{\circ} \mathrm{C}$ en el "óptimo climático". En el mismo gráfico se señalan los niveles de humedad, evapotranspiración y temperatura anual promedio en Piedras Gordas, en el presente, con fines comparativos.

\section{Técnicas de excavación}

Se eligió la cumbre del talud, cerca de la entrada al abrigo rocoso, para realizar la excavación, por ser el área que ofrecía las mayores posibilidades de encontrar estratigrafía horizontal, como resultado de patrones de deposición del material cultural con un mínimo del efecto disturbador propio del declive predominante en el resto del talud.
En este lugar (ver Figura 4) se inició una trinchera de 2 x $2 \mathrm{~m}$. Con la finalidad de generar un control posicional del material extraído, se dividió este cuadro en cuatro cuadrículas de 1 x $1 \mathrm{~m}$, cada una de las cuales fue a su vez subdividida en cuatro subcuadrículas de $50 \times 50 \mathrm{~cm}$. No se intentó orientar la excavación con el norte, sino que se la alineó con una línea imaginaria determinada como el eje transversal del sitio que lo divide en dos mitades (la línea A-A 1 en Figura 4).

Una segunda trinchera fue abierta en la parte inferior del talud, en el sector plano del antiguo camino abandonado. Esta trinchera, denominada cuadrícula $\mathrm{P}$, de 1 x $1 \mathrm{~m}$, se hizo con la intención de comprobar patrones de depositación del material cultural en la parte más baja del sitio. De otro lado, hubo necesidad de excavar una pequeña extensión (E) de $50 \times 80 \mathrm{~cm}$ al sureste, y adyacente, de la cuadrícula $\mathrm{D}$, a fin de extraer un entierro humano intrusivo que comprometía los niveles 2 y 3 de la excavación.

Cuando se considera el área total del sitio, estimada en unos $180 \mathrm{~m}^{2}$, de los cuales $30 \mathrm{~m}^{2}$ corresponden al piso del abrigo rocoso mismo, resulta que el área excavada, de poco más de $5 \mathrm{~m}^{2}$, no pasa de ser una muestra ligeramente mayor que el $2.8 \%$. Sin embargo, el acumulamiento masivo del material cultural debe ayudar a contrarrestar la impresión de estar trabajando con información insuficiente.

La excavación misma se realizó en niveles arbitrarios de $20 \mathrm{~cm}$ cada uno. Intentos preliminares por definir estratigrafía "natural" se vieron frustrados por la humedad considerable que se encontró, la que aumentó a mayores profundidades hasta dificultar el trabajo a partir del nivel 9, dada la presencia de fuertes filtraciones desde lagunas ubicadas en terrenos altos cerca del sitio. El perfil que se ofrece en la Figura 5 fue reconstruido días después de realizada la excavación de la cuadrícula $\mathrm{C}$, cuando la pared sureste se secó lo suficiente como para facilitar el discernimiento de diferencias en la coloración de suelos.

Tampoco se pudo continuar con la intención original de llevar un registro tridimensional de los artefactos que se encontraran. Estos aparecían en tan grandes cantidades que la operación de registro individual retardaba considerablemente el progreso de la excavación. Una idea de esto puede darla el hecho de que sólo la subcuadrícula A1, una columna de 
50 x $50 \mathrm{~cm}$ y nueve niveles de $20 \mathrm{~cm}$ cada uno, produjo casi 11000 especímenes líticos de tamaño mayor que 1/2", de los cuales, unos 500 se clasificaron como artefactos. En la cuadrícula $\mathrm{C}$, de 1 x $1 \mathrm{~m}$ y 11 niveles, se encontraron más de 30000 piezas de huesos de animales, de los que se han podido identificar más de 11000, como correspondientes a algún Género, y 174 especímenes fueron reconocidos como artefactos de hueso o asta.

El relleno fue retirado con ayuda de baldes con capacidad para $8 \mathrm{dm}^{3}$, después de determinar "bloques" de 50 x 50 × $20 \mathrm{~cm}$, como unidades de excavación correspondientes a cada nivel de $20 \mathrm{~cm}$ en cada subcuadrícula. En ningún caso se utilizaron herramientas de excavación más grandes que el badilejo, a fin de evitar daños considerables al material óseo que ya presentaba un grado muy alto de fragmentación.

El volumen de relleno, incluyendo material cultural, huesos, tierra y grava, resultó muy variable. Además de ligeras diferencias en el grado de compactación del suelo, hay que hacer notar que esta variabilidad fue también una consecuencia de la proporción bastante alta de rocas sueltas y fragmentos del conglomerado que formaban parte del relleno. De otro lado, por lo menos en los cinco primeros niveles, una serie de restos de estructuras burdas, construidas con piedras de campo, seguramente rompevientos, comprometían segmentos considerables del depósito.

Todo el material recuperado fue tamizado en el mismo sitio, a medida que era extraído, utilizando zarandas (harneros) de 1/2" y de 1/4", consecutivamente. Toda pieza de hueso, cerámica y piedra fue escogida y puesta en bolsas de tela, por separado, marcándolas con tarjetas tanto en el interior como en la parte externa de cada bolsa. Se separaron muestras de tierra de $2 \mathrm{dm}^{3}$ provenientes de cada nivel, con la intención de ser utilizadas en análisis de suelos, polen y flotación. También se conservaron muestras de $2 \mathrm{dm}^{3}$ de la tierra que permanecía en las zarandas de 1/4", a fin de someterlas posteriormente a lavado en una zaranda más fina, de $1 / 8$ ". Esto último fue decidido en el campo, al comprobarse que los pequeños terrones y grumos provenientes de estratos particularmente húmedos estaban reteniendo una cantidad apreciable de restos culturales muy pequeños y huesos de microfauna que merecían ser analizados para incluir los datos en nuestro banco de información.
Si es que además del material zarandeado se considera el concentrado obtenido mediante la técnica de flotación, entonces se puede contar con cuatro categorías dimensionales de lascas provenientes de la elaboración y uso de artefactos líticos en el sitio. Es de esperar que su cuantificación y comparación proporcional provean indicios respecto de posibles cambios en la tecnología lítica utilizada en diversas fases ocupacionales del sitio. La sola masividad cuantitativa del material cultural y de los restos de fauna en Piedras Gordas deben garantizar una calidad excepcional en los datos recuperables respecto de patrones de cambio cultural durante el lapso ocupacional del sitio.

\section{Clasificación y análisis de artefactos}

Como se ha expuesto, a la fecha de preparación de este informe no todo el material cultural recuperado de Piedras Gordas había sido sometido a clasificación y análisis. Lo que sigue, está hecho a base de la observación del material lítico de la cuadrícula A, solamente; mientras que los artefactos de hueso provienen de la cuadrícula C. La descripción del material cerámico, por otro lado, se hace teniendo en cuenta la colección obtenida en las cuadrículas A y B de la trinchera principal.

\section{El material lítico}

Los 11 niveles excavados en la Cuadrícula A de Piedras Gordas (PG-1) han producido un total de 64343 especímenes líticos culturales. De éstos, 1699 han sido clasificados como artefactos pertenecientes a 11 categorías o tipos (Tabla 3 ). El resto corresponde a las tres categorías de material de desecho: núcleos, lascas de más de 1/2", y lascas de entre $1 / 2$ " y $1 / 4$ ".

Debe tenerse en cuenta que esta última categoría no está representada en su totalidad recuperable, sino que es sólo una muestra obtenida del concentrado retenido por la zaranda de 1/4". También hay que advertir que no se han incluido en este análisis las microlascas o esquirlas de los concentrados de la zaranda de $1 / 8$ ", ni del concentrado obtenido por flotación.

El examen de los datos que se ofrece en la Tabla 3 pone de inmediato en evidencia el patrón irregular de distribución del material lítico en los diversos niveles de excavación. Las mayores proporciones de artefactos y desecho aparecen concentradas en 
los niveles 5 y 6 , mientras los niveles extremos 1 , 2, 10 y 11 muestran una marcada escasez relativa de material lítico. La Figura 7 ilustra gráficamente estas desproporciones, al mismo tiempo que señala la correspondencia muy alta que existe entre las distribuciones de artefactos y debitage (desecho).

Es posible suponer que este patrón irregular en la distribución proporcional de los restos líticos en el sitio debe responder a factores que tienen que ver con el uso del sitio a través del tiempo. De primera intención, parecería factible que en tiempos representados por los niveles 5 y 6 el uso del sitio hubiera sido más intenso que en tiempos anteriores y posteriores. Sin embargo, puesto que el relleno probó estar afectado por la presencia indiscriminada de rocas y restos de estructuras, cabía la posibilidad de que los patrones de depositación observados no reflejaran una situación real.

Para obviar tal posibilidad, se decidió cuantificar los datos en función de la cantidad de relleno efectivamente recuperado durante la excavación. Esto es, se determinaron para cada nivel las cantidades de especímenes líticos por unidad volumétrica del relleno. El resultado de este tratamiento es mostrado en la Tabla 4 y su representación gráfica en la Figura 8.

Aun cuando esta vez la curva distribucional observada anteriormente parece replicarse en gran medida, lo cierto es que se ha logrado un incremento significativo en la calidad y detalle de la información. En efecto, tanto la curva de la densidad de artefactos como la de densidad del material lítico de desecho indican ahora que hubo no una sino dos fases de uso intenso del sitio. En la primera fase, representada por el nivel 9 , se puede observar una alta correspondencia entre artefactos y desecho, definible en términos de una razón de 11.2 piezas de desecho por cada artefacto. En cambio, en la segunda fase de uso intenso, en los niveles 5 y 6 , esta razón se levanta hasta casi 22 unidades de desecho por cada artefacto. Mientras la densidad de artefactos en las dos fases descritas no muestra diferencias significativas, es la densidad del desecho la que aumenta considerablemente en el segundo caso.

Resulta interesante que estas fases de supuesto uso intensivo del sitio coincidan con aquellos tiempos en que, de acuerdo a la curva de temperatura generada por los porcentajes de arcilla en los suelos de Piedras Gordas, se habrían dado períodos de "mejoramiento" del clima. Pero estas coincidencias no se repiten en el caso de un tercer período de mayor temperatura durante la fase ocupacional representada por el nivel 2. En este caso, las curvas de densidad del material lítico, lejos de experimentar un aumento, sufren una depresión hasta niveles extremos.

Una posible razón que explique esta contradicción es que el nivel 2, afiliable con el estadio Cerámico Inicial, corresponde a tiempos en que el modo de vida basado en la caza y recolección estaba siendo ya sustancialmente reemplazado por el que se fundamentaba en la domesticación de plantas y animales.

La relación entre clima benigno y uso más intensivo del sitio parece mesurable estadísticamente, por lo menos en el lapso ocupacional representado por los niveles 5 al 10, esto es, eliminando los primeros niveles superiores, los que estarían afectados por la transición a un nuevo modo de vida. Cuando se procedió a calcular la posible correlación entre valores de densidad de artefactos líticos y porcentaje de arcilla mediante una fórmula de regresión lineal, se encontró que éstas mantenían una correlación negativa algo moderada $(r=-0.43)$, pero al comparar porcentajes de arcilla con densidad de material lítico de desecho, la correlación negativa cobró un gran incremento $(r=-0.68)$.

Estos resultados apoyan la apreciación descrita anteriormente, respecto a que por lo menos durante el Precerámico, cuando la base económica principal era la caza y recolección, las mejores posibilidades de explotación se daban cuando la temperatura medioambiental era relativamente alta, mientras que las depresiones climáticas habrían resultado detrimentales, suscitando restricciones de las actividades de subsistencia. Sin embargo, a despecho de lo razonable que podría parecer esta deducción, cuando se incluyen en el análisis otras variables como las que describen patrones de explotación de fauna, representados por la colección de huesos de animales, nos encontramos con un panorama más complejo, como se verá más adelante.

Para no distraernos del análisis específicamente lítico, baste aquí señalar la posibilidad de que el aumento en la actividad de uso del sitio, detectable en los niveles 5 y 6 , asociable a un "mejoramiento" significativo del clima, no se deba tanto a mejores condiciones de explotación de recursos, sino más bien a una crisis de interrelación entre las poblaciones humanas, que 


\begin{tabular}{|c|c|c|c|c|c|c|c|c|c|c|c|c|}
\hline \multirow{2}{*}{ Tipos } & \multicolumn{11}{|c|}{ Niveles } & \multirow{2}{*}{$\begin{array}{c}n \\
\text { por tipos }\end{array}$} \\
\hline & 1 & 2 & 3 & 4 & 5 & 6 & 7 & 8 & 9 & 10 & 11 & \\
\hline \multicolumn{13}{|l|}{ Artefactos: } \\
\hline Puntas & 16.3 & 9.1 & 14.4 & 10.3 & 5.9 & 7.8 & 10.9 & 4.7 & 8.6 & 4.2 & 0.0 & 143 \\
\hline Cuchillos & 0.0 & 7.3 & 3.1 & 2.9 & 1.2 & 1.2 & 0.0 & 2.3 & 3.3 & 0.0 & 0.0 & 31 \\
\hline Preformas & 14.0 & 21.8 & 23.8 & 17.8 & 14.4 & 12.7 & 10.9 & 7.0 & 17.2 & 8.3 & 11.8 & 249 \\
\hline Perforadores & 0.0 & 0.0 & 0.0 & 0.0 & 0.5 & 1.8 & 0.6 & 0.0 & 0.7 & 0.0 & 0.0 & 10 \\
\hline Bifaces indet. & 2.3 & 3.6 & 2.5 & 0.0 & 2.1 & 1.8 & 0.6 & 2.3 & 0.0 & 2.1 & 0.0 & 27 \\
\hline Raspadores & 27.9 & 36.4 & 25.0 & 33.3 & 29.6 & 24.4 & 27.9 & 34.9 & 33.1 & 31.3 & 23.5 & 497 \\
\hline Buriles & 0.0 & 0.0 & 0.6 & 2.3 & 3.3 & 3.0 & 7.9 & 0.0 & 3.3 & 6.3 & 0.0 & 50 \\
\hline Lascas retocadas & 0.0 & 0.0 & 3.8 & 1.7 & 3.5 & 1.2 & 0.0 & 7.0 & 0.0 & 0.0 & 0.0 & 37 \\
\hline Lascas usadas & 39.5 & 20.0 & 26.3 & 29.9 & 38.4 & 44.9 & 41.2 & 39.5 & 33.1 & 47.9 & 64.7 & 637 \\
\hline Hojas prismáticas & 0.0 & 1.8 & 0.6 & 1.7 & 0.7 & 0.6 & 0.0 & 0.0 & 0.0 & 0.0 & 0.0 & 10 \\
\hline Otros tipos & 0.0 & 0.0 & 0.0 & 0.0 & 0.5 & 0.6 & 0.0 & 2.3 & 0.7 & 0.0 & 0.0 & 8 \\
\hline n $(100 \%)$ por nivel: & 43 & 55 & 160 & 174 & 425 & 332 & 165 & 129 & 151 & 48 & 17 & 1699 \\
\hline \multicolumn{13}{|l|}{ Desecho: } \\
\hline Núcleos & 0.1 & 0.3 & 1.3 & 0.5 & 0.5 & 0.6 & 1.0 & 2.7 & 1.0 & 2.1 & 2.5 & 205 \\
\hline Lascas + 1/2" & 99.9 & 99.7 & 98.7 & 99.5 & 99.5 & 99.4 & 99.0 & 97.3 & 99.0 & 97.9 & 97.5 & 27309 \\
\hline n $(100 \%)$ por nivel: & 716 & 951 & 1075 & 2470 & 8540 & 7842 & 2894 & 876 & 1698 & 334 & 118 & 27514 \\
\hline \multicolumn{13}{|l|}{ Microdesecho: ${ }^{1}$} \\
\hline Lascas 1/2"-1/4" & 1495 & 2088 & 1504 & 2782 & 9140 & 14500 & 3100 & s.i.. & s.i. & 324 & 197 & 35130 \\
\hline
\end{tabular}

Tabla 3. Frecuencias relativas de artefactos y desechos líticos en Piedras Gordas (PG-1), cuadrícula A., por niveles. ${ }^{1}=$ Submuestra no comparable cuantitativamente con el resto de la colección. Niveles 8 y 9 sin datos.

\begin{tabular}{|c|c|c|c|c|c|c|c|}
\hline Nivel & $\begin{array}{c}\text { Relleno } \\
\mathbf{d m}^{\mathbf{3}}\end{array}$ & $\begin{array}{c}\text { Artefactos } \\
\mathbf{n} / \mathbf{1 0} \mathbf{d m}^{\mathbf{3}}\end{array}$ & $\begin{array}{c}\text { Desecho } \\
\mathbf{n} / \mathbf{d m}^{\mathbf{3}}\end{array}$ & $\begin{array}{c}\text { Puntas } \\
\mathbf{n} / \mathbf{1 0 0} \mathbf{d m}^{\mathbf{3}}\end{array}$ & $\begin{array}{c}\text { Preformas } \\
\mathbf{n} / \mathbf{1 0 0} \mathbf{d m}^{\mathbf{3}}\end{array}$ & $\begin{array}{c}\text { Raspadores } \\
\mathbf{n} / \mathbf{1 0 0} \mathbf{d m}^{\mathbf{3}}\end{array}$ & $\begin{array}{c}\text { Lascas usadas } \\
\mathbf{n} / \mathbf{1 0 0}_{\mathbf{d m}} \mathbf{3}\end{array}$ \\
\hline 1 & 136 & 3.2 & 5.3 & 5.1 & 4.4 & 8.8 & 12.5 \\
2 & 264 & 2.1 & 3.6 & 1.9 & 4.5 & 7.6 & 4.2 \\
3 & 296 & 5.4 & 3.6 & 7.8 & 12.8 & 13.5 & 14.2 \\
4 & 284 & 6.1 & 8.7 & 6.3 & 10.9 & 20.4 & 18.3 \\
5 & 300 & 14.2 & 28.5 & 8.3 & 20.3 & 42.0 & 54.3 \\
6 & 204 & 16.3 & 38.4 & 12.7 & 20.6 & 39.7 & 73.0 \\
7 & 220 & 7.5 & 13.1 & 8.2 & 8.2 & 20.9 & 30.9 \\
8 & 168 & 7.7 & 5.2 & 3.6 & 5.4 & 26.8 & 30.4 \\
9 & 88 & 17.2 & 19.3 & 14.8 & 29.5 & 56.8 & 56.8 \\
10 & 92 & 5.2 & 3.6 & 2.2 & 4.3 & 16.3 & 25.0 \\
11 & 48 & 3.5 & 2.5 & 0.0 & 4.2 & 8.3 & 22.9 \\
\hline
\end{tabular}

Tabla 4. Densidad de artefactos y desecho líticos en Piedras Gordas (PG-1), cuadrícula A, por niveles.

habrían aumentado, y el ecosistema de Puna que se habría deteriorado como resultado de temperaturas excesivamente altas para el mantenimiento del delicado equilibrio medioambiental.

Otro aspecto que precisa discusión es la discrepancia entre las razones establecidas entre el material de desecho y los artefactos líticos, para las dos fases de incremento de la intensidad en el uso del sitio. Esta razón se duplica en los niveles 5 y 6, respecto de su similar en el nivel 9 (Figura 8). Cuando se desdobla la curva de artefactos en algunos de sus componentes o tipos de artefactos, encontramos indicios de variabilidad que son propias de cada tipo de artefactos, lo que parece ayudar en la interpretación de la discrepancia observada. 


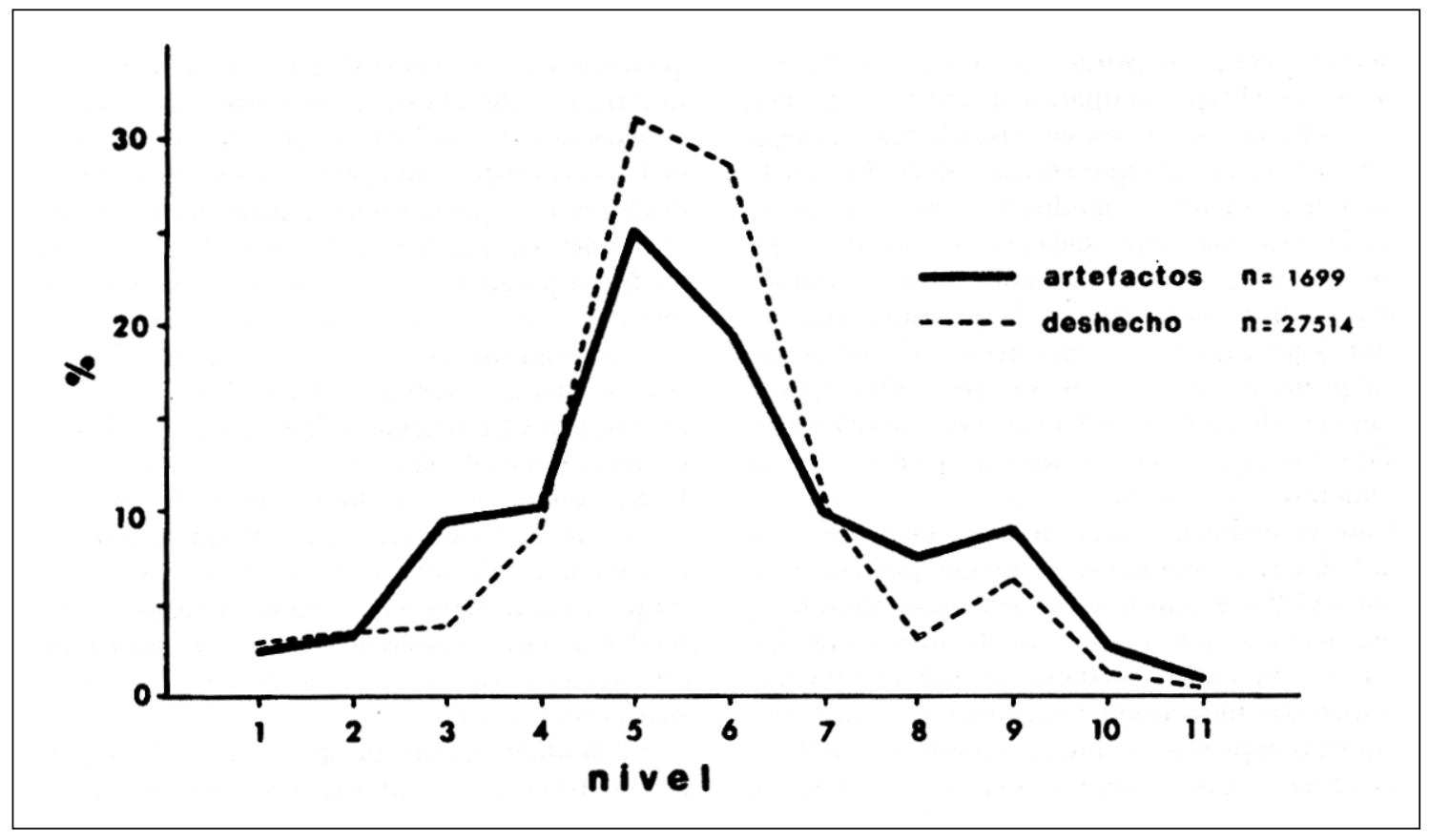

Figura 7. Fluctuación porcentual de artefactos y desechos líticos en Piedras Gordas (PG-1), cuadrícula A, por nivel.

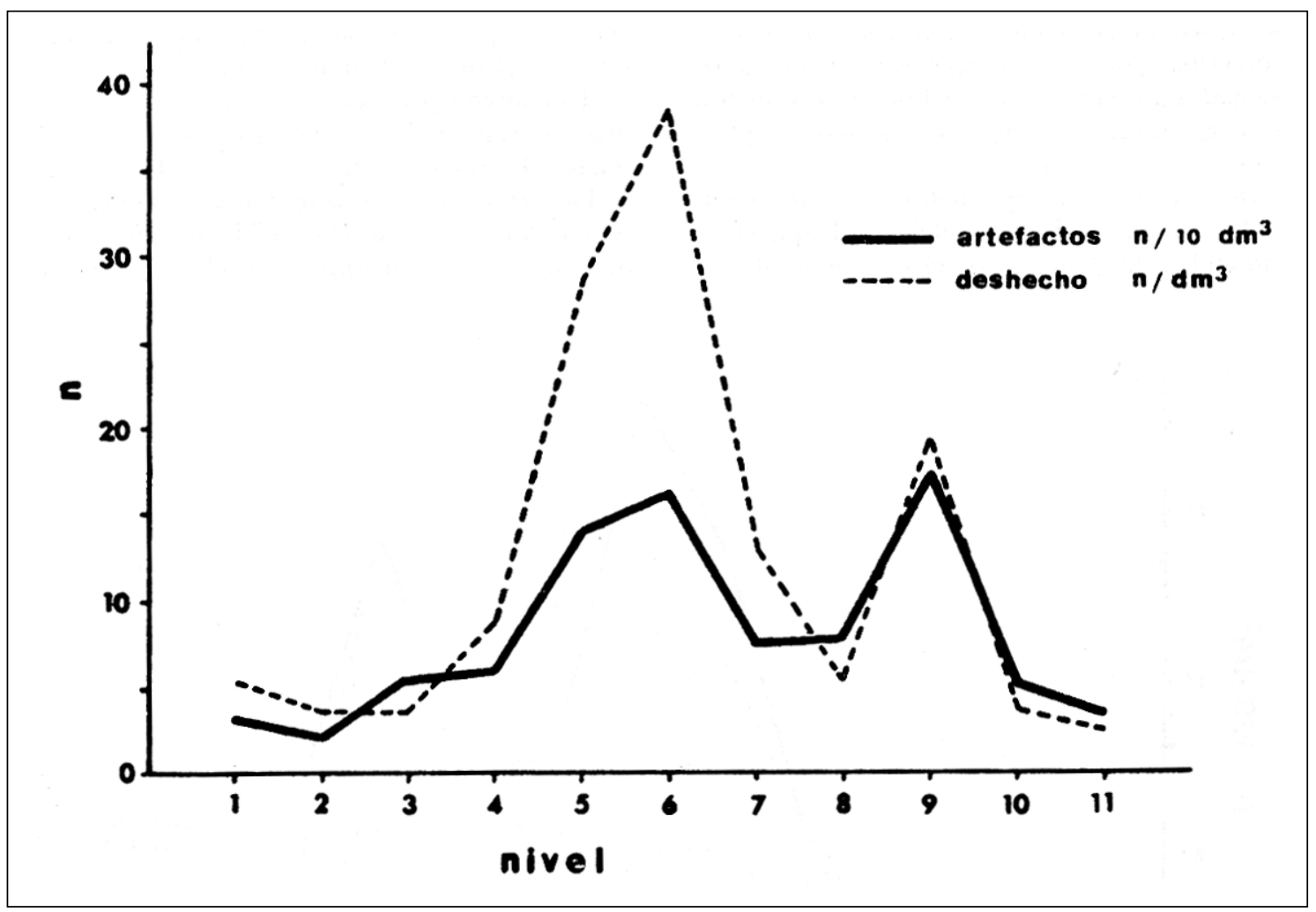

Figura 8. Fluctuación de la densidad de material lítico, respecto del volumen del relleno. 
El desdoblamiento de la curva de densidad de artefactos en cuatro de sus componentes más relevantes está ilustrado en la Figura 9. Si se comparan los segmentos de curvas de densidad de cada tipo de artefacto, que corresponden a las dos fases de uso intenso del sitio, hallamos que mientras las puntas, preformas y raspadores disminuyen en densidad de una a otra fase, hasta en $30 \%$, las lascas con señales de uso aumentan en más del $12 \%$.

Las razones de estas diferencias no son muy aparentes. Por lo menos dos posibilidades han sido consideradas: una, en el simple sentido de que siendo mayor la muestra de material provista por los dos niveles (5 y 6) de la segunda fase, respecto de sólo el nivel 9 en el caso de la primera fase, se habría suscitado un efecto multiplicador en la producción de lascas, habiéndose utilizado un número mayor de ellas; sin embargo, este argumento no parece intuitivamente convincente. La otra posibilidad se fundamenta en la posible relación entre el incremento desproporcionado de lascas, tanto usadas como las de desecho, y el drástico reemplazo de tipos de piedra utilizados como materia prima en Piedras Gordas.

Este reemplazo es notorio en el gráfico de fluctuaciones en el porcentaje de cuatro tipos de piedra, que se ofrece en la Figura 10. El gráfico se ha estructurado a base de una submuestra de 4128 artefactos y material de desecho provenientes de los once estratos de la cuadrícula A. El reemplazo es más dramático en el caso de la calcedonia y el horsteno (chert), mientras que el pedernal acusa una situación menos extrema, siendo notorio que su fase de menor popularidad sucede después del nivel 6 , recuperándose en algo en los niveles 2 y 3 . El cuarzo, por su lado, ofrece un patrón más o menos inverso al ilustrado para el pedernal.

Lo que resulta significativo en este gráfico es que es en el nivel 6 y en el nivel 5, esto es, aquellos que representan la fase ocupacional más intensa del sitio, donde se cruzan las curvas del horsteno y de la calcedonia, dando lugar a las tasas de variabilidad más drásticas, según se puede deducir del empinamiemo de las curvas. Es también en estos niveles que el pedernal experimenta la mayor depresión, mientras el cuarzo goza de la mayor popularidad en toda la secuencia. Es muy posible, que conjuntamente con la imposición de los horstenos como materia prima en Piedras Gordas, se hubiera popularizado una tecnología lítica más sofisticada, requiriendo de mayores labores de reducción de matrices por lasqueado. Si es que esta segunda posibilidad está correctamente

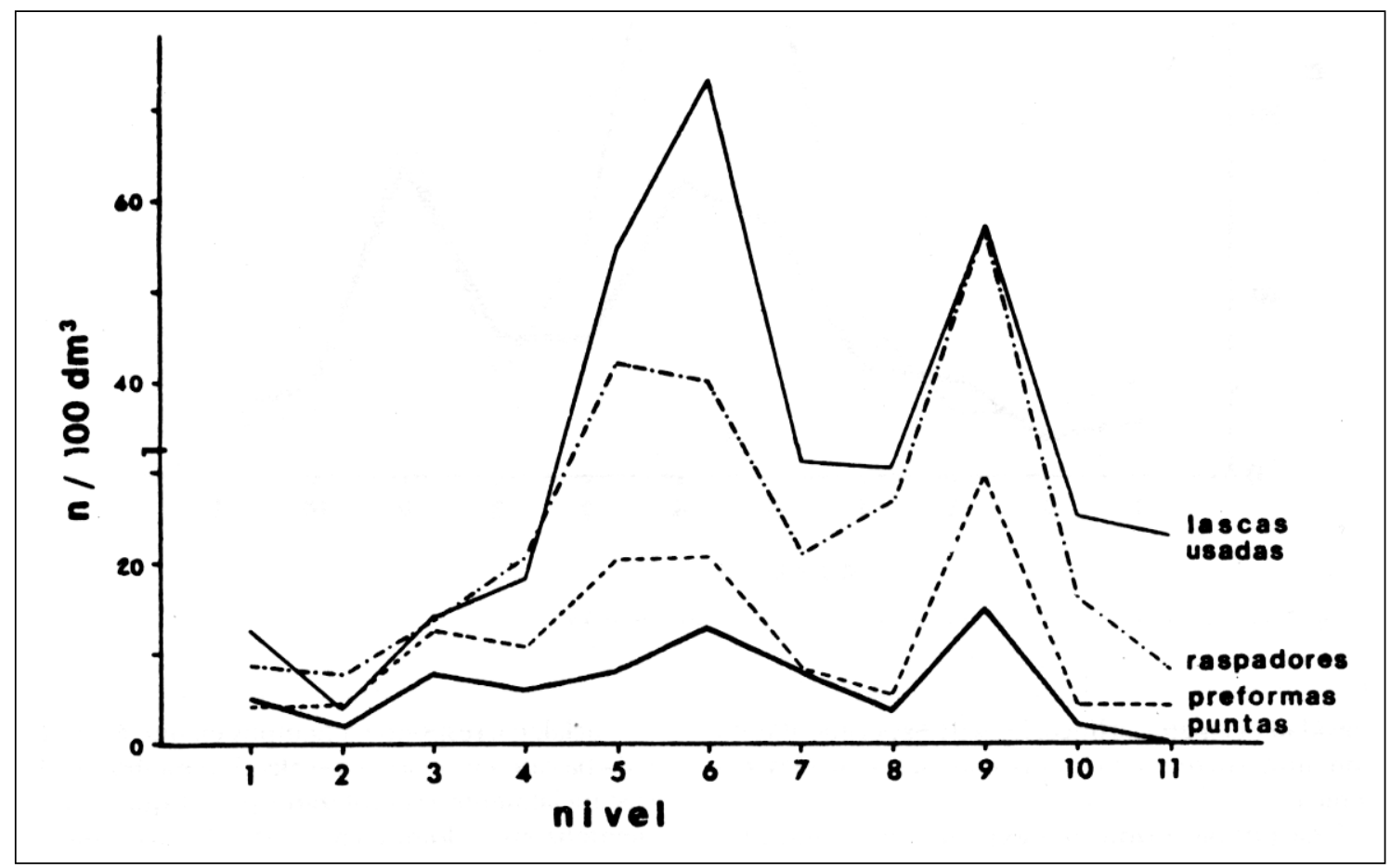

Figura 9. Densidad de algunos tipos de artefactos por cada $100 \mathrm{dm}^{3}$ de relleno. 


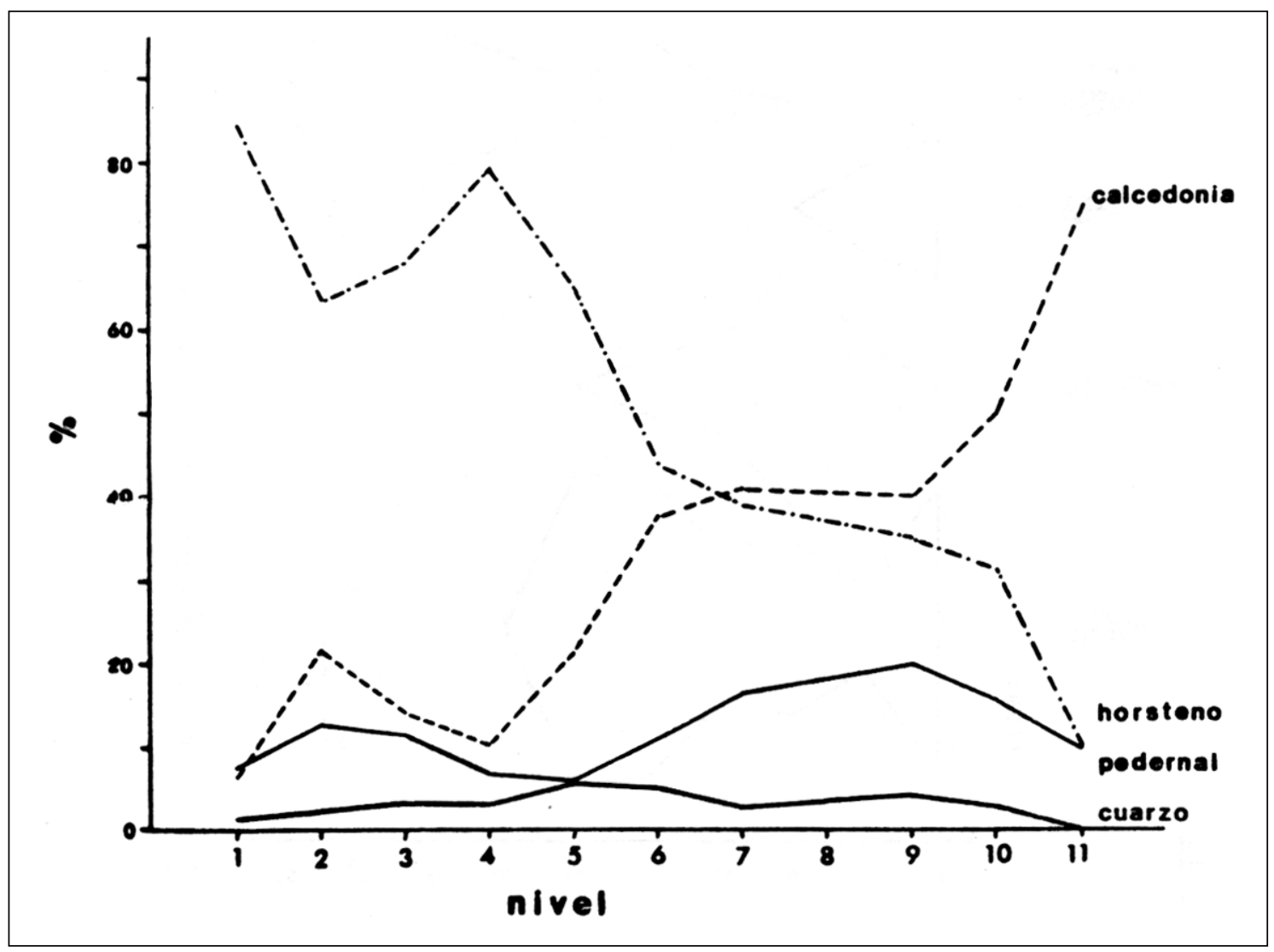

Figura 10. Fluctuaciones porcentuales en el uso de cuatro tipos de materia prima lítica en Piedras Gordas (PG-1), cuadrícula A, por niveles.

establecida, entonces se puede concluir que estamos confrontados con evidencia muy clara de una fase ocupacional del sitio, cuando se suscitaron formas de cambio cultural.

Efectivamente, si bien esta fase no es la única en que ha sido posible detectar patrones de cambio cultural, como veremos más adelante, en cambio sí se puede asegurar que por lo menos en los niveles 5 y 6 es donde se puede apreciar mejor el hecho de que el incremento en el uso de lascas como artefactos no es un fenómeno aislado, sino que, por el contrario, es sólo un aspecto más de todo un proceso cultural y social complejo y profundo. Concomitantemente, se ha observado una evidente modificación en la tipomorfología de importantes tipos de artefactos como puntas y raspadores. Esta modificación es tan pronunciada, que permite postular la ocurrencia de una marcada crisis sociocultural en tiempos representados por los niveles 5 y 6 , cuyas características deben ser tema de investigación, inmediatamente. Aquí, hay que limitarse a ilustrarla utilizando los patrones observados de variabilidad temporal de tipos morfológicos de puntas y raspadores.

La Figura 11 representa gráficamente estos patrones de variabilidad en el caso de tipos de puntas de proyectil. A pesar del tamaño relativamente pequeño de las muestras para cada nivel, es posible notar tendencias significativas; pero si las proporciones determinadas se encontraran cuestionables, aún se podría utilizar el gráfico sólo en términos de presencia y persistencia de tipos de puntas.

Un examen minucioso, basado en consideraciones no sólo morfológicas, sino además tecnológicas, produjo hasta 10 tipos de puntas en la colección de Piedras Gordas. Ocho de estos tipos son mostrados en la Figura 12. La inclusión del criterio tecnológico para distinguir tipos fue muy útil. Por ejemplo, los tipos 2 y 3 son morfológicamente iguales, con una forma lanceolada y la base redondeada, propias de puntas que se suelen reconocer dentro del Complejo Ayampitín de Sudamérica. Sin embargo, difieren en 


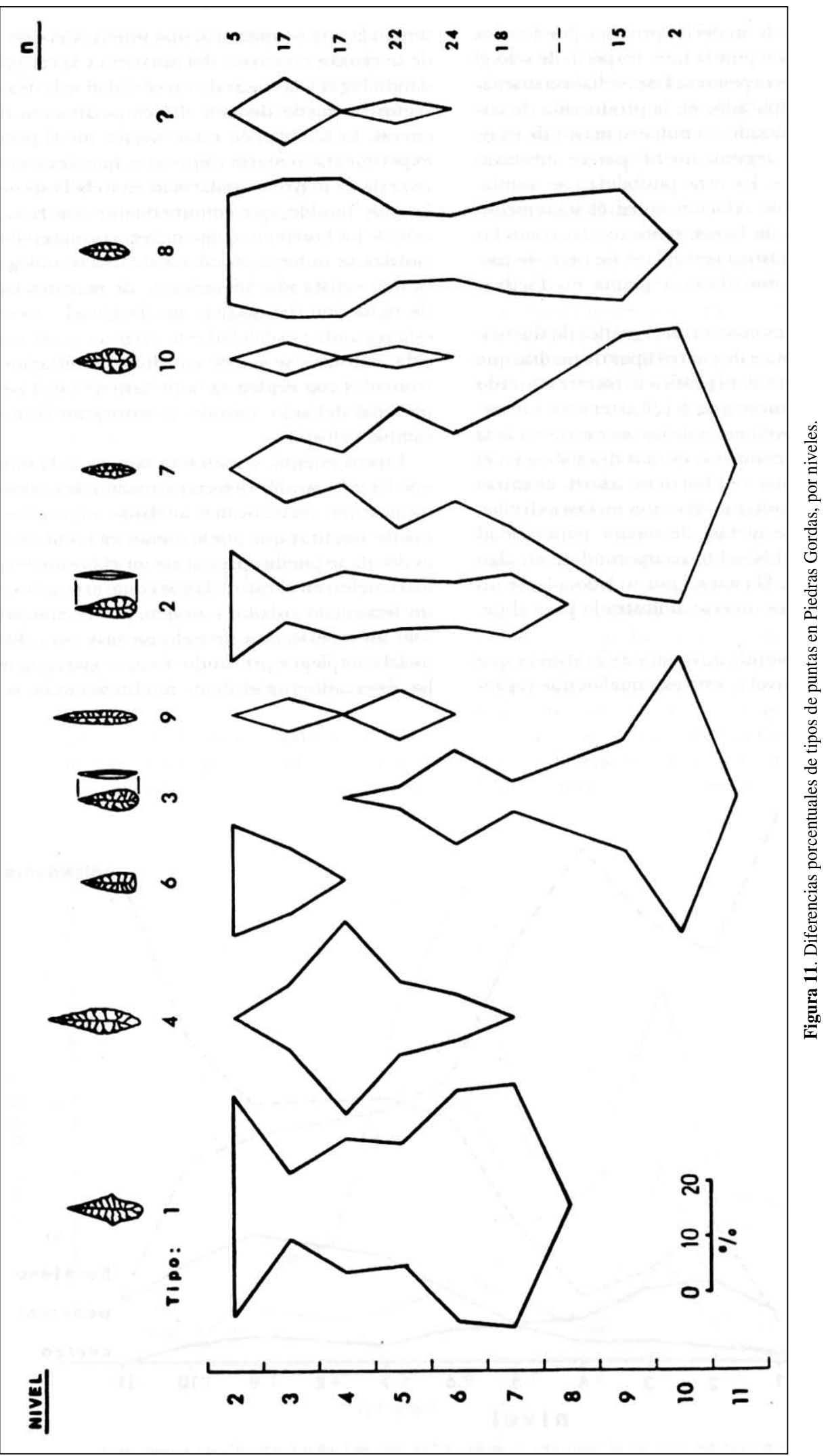




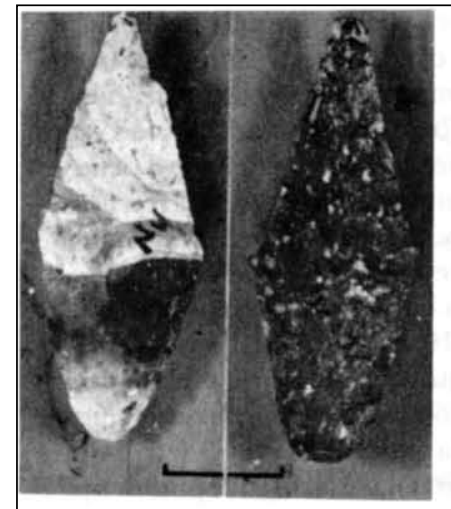

a

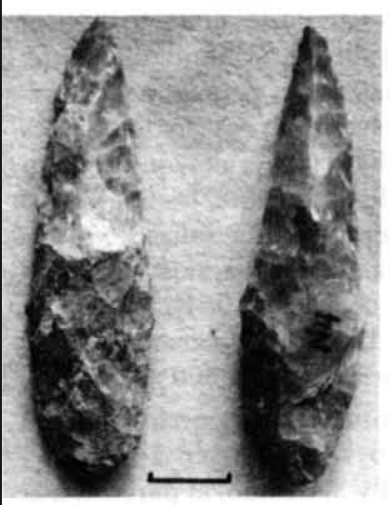

d

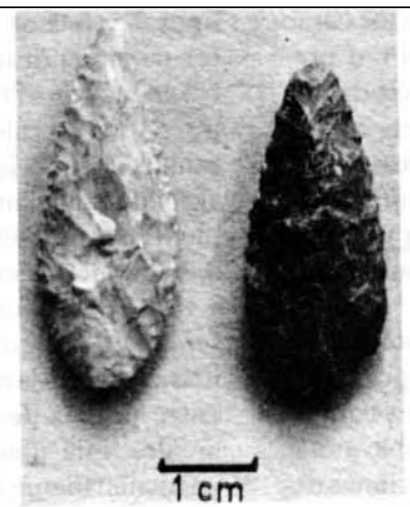

b

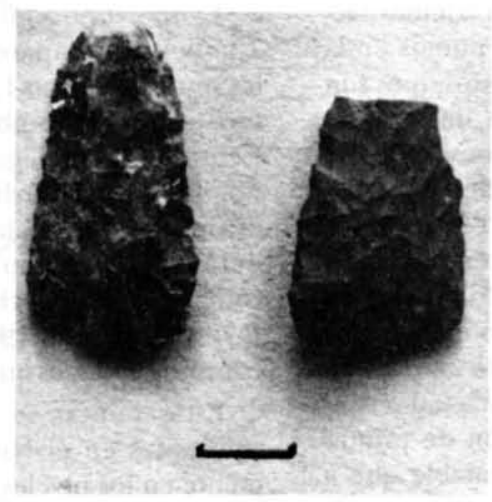

e

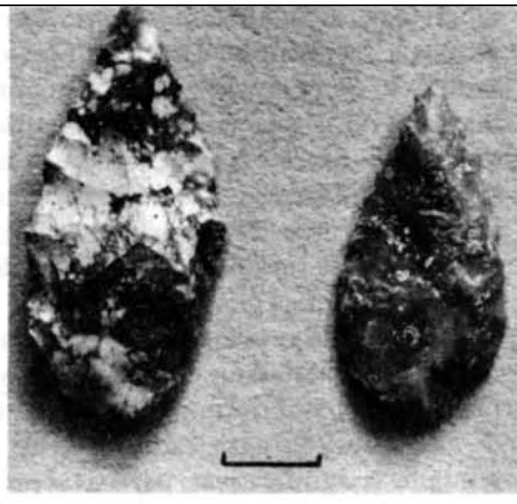

C

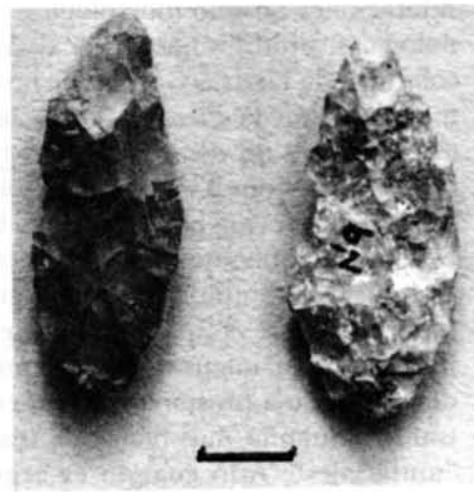

f

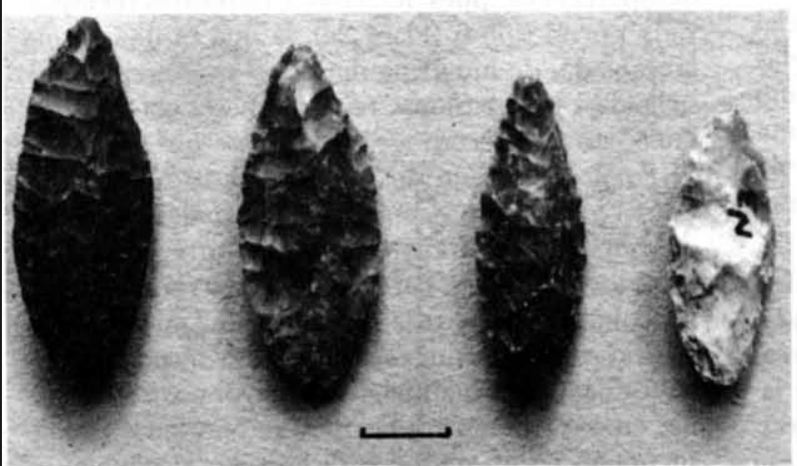

g

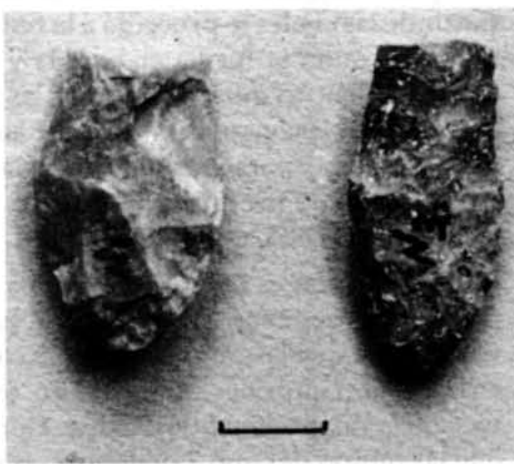

h

Figura 12. a) Puntas de proyectil Tipo 1, "pentagonales"; b) Puntas de proyectil Tipo 2, "Ayampitín" bifaciales; c) Puntas de proyectil Tipo 3, "unifaciales"; d) Puntas de proyectil Tipo 4, "hoja de laurel"; e) Puntas de proyectil Tipo 6, "base recta"; f) Puntas de proyectil Tipo 7, "base punteada, avellanadas"; g) Puntas de proyectil Tipo 8, "base punteada, finas"; h) Puntas de proyectil Tipo 10, "hombro incipiente". 
que el tipo 2 es un artefacto inequívocamente bifacial, mientras el tipo 3 muestra un mínimo de lasqueado a presión en su superficie basal o ventral, insinuando más bien una tradición de puntas "unifaciales". Aun cuando es argumentable que a despecho de la forma resultante, en ambos casos la técnica de elaboración parece igual, lo cierto es que existe una diferencia fundamental en la técnica general de elaboración de cada tipo de puntas. En el caso de las puntas del tipo 2 , resulta aparente que se han cumplido requisitos de selección de lascas grandes, a partir de las cuales se procedió a la reducción bifacial que determinó la forma elaborada y estética de las puntas; mientras que en el caso de las puntas del tipo 3, no se habría contado con lascas lo suficientemente grandes como para permitir toda la secuencia de preparación de preformas necesaria para la consecución de un bifaz perfecto.

La distinción es operativa bajo dos aspectos diferentes pero conexos. De un lado se ha percibido la tendencia a que las puntas del tipo 3 corresponden a ensamblajes culturales antiguos, en términos de la secuencia ocupacional de Piedras Gordas, mientras que las puntas del tipo 2 tienden a ser más recientes, como puede verse en la Figura 11. De otro lado, se ha observado, aunque en forma asistemática, que hay una predisposición a que las puntas del tipo 3 sean a calcedonia, mientras las del tipo 2 son predominantemente de horsteno.

Algo bastante similar ocurre con las puntas de los tipos 7 y 8. Los dos tipos son puntas pequeñas de forma almendrada, con base muy aguzada. Sin embargo, es notoria la mayor frecuencia de un acabado tosco, uso de calcedonia, y mayor antigüedad entre puntas del tipo 7, mientras que las del tipo 8 tienen un acabado notoriamente más fino, usan más frecuentemente el horsteno y pedernal y son definitivamente más populares en tiempos más recientes.

Si se observan las curvas ontogénicas que se presentan en la Figura 11, se notan estas tendencias. Es más, resulta claro que el área de reemplazo crítico entre puntas de unos y otros tipos aparentemente iguales está ubicada en los niveles 5 y 6 . Esto es particularmente claro en el caso de las puntas tipo 3 "unifaciales", las que después del nivel 5, simplemente desaparecen, mientras que las de tipo 2 permanecen sin variar mayormente su proporción ya establecida desde el nivel 7.

Es oportuno aquí agregar que es también en el nivel 7 , donde aparecen abrupta y abundantemente las puntas del tipo 1, una forma "pentagonal" característica de ensamblajes tempranos en los Andes Centrales. Sus espigas o barbas laterales, que definen una forma primordial de pedúnculo, las han hecho inconfundibles en la literatura especializada, considerándoselas como una forma diagnóstica de los complejos Lauricocha I (Cardich 1964), y Puente y Jaywa (McNeish 1969, 1971; McNeish et al. 1970) con antigüiedades que oscilan entre 5500 y $9500 \mathrm{AC}$.

Estas puntas se mantienen proporcionalmente constantes en el nivel 6 y disminuyen apreciablemente en los niveles 5, 4 y 3, debido, al parecer, a la aparición en los niveles 5 y 6 , de por lo menos otros cuatro tipos de puntas. De estos nuevos tipos, sólo el tipo 4, una forma de hoja de laurel de tamaño grande y acabado tosco (Figura 12d), adquiere mayor popularidad después del nivel 5, pero sólo para disminuir y desaparecer después del nivel 3 , cuando es reemplazada por el tipo 6 (Figura 12e), la que es una forma lanceolada, de muy fina manufactura, sección muy delgada y base bastante rebajada hasta obtener una línea bastante recta.

Por lo menos en dos de estos últimos casos, los tipos 1 y 6 de puntas están asociadas al uso del horsteno como materia prima. Agregado esto a los casos anteriores, parecen evidenciar con bastante probabilidad de certeza que hubo una introducción al sitio de varias nuevas tradiciones tecnológicas y culturales que demandaban un mayor uso del horsteno, en oposición a tradiciones más antiguas fundamentadas en un mayor énfasis en la calcedonia.

Los patrones de variabilidad observados son también perceptibles en el caso de los raspadores de piedra recuperados de Piedras Gordas. La Figura 13 muestra una serie de curvas ontogénicas basadas en las variaciones porcentuales de 12 tipos de raspadores identificados. Ocho de estos tipos son mostrados en la Figura 14. Por lo menos tres de estos tipos: B, "thumb scrapers"; C, "laterales", y F, "en zona", acusan un patrón distribucional muy constante durante casi todo el lapso ocupacional del sitio. En cambio, los tipos "semicircular grueso" (I), "denticulado tosco" (J) y "semicircular grueso pequeño" (K), aparecen en niveles inferiores y tienden a desaparecer en los niveles 6 y 5, cuando otros tipos los reemplazan: "terminales" (A), "spoke-shave" (G) y "circulares" (H). Finalmente, dos tipos semicirculares de prolongada vigencia, D y E, muestran una distribución complementaria, donde las lascas gruesas "plano convexas" (D) tienen mayor popularidad en niveles 


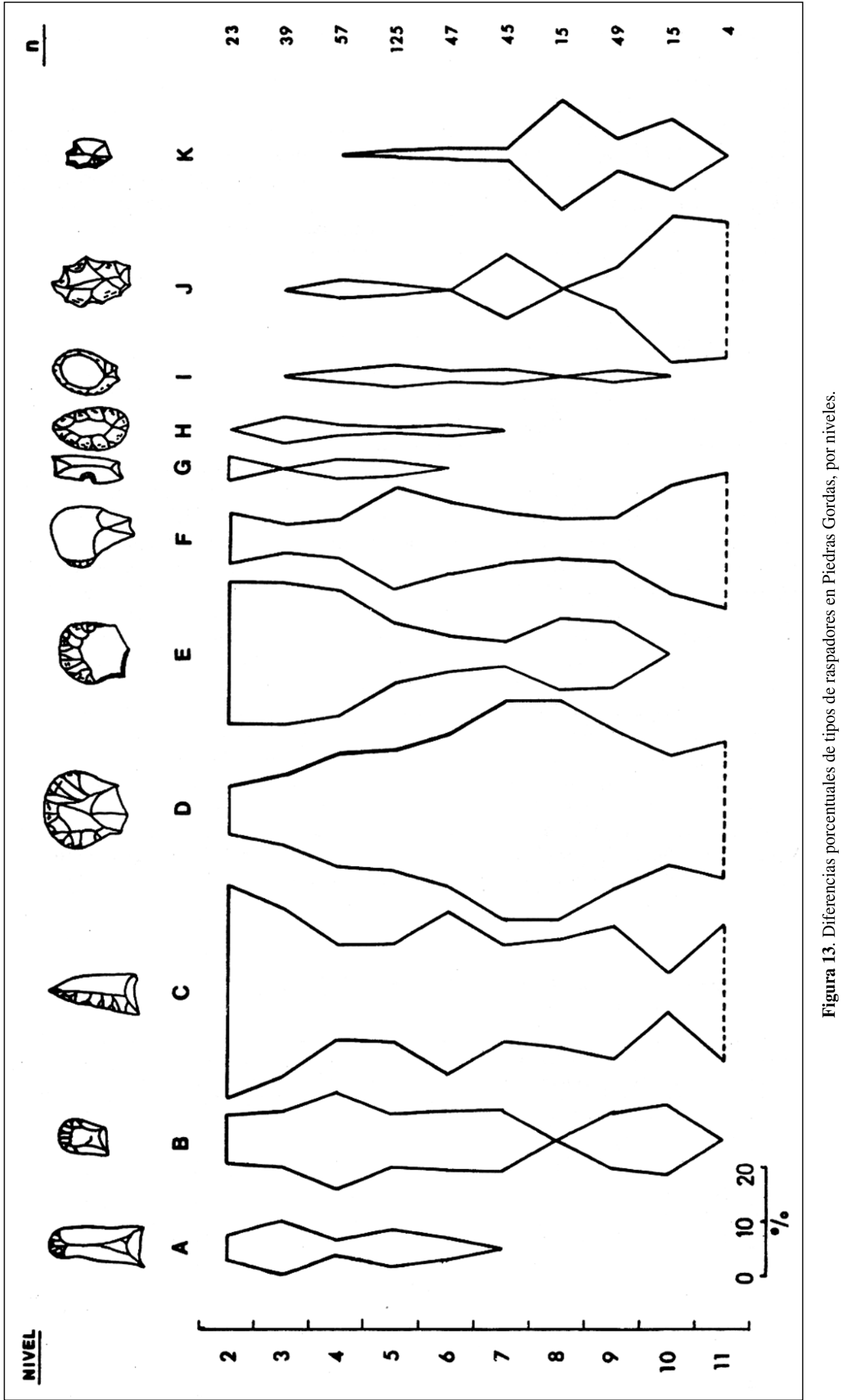




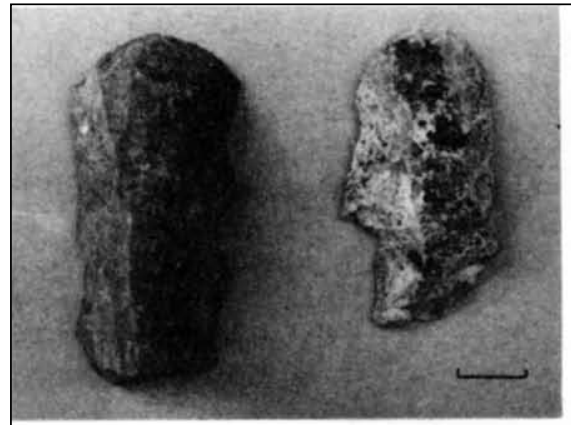

a

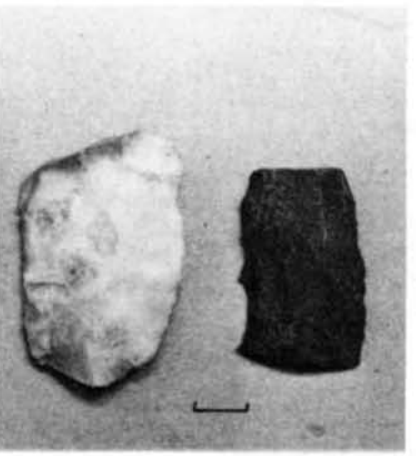

C

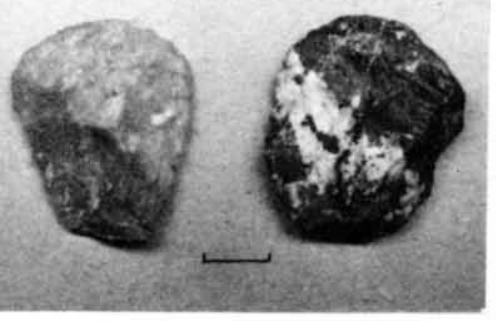

e

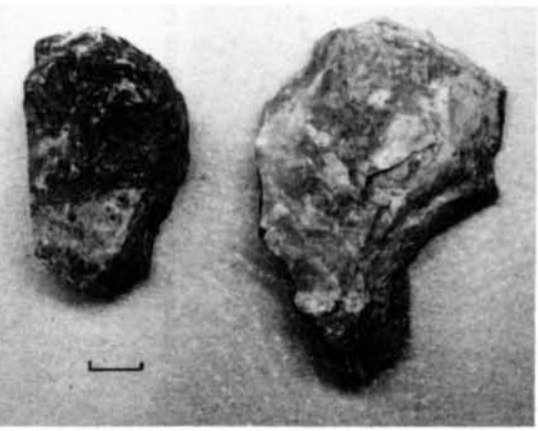

g

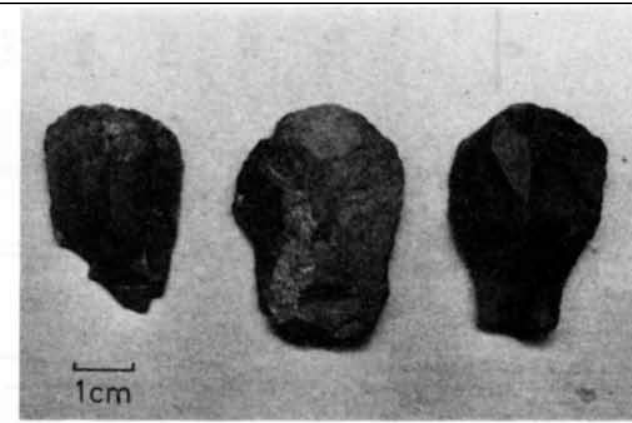

b

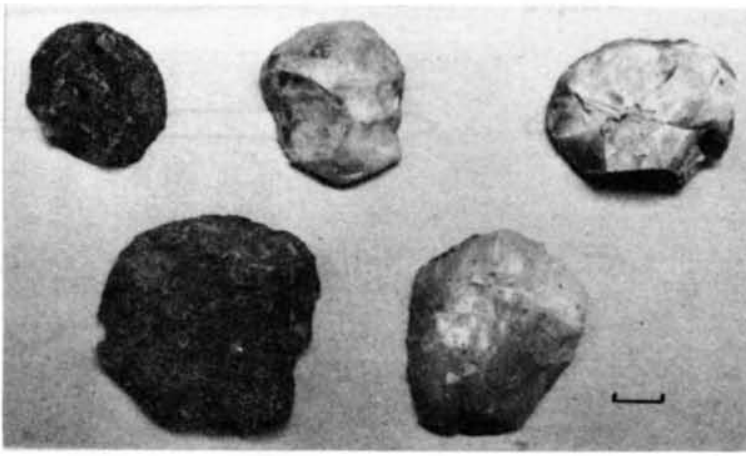

d

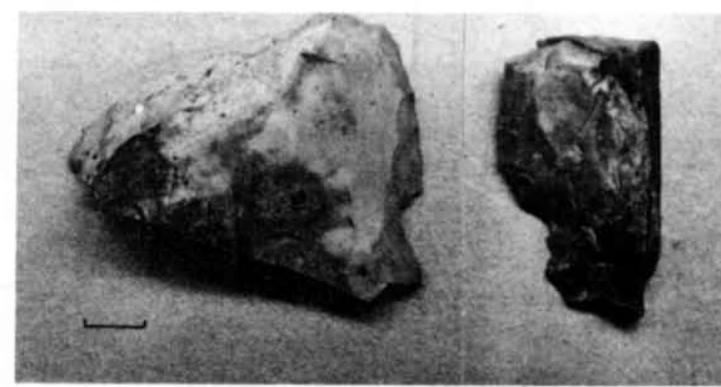

f

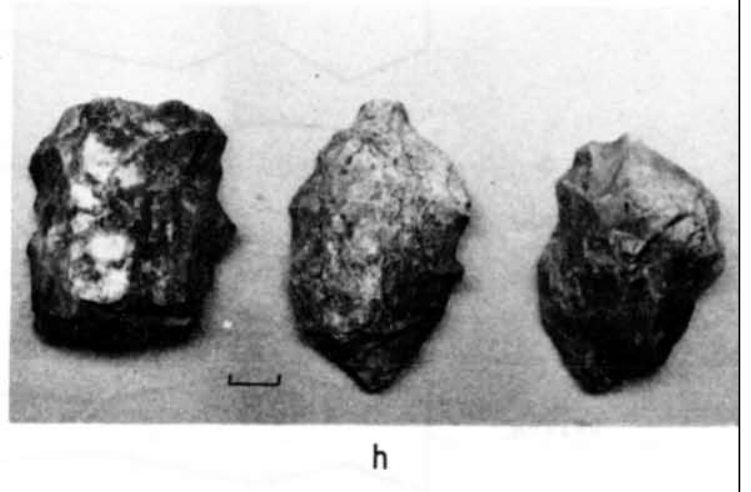

Figura 14. a) Raspadores Tipo A, "terminales"; b) Raspadores Tipo B, "thumb scrapers"; c) Raspadores Tipo C, "laterales"; d) Raspadores Tipo D, "plano-convexo, semicircular"; e) Raspadores Tipo E, "plano, semicircular"; f) Raspadores Tipo G, "spoke shave"; g) Raspadores Tipo I, "semicircular grueso"; h) Raspadores Tipo J, "denticulado tosco". 
inferiores, mientras las lascas delgadas "planas" (E) se imponen en niveles superiores.

Aquí nuevamente se nota la tendencia a que tradiciones morfológicas y tipológicas encuentren en los niveles 5 y 6 una fase crítica de inclusión, disminución o reemplazo. La naturaleza tecnológico-cultural de tales cambios se ha ilustrado en el análisis tipológico de artefactos que ha precedido a esta sección, y su asociación con posibles variaciones climáticas en el pasado, fue también propuesta. Pero un intento de especificar el fenómeno en términos funcionales no tuvo mayor éxito.

Específicamente, se exploró la posibilidad de que, conjuntamente con los patrones de cambio climático y cultural detectados, se podrían haber producido cambios en los patrones de uso económico del sitio. Con esta finalidad se observó la constitución funcional de los ensamblajes líticos de cada nivel, determinando distribuciones relativas de frecuencias de diversos tipos de artefactos. El resultado de este tratamiento, basado en los datos de la Tabla 3, está ilustrado en la Figura 15. Las curvas ontogénicas para cada tipo de artefacto muestran una alta consistencia monotónica a lo largo de toda la historia ocupacional del sitio. Sólo la ausencia de puntas en el nivel más profundo de la excavación y la presencia restringida de hojas prismáticas en los niveles superiores, parecen indicar situaciones particulares que merecen un mayor examen. Sin embargo, estas dos observaciones no parecen objetar significativamente la conclusión de que el sitio mantuvo un patrón constante de actividades económico-funcionales, obviamente propias de tareas resultantes de un modo de vida basado en la caza.

\section{Artefactos de hueso y asta}

Un total de 180 especímenes de hueso y asta han sido clasificados en 6 categorías o tipos de artefactos. El criterio de clasificación ha sido funcional, esto es, en términos del uso más probable que puede habérsele dado a cada pieza. El resultado cuantificado de esta clasificación está detallado en la Tabla 5. Debe notarse que la categoría "Indeterminado" reúne aquellos ejemplares que exhiben señales de uso, desgaste y/o modificación por manos humanas, pero que no ha sido posible identificar su aplicación a algún tipo específico de actividad. Esta categoría es diferente de la que incluye huesos que poseen huellas resultantes de labores de carneo, los que no pueden ser considerados artefactos.
Los lasqueadores son segmentos terminales del asta de cérvidos (Figura 16a), cuyos extremos muestran un alto grado de pulimento resultante de su uso en trabajos de reducción de bifaces, seguramente. Los raspadores suelen ser fragmentos de escápula o de ulna, que muestran un extremo cortado y fuertemente desgastado a lo largo de un segmento considerable del borde (Figura 16b y 16c).

Los artefactos punzantes y cortantes incluyen una amplia diversidad de especímenes que no muestran modificación previa a su uso, pero tratándose de fragmentos de huesos largos, cuyos bordes y puntas ofrecieron posibilidades de ser utilizados, debieron ser seleccionados para tareas que dejaron muestras de desgaste. Se les ha separado en dos categorías de utensilios, a base del área que muestra la mayor utilización, pero debe anotarse que hay cierta tendencia a que estos artefactos tengan un uso combinado como tajadores y como perforadores.

Los adornos son especímenes diversos que muestran señales de modificación intencional dirigida al logro de una forma estética propia de objetos de decoración personal. Algunos de estos artefactos son mostrados en la Figura 17a, siendo notoria la intención de su uso como elementos de un collar. Otro artefacto tiene señales inequívocas de haber sido sometido a cortes, seguramente para darle a este fragmento de escápula una forma particular (Figura 17b).

La categoría de artefactos de tipo indeterminado incluye objetos como los que se muestran en las Figuras $17 \mathrm{c}$ y $17 \mathrm{~d}$. El primero de estos artefactos es un fragmento proximal del fémur derecho de algún mamífero pequeño, aparentemente Canis sp., del que se han obtenido cuentas cilíndricas como las mostradas en la Figura 17a, mediante una técnica de cortado por cordel. El segundo objeto es un fragmento de hueso largo que ha sido sometido a una acción de "raspado" o "limado", a fin de reducir uno de los extremos y redondear el otro. La finalidad de tal elaboración no ha podido ser establecida.

Los artefactos de hueso, considerados en conjunto (Tabla 5), evidencian una variabilidad cuantitativa apreciable a lo largo del tiempo de ocupación de Piedras Gordas. Si recurrimos a una medida de la densidad de artefactos de hueso por unidad de relleno en cada nivel de la excavación, similar a la que se utilizó en el caso de los artefactos de piedra, contamos con un medio de comparación muy eficaz. Este tipo de tratamiento tiene la ventaja de corregir 


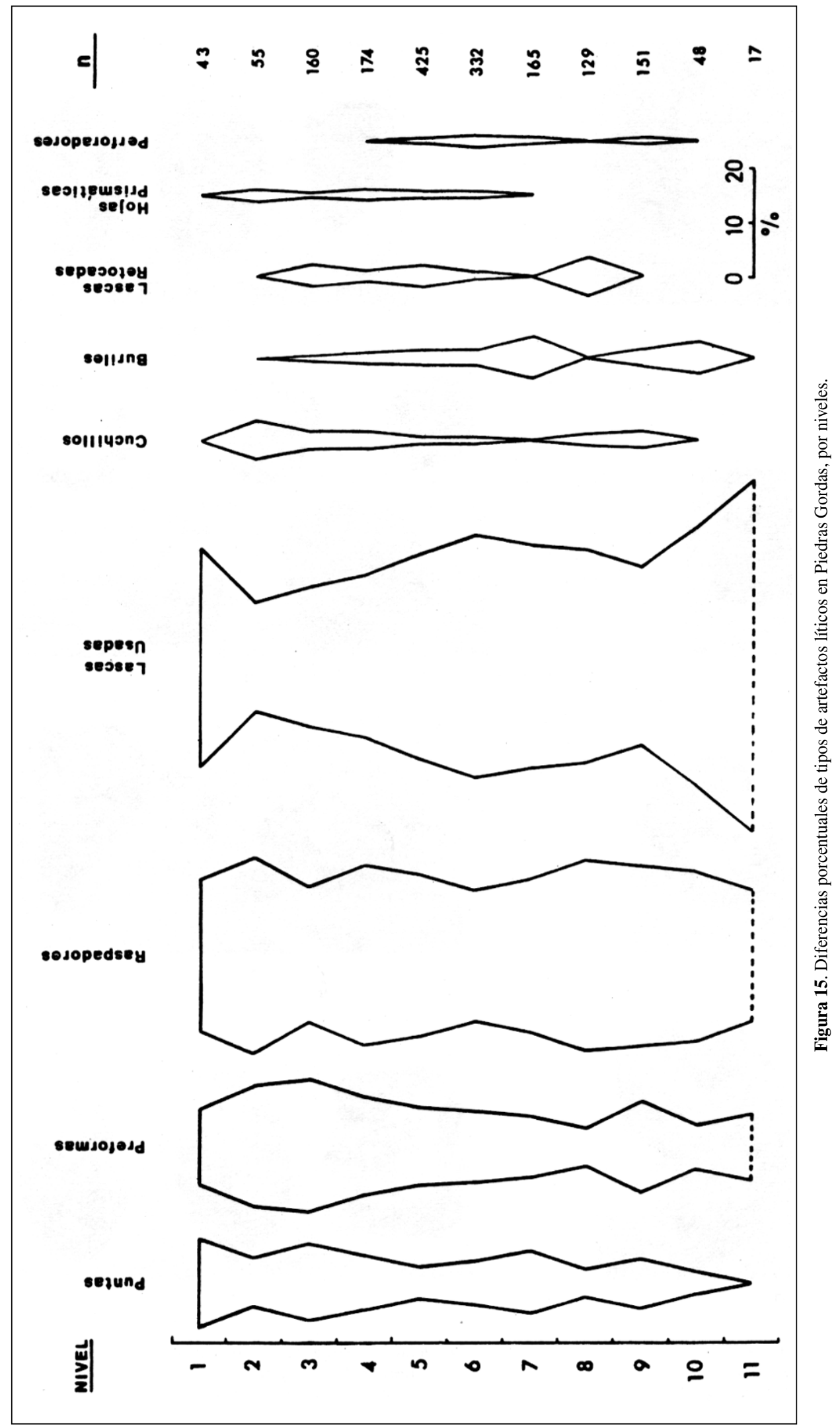




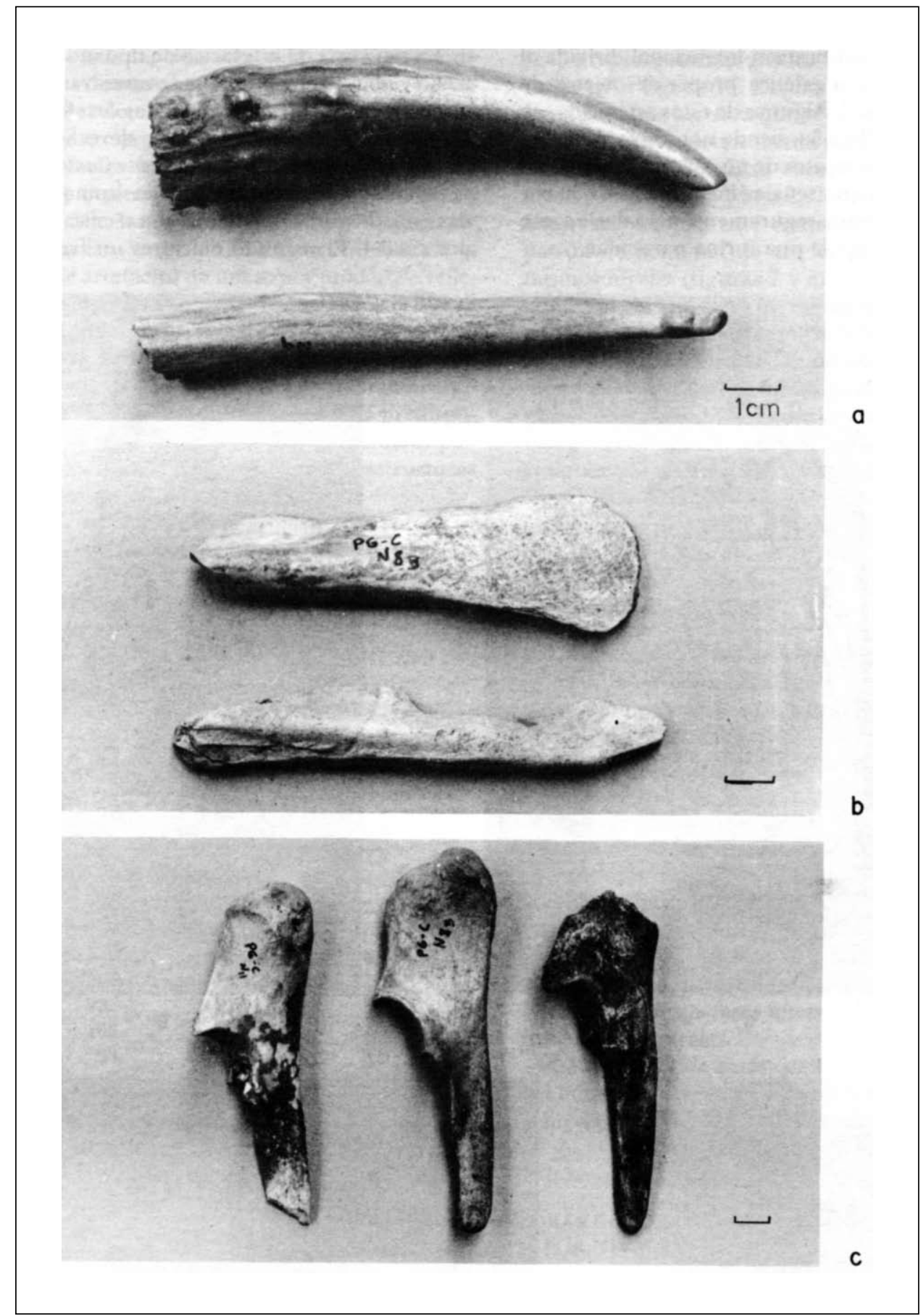

Figura 16. a) Lasqueadores de asta de venado; b) Raspadores en fragmentos de escápula; c) Raspadores en fragmentos de fíbula. 


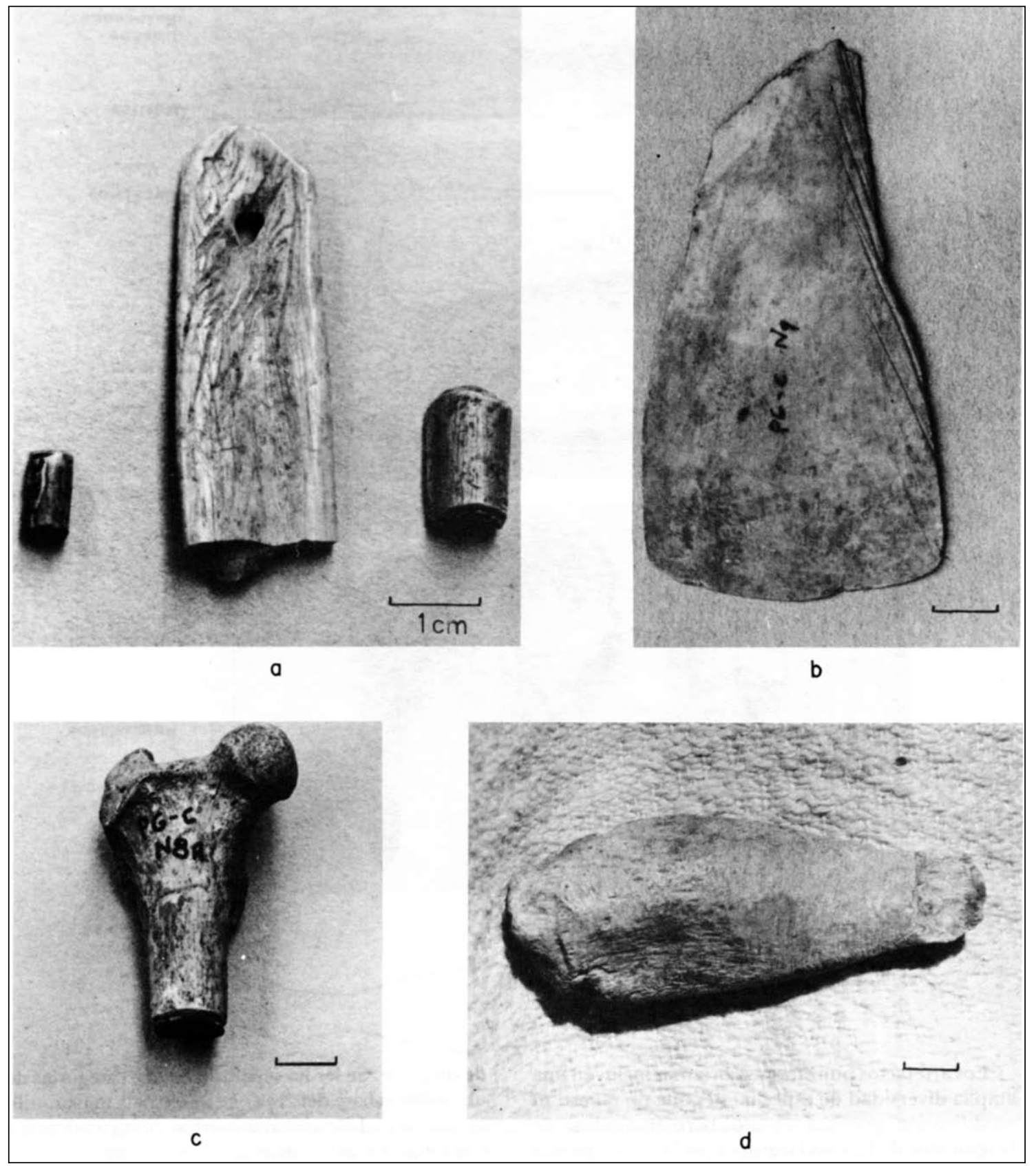

Figura 17. a) Pendiente y cuentas; b) Fragmento de escápula con cortes; c) Fragmento de fémur del que se han obtenido cuentas; d) Fragmento de hueso largo, mostrando muestras de limado. 


\begin{tabular}{|r|c|c|c|c|c|c|c|}
\hline Nivel & Lasqueadores & Raspadores & $\begin{array}{c}\text { Artefactos } \\
\text { punzantes }\end{array}$ & $\begin{array}{l}\text { Artefactos } \\
\text { cortantes }\end{array}$ & Adorno & Indeterminado & Total \\
\hline 1 & - & 2 & 2 & 1 & - & 1 & 6 \\
2 & - & - & 1 & - & - & 1 & 2 \\
3 & - & 1 & 5 & 5 & - & 1 & 12 \\
4 & - & 1 & 2 & 1 & - & - & 4 \\
5 & 1 & 2 & 12 & 15 & - & 3 & 33 \\
6 & 1 & 1 & 6 & 10 & - & - & 18 \\
7 & - & 3 & 8 & 20 & 3 & 1 & 35 \\
8 & - & 2 & 4 & 6 & - & - & 35 \\
9 & 1 & 6 & 8 & 20 & - & 2 & 8 \\
10 & 1 & - & - & 3 & 2 & 2 & 5 \\
11 & - & 1 & 1 & 1 & - & 4 & 9 \\
12 & - & 2 & - & 3 & - & $\mathbf{1 6}$ & $\mathbf{1 8 0}$ \\
\hline Total & $\mathbf{4}$ & $\mathbf{2 1}$ & $\mathbf{4 9}$ & $\mathbf{8 5}$ & $\mathbf{5}$ & & \\
\hline
\end{tabular}

Tabla 5. Artefactos de hueso y asta provenientes de Piedras Gordas (PG-1), cuadrícula C.

los efectos de la predisposición propia de un relleno que tiene incluidas piedras desprendidas de la matriz y restos de estructuras y hornos.

La tabla 6 ofrece estas medidas para cada nivel, así como la manera en que han sido calculadas.

\begin{tabular}{|c|c|c|c|}
\hline Nivel & $\begin{array}{c}\text { Relleno } \\
\mathbf{d m}^{\mathbf{3}}\end{array}$ & $\begin{array}{c}\text { Artefactos } \\
\mathbf{n}\end{array}$ & $\begin{array}{c}\text { Densidad } \\
\mathbf{n} / \mathbf{1 0 0} \mathbf{d m}^{\mathbf{3}}\end{array}$ \\
\hline 1 & 55 & 6 & 10.9 \\
2 & 92 & 2 & 2.2 \\
3 & 256 & 12 & 4.7 \\
4 & 204 & 4 & 2.0 \\
5 & 200 & 33 & 16.5 \\
6 & 270 & 18 & 6.7 \\
7 & 296 & 35 & 11.8 \\
8 & 236 & 13 & 5.5 \\
9 & 166 & 35 & 21.1 \\
10 & 98 & 8 & 8.2 \\
11 & 16 & 5 & 31.2 \\
12 & 42 & 9 & 21.4 \\
\hline
\end{tabular}

Tabla 6. Densidades de artefactos de hueso y asta en Piedras Gordas (PG-1), cuadrícula C.

La representación gráfica de estos datos es mostrada en la Figura 18. Resulta evidente, de primera intención, que la curva que se obtiene es mucho más compleja que la determinada para artefactos de piedra. Hay una densidad excepcionalmente alta de artefactos de hueso y asta en los niveles 11 y 12 , una observación totalmente contradictoria respecto del patrón de densidad de artefactos de piedra en los mismos niveles (ver Figuras 8 y 9). Muy bien podría ser que estos dos niveles correspondan a una fase primordial en la ocupación de Piedras Gordas, durante la cual el uso de artefactos de hueso y asta podría haber sido mucho más importante que en tiempos posteriores, cuando la piedra fue una alternativa más generalizada. Sin evidencias de ocupaciones más antiguas que las del sitio, no es posible asegurar si tal fue el caso o no, por lo que debe dejarse aquí el asunto como un simple comentario a tener en cuenta en futuras investigaciones.

Restos cerámicos

Las muestras de cerámica provenientes de Piedras Gordas están compuestas sólo por fragmentos pequeños recogidos de los tres niveles superiores de la excavación. El inventario total de las cuadrículas A y B de la trinchera principal, consta de 58 tiestos, de los cuales 31 son del nivel 1, 24 son del nivel 2 y 3 del nivel 3.

El examen de esta muestra, efectuado por Carlos Chahud, de la Universidad Nacional del Centro, Huancayo, puso en evidencia una multiplicidad de estilos bastante considerable (Hurtado de Mendoza y Chahud 1978). La lista, mostrada en la Tabla 7 , cuenta con nueve tipos, todos afiliables al Período Formativo, en sus fases intermedias conocidas para los Andes Centrales.

La tradición de cerámica bruñida, no decorada, formativa, no suele ser muy tenida en cuenta en la 


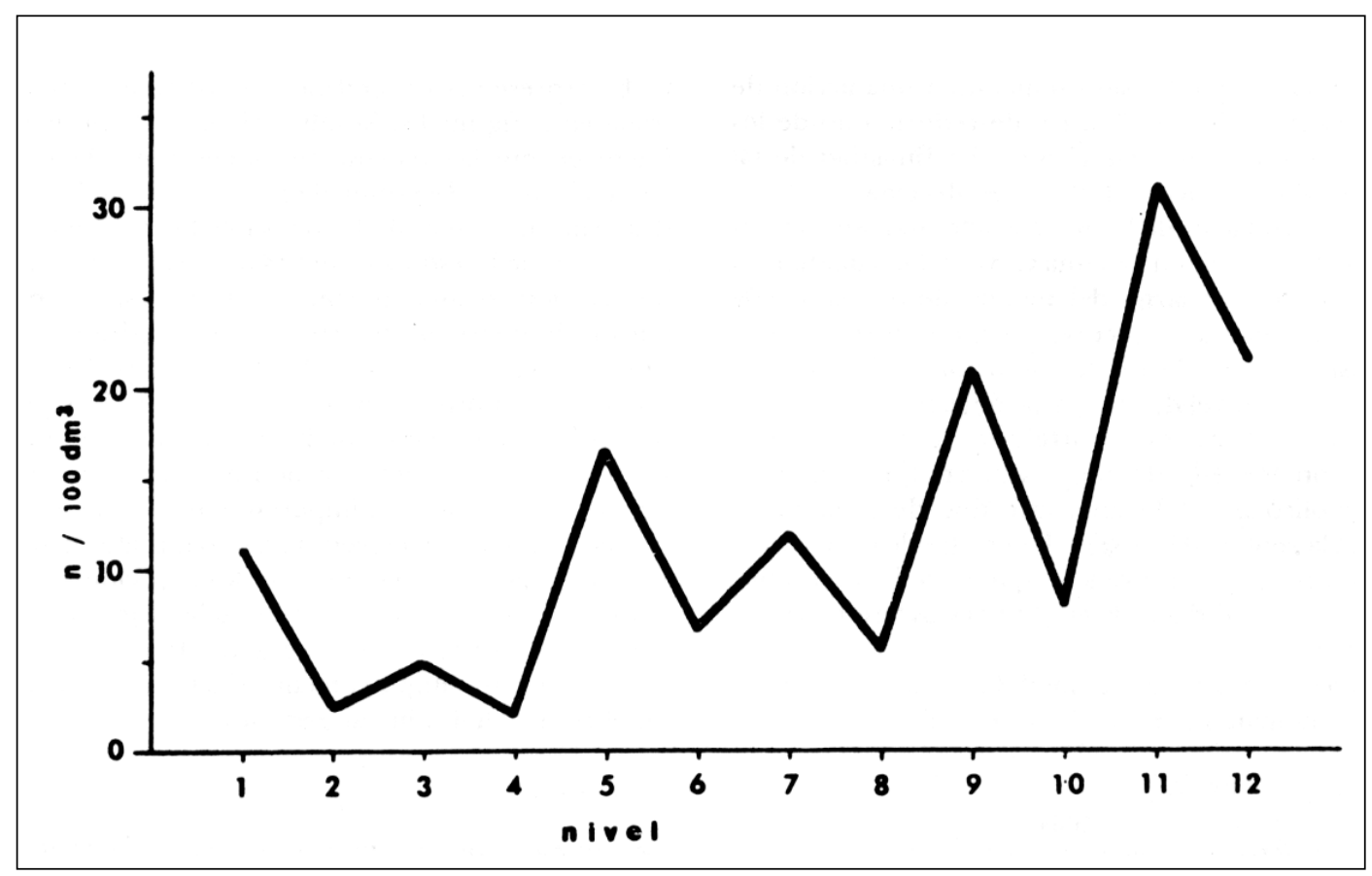

Figura 18. Fluctuaciones de la densidad de artefactos de hueso y asta en Piedras Gordas, por unidad de relleno.

\begin{tabular}{|l|c|c|c|r|r|}
\hline Tipo de cerámica & Nivel 1 & Nivel 2 & Nivel 3 & Total & \% \\
\hline Waira-Jirca Inciso Superficial & 2 & - & - & 2 & 3.4 \\
Piedras Gordas Negro Bruñido & 5 & 12 & 3 & 20 & 34.5 \\
PG Negro Pulido Fino & 1 & - & - & 1 & 1.7 \\
PG Gris Claro Bruñido & 1 & 3 & - & 4 & 6.9 \\
PG Marrón Oscuro Bruñido & 6 & - & - & 6 & 10.3 \\
PG Marrón Claro Bruñido & 1 & 1 & - & 2 & 3.4 \\
PG Marrón Claro & 11 & 5 & - & 16 & 27.6 \\
PG Rojo Oscuro Bruñido & 3 & 2 & - & 5 & 8.6 \\
PG Rojo Claro Bruñido & 1 & 1 & - & 2 & 3.4 \\
\hline Total & $\mathbf{3 1}$ & $\mathbf{2 4}$ & $\mathbf{3}$ & $\mathbf{5 8}$ & $\mathbf{9 9 . 8}$ \\
\hline
\end{tabular}

Tabla 7. Tipos de cerámica en Piedras Gordas (PG-1), Cuadrículas A y B. Por niveles.

literatura especializada. Sin embargo, la presencia consistente de su versión en color negro, en los niveles 2 y 3 de Piedras Gordas, puede que atestigüe una antigüedad por lo menos comparable con la de la cerámica incisa superficial ("shallow incised") del Complejo Waira-Jirca, representado en el sitio por dos ejemplares. Esta cerámica suele ubicarse temporalmente entre 1800 y 1150 AC (Izumi y Sono 1963).

Otros estilos tienen obvias asociaciones con tipos encontrados en Ataura, sitio Formativo cerca de Huancayo (Matos 1972), y Wichqana, en Ayacucho (Flores 1960), cuyas dataciones se remontan alrededor del 500 AC, marcando el fin de la ocupación humana prehistórica de Piedras Gordas.

El aparente abandono del sitio por estos tiempos no es incongruente respecto de los patrones ocupacionales de regiones de Puna en la Sierra Central de Perú. Un reconocimiento arqueológico, realizado en una vasta región al sur de Cerro de Pasco, entre Yauli y Huancavelica, ha mostrado una reducción drástica de las ocupaciones humanas en las punas, a partir del Intermedio Temprano, no encontrándose evidencias de reocupación sino hasta el Intermedio Tardío (Chahud 1979). La correlación de estos procesos con oscilaciones climáticas parece muy posible, por lo que está 
siendo tratado como tema de investigación por algunos especialistas (Mercer 1970; Cardich 1975).

\section{Análisis de fauna}

Las excavaciones en Piedras Gordas (PG-1) produjeron una cantidad muy considerable de huesos de animales. Las cinco cuadrículas que se trabajaron en la estación de campo de 1978 contenían un total de 106.880 especímenes; pero hasta la fecha de preparación de este artículo sólo se había analizado una muestra de 30879 piezas correspondiente a los 12 niveles de la cuadrícula $\mathrm{C}$.

El análisis de la fauna representada en la colección osteológica del sitio ha sido realizado en dos niveles. El primero, de índole cualitativa, estuvo a cargo de Alfredo Altamirano y Emma Guerra, técnicos del Laboratorio de Paleoetnozoología de la Universidad de San Marcos, Lima, quienes identificaron 11446 huesos o fragmentos de hueso, en base a comparaciones con la amplia colección de referencia disponible en dicho laboratorio (Málaga et al. 1976). El resto de la colección no fue incluido por tratarse de artefactos, o por su estado extremo de fragmentación que imposibilitó su identificación.

Las identificaciones realizadas cubrieron por lo menos tres variables: 1) Parte anatómica; 2) Categoría taxonómica animal; y 3) Madurez o inmadurez del individuo representado por cada pieza examinada. No se realizaron intentos de establecer ni edad específica ni sexo. Tampoco se buscó establecer el número de individuos mínimo representados, dado que no se ha recuperado la colección total del sitio. Por otro lado, problemas no resueltos aún por los especialistas en fauna andina impidieron la determinación de géneros y especies en la mayoría de los restos de camélidos y cérvidos. Finalmente, la discriminación de adultos y subadultos se hizo en función no sólo del tamaño, sino también del estado de desarrollo del tejido óseo, estado de crecimiento y soldamiento de las epífisis en huesos largos, unión de suturas, etc., siempre utilizando especímenes de edad conocida en la colección de referencia del laboratorio de San Marcos. En todo caso, la categoría de subadultos debe ser entendida como aquella que está compuesta por individuos de menos de un año de edad, mientras que se han considerado adultos a aquellos que superan dicha edad.

El segundo nivel de análisis, cuantitativo, es consecuencia del anterior y se compone de una serie de observaciones estadísticas de la información obtenida sobre la composición de la fauna encontrada en Piedras Gordas, y sobre su variabilidad a través del tiempo. Este análisis tiene una serie de posibilidades descriptivas e interpretativas, algunas de las cuales se exponen más adelante.

En este punto, resulta conveniente hacer algunas observaciones generales acerca de la colección de huesos de Piedras Gordas. En primer lugar, es necesario destacar el admirable estado de preservación orgánica de los huesos, a pesar de la humedad reinante, sobre todo en los niveles más bajos de la excavación. Sin duda alguna, el clima de la Puna, con bajas temperaturas que restringen la proliferación de microorganismos, es uno de los factores responsables de esto. Sin embargo, debe también tenerse en cuenta otra observación acerca de otro hecho que debe haber contribuido a la preservación. Se trata del estado de fragmentación extrema de los huesos, al punto que resulta muy difícil recuperar piezas completas, a no ser que se trate de elementos anatómicos muy pequeños y compactos, como son los huesecillos de las extremidades (p.e., carpos, calcáneo, etc.).

Un examen asistemático de muchos especímenes no apoyó la posibilidad de que tal fragmentación haya sido causada principalmente, ni por el tráfico humano en el sitio, ni por la acción de depredadores carnívoros. Las señales de quebrantamiento intencional de los huesos, principalmente fracturas radiales y presencia de conos de fragmentación, sugieren una constante preocupación humana por sacar provecho de los animales capturados de forma muy completa y meticulosa. Aparentemente, los cazadores de Piedras Gordas no se concretaban a separar la carne de los huesos, sino que además de desarticularlos los quebraban, incluso huesos pequeños como las falanges, para obtener el tuétano. Obviamente, la separación exhaustiva de tejidos blandos antes de descartar los huesos debe haber contribuido a eliminar fuentes de putrefacción que pudieran dañar los huesos, contribuyendo al grado de preservación que se ha observado.

Un aspecto también importante de la colección estudiada, es la ausencia de formas extintas. A pesar de la posibilidad de que los niveles más bajos del sitio tuvieran una filiación vecina del Pleistoceno Final, no se han identificado restos de animales de otras que no sean formas de fauna moderna. Dadas las dificultades en la discriminación de géneros y 
especies entre camélidos andinos, no es posible aún sistematizar la distribución cuantitativa de estos animales, a nivel de especie. Sin embargo, es posible adelantar que todos los niveles de Piedras Gordas cuentan con representación de las especies conocidas en el presente.

Las dos únicas peculiaridades observadas, son las siguientes: 1) Las vicuñas (Vicugna vicugna) y los guanacos (Lama guanicoe) parecen ser más abundantes en niveles inferiores, cediendo su popularidad relativa a las llamas (Lama glama) y, sobre todo, alpacas (Lama pacos) en los niveles superiores; y 2) A partir del nivel 6 se nota la presencia de formas cruzadas de auquénidos, especialmente guarizos (Lama glama x Lama pacos). Ambas tendencias pueden atribuirse a procesos de desarrollo de domesticación de camélidos, los que deben de tener una gran antigüedad en las punas andinas. El nivel 6 de Piedras Gordas tiene una fecha radiocarbónica en el sexto milenio AC (SI-4073).

En lo que se refiere a cérvidos, se han notado dos especies representadas. Las identificaciones, basadas en astas y partes del cráneo, indican la presencia en todos los niveles de tarucas (Hippocamelus antisensis) y venados de cola blanca (Odocoileus virginianus).

Dos especies de cánidos están presentes en la colección. Su distribución está significativamente polarizada con los perros domésticos (Canis familiaris) en niveles superiores, mientras el zorro culpeo (Dusicyon culpaeus) aparece sólo en los niveles más inferiores. En ambos casos se trata de especímenes que fueron sometidos al mismo tratamiento de consumo humano que el resto de animales.

Otras dos especies de mamíferos que se han identificado en Piedras Gordas son una Chinchillidae local, la vizcacha (Lagidium peruanum) y un Mustelidae, el zorrino o añash (Conepatus rex). Mientras la primera se encuentra en prácticamente todos los niveles de la excavación, constituyendo un complemento constante en la dieta de los ocupantes del sitio, la segunda aparece sólo en un nivel intermedio, en forma muy circunstancial y poco significativa.

Finalmente, otras formas de fauna corresponden a diversas especies de aves y batracios lacustres propios de la Puna. Las primeras no han sido clasificadas más allá del rubro general de aves, por carecerse de criterios de identificación. La colección comparativa de San Marcos es muy pobre respecto de aves. Los batracios, de otro lado, corresponden a un género de rana muy común en la actualidad, factible de ser hallada en orillas de lagos y riachuelos (Batrachophrynus sp.).

\section{Distribución de fauna por niveles}

Según se puede apreciar en la Tabla 8, los camélidos andinos fueron los principales contribuyentes a la dieta animal de los habitantes de Piedras Gordas. El $80 \%$ de la colección de huesos identificados corresponden a esta familia. Si se calcula una cifra promedio para todos los niveles, se puede notar que la única desviación significativa corresponde

\begin{tabular}{|l|c|c|c|c|c|c|c|c|}
\hline Nivel & Camelidae & Cervidae & Canidae & Ave & $\begin{array}{c}\text { Lagidium } \\
\text { peruanum }\end{array}$ & $\begin{array}{c}\text { Batracho- } \\
\text { phrynus sp. }\end{array}$ & $\begin{array}{c}\text { Conepatus } \\
\text { rex }\end{array}$ & $\begin{array}{c}\text { Total } \\
\text { Id. }\end{array}$ \\
\hline Sup. & 80.0 & 0.0 & 13.3 & 6.7 & 0.0 & 0.0 & 0.0 & 15 \\
1 & 31.9 & 53.3 & 6.6 & 0.0 & 8.2 & 0.0 & 0.0 & 182 \\
2 & 77.7 & 20.9 & 0.0 & 0.5 & 1.0 & 0.0 & 0.0 & 206 \\
3 & 59.7 & 33.2 & 0.3 & 4.4 & 2.3 & 0.0 & 0.0 & 340 \\
4 & 67.3 & 26.4 & 0.0 & 2.0 & 3.4 & 0.8 & 0.0 & 349 \\
5 & 80.1 & 14.0 & 0.0 & 1.0 & 2.8 & 1.7 & 0.3 & 921 \\
6 & 86.6 & 12.1 & 0.0 & 0.1 & 0.9 & 0.2 & 0.0 & 1542 \\
7 & 78.9 & 20.0 & 0.0 & 0.3 & 0.8 & 0.0 & 0.0 & 2484 \\
8 & 86.3 & 13.2 & 0.04 & 0.3 & 0.2 & 0.0 & 0.0 & 2400 \\
9 & 79.7 & 19.4 & 0.0 & 0.2 & 0.6 & 0.0 & 0.0 & 1708 \\
10 & 77.1 & 20.9 & 0.2 & 0.8 & 1.0 & 0.0 & 0.0 & 589 \\
11 & 77.4 & 22.2 & 0.3 & 0.0 & 0.0 & 0.0 & 0.0 & 301 \\
12 & 71.9 & 25.4 & 0.0 & 1.9 & 0.7 & 0.0 & 0.0 & 409 \\
\hline Total & $\mathbf{7 9 . 7}$ & $\mathbf{1 8 . 3}$ & $\mathbf{0 . 1 5}$ & $\mathbf{0 . 6}$ & $\mathbf{1 . 0}$ & $\mathbf{0 . 2}$ & $\mathbf{0 . 0 2}$ & $\mathbf{1 1 4 4 6}$ \\
\hline
\end{tabular}

Tabla 8. Distribución relativa de fauna en Piedras Gordas (PG-1), cuadrícula C, por niveles y tipos de fauna. 
al nivel 1, el que presenta un frecuencia relativa de camélidos inferior que su correspondiente para el caso de cérvidos. Esta situación aberrante, respecto del patrón general, no puede tenerse en cuenta, considerando que el nivel 1 es producto de disturbamiento, como ya se ha dicho. Por lo tanto, es factible asegurar que a lo largo del lapso ocupacional del sitio, la preponderancia de camélidos sobre cérvidos fue constante, aunque no es posible afirmar si las variaciones que se aprecian de nivel a nivel puedan resultar de simples situaciones azarosas. En la mayoría de los casos, como se verá en la discusión final, estas variaciones parecen estar conectadas con situaciones de relevancia cultural.

Las mismas conclusiones pueden extraerse de la observación de las frecuencias relativas de cérvidos. El 18\% de la colección corresponde a esta familia, y su variabilidad en los diversos niveles, respecto de una cifra promedio de $21.6 \%$, no parece alcanzar mayor significación estadística, excepto en el nivel 1 que, como ya se ha visto, debe ser descartado para análisis. En ambos casos hay que entender que se considera significativo todo desvío de más de una desviación estándar respecto del promedio para todos los niveles.

Tanto camélidos como cérvidos constituyen los recursos animales más importantes en Piedras Gordas. Conjuntamente, representan el $98 \%$ de la colección. El $2 \%$ restante corresponde a las otras formas de fauna listadas en la Tabla 8. Es notorio que las dos únicas otras columnas que acusan una situación complementaria y constante, son las de aves y de vizcachas.

El alto grado de aparente invariabilidad temporal en la distribución de fauna representada en la colección de Piedras Gordas podría utilizarse como refuerzo a la observación anterior acerca de la homogeneidad funcional del sitio a lo largo de todo el lapso ocupacional. Sin embargo, este refuerzo no es consistente en sus características secundarias. Por ejemplo, se puede observar en la misma Tabla 8 que especies relativamente menos importantes como zorros, perros y ranas acusan patrones distributivos más variables. Mientras los cánidos se agrupan en niveles inferiores y superiores, estando ausentes de los niveles intermedios, en cambio las ranas se hacen obvias en estos niveles, especialmente el 5 , siendo conspicua su ausencia de los demás niveles.
Estas tendencias, diferentes a las observadas para los otros tipos de fauna, no pueden interpretarse como el resultado de una mayor frecuencia de huesos en algunos niveles, puesto que los niveles $6,7,8$ y 9, que cuentan con la proporción mayor de huesos de la colección (72\%), no ofrecen mayor evidencia de variabilidad, ni proporcional ni en términos de complejidad de fauna. El nivel 5, que sí muestra mayor complejidad, no pasa de representar el $7 \%$ de la colección total, por lo que su estructura de fauna, que comparte características con los niveles 4 y 6 , debe ser el resultado de factores que necesitan ser examinados con mayor cuidado.

La posibilidad explicativa más aparente debe hallarse en aspectos medioambientales. Si retornamos a la discusión acerca del paleoclima, podemos apreciar que es precisamente el nivel 5 el que presenta las condiciones más extremas de menor humedad y mayor temperatura. Correlaciones de índole medioambiental y cultural han permitido concluir que este nivel debe corresponder con la Fase Climática que se denomina Yunga 1, en el Postglacial Medio (Cardich 1964) fechable en el cuarto milenio AC. Estos fueron tiempos en que se inicia una marcada disminución en el predominio relativo de los grandes herbívoros, en favor de un aumento significativo en la proporción de fauna complementaria, la que por primera vez asciende a $6 \%$, comparado con el $2 \%$ más común en los niveles más antiguos de Piedras Gordas.

La interpretación aparentemente más racional de esta observación es que en un período de menos frío, como ha sido el caso del denominado "óptimo climático", tendrían que haber mejorado las condiciones de vida, gracias a un clima aparentemente favorable, que habría diversificado la fauna y las posibilidades de explotación humana. Pero lo que mejor parece desprenderse de la información obtenida de Piedras Gordas, es que tal período habría más bien desequilibrado las condiciones ambientales, al punto de generar una crisis ecológica muy seria en la Puna. Esta crisis habría afectado la disponibilidad de mamíferos grandes, obligando a los pobladores de Piedras Gordas a buscar alternativas entre la fauna complementaria de la región, que siempre habría estado disponible.

Esta posibilidad, factible de ser organizada como hipótesis de trabajo, puede ser examinada más a fondo todavía con otro tipo de análisis de la colección osteológica de Piedras Gordas. Cuando se observa 
el inventario de huesos, por niveles, en la Tabla 8, se hace notorio que la mayor cantidad de huesos se da, aparentemente, en los niveles intermedios, del 6 al 9, mientras que disminuye su número tanto en los niveles inferiores como en los superiores. Este patrón distribucional es engañoso, por el simple hecho de que no todos los niveles han mostrado un relleno homogéneo. El espacio disponible para la deposición de huesos y material cultural en el depósito fue muy variable debido a la presencia de rocas desprendidas de las paredes y techo del abrigo rocoso, así como por estructuras construidas con piedras de campo en el frente del abrigo, a modo de rompevientos.

Si se desea comparar objetivamente la concentración de huesos, de nivel a nivel, entonces surge la necesidad de generar un índice basado en la frecuencia de huesos por unidad efectiva de relleno, en cada nivel. Tal índice de concentración de huesos ha sido obtenido mediante la simple determinación del peso en gramos de los huesos, en cada nivel, y dividirlo entre el número de decímetros cúbicos de relleno. La Tabla 9 describe el procedimiento. A fin de ampliar la confiabilidad de los resultados se consideró el peso conjunto de los huesos provenientes tanto de la cuadrícula $\mathrm{C}$ como de la cuadrícula $\mathrm{A}$.

Como se puede notar, el patrón de variabilidad en la distribución de huesos por niveles es diferente en este caso. Si bien sólo las cifras obtenidas resultan

\begin{tabular}{|c|c|c|c|}
\hline Nivel & $\begin{array}{c}\text { Peso de } \\
\text { huesos } \mathbf{( g )}\end{array}$ & $\begin{array}{c}\text { Volumen } \\
\text { relleno } \\
\mathbf{( d m}^{\mathbf{3}} \mathbf{)}\end{array}$ & $\begin{array}{c}\text { Densidad } \\
\text { huesos } \\
\left(\mathbf{g} / \mathbf{d m}^{\mathbf{3}}\right)\end{array}$ \\
\hline Sup. & 510 & 56.0 & 9.1 \\
1 & 4010 & 191.2 & 21.0 \\
2 & 5350 & 356.0 & 15.0 \\
3 & 15090 & 560.0 & 27.0 \\
4 & 15300 & 488.0 & 31.3 \\
5 & 14320 & 500.0 & 28.6 \\
6 & 27900 & 474.0 & 59.0 \\
7 & 34710 & 516.0 & 67.3 \\
8 & 24760 & 404.0 & 61.3 \\
9 & 21720 & 254.0 & 85.5 \\
10 & 11020 & 190.0 & 58.0 \\
11 & 7150 & 64.0 & 111.7 \\
12 & 3190 & 42.0 & 75.9 \\
\hline
\end{tabular}

Tabla 9. Indices de concentración de huesos de animales en Piedras Gordas (PG-1), cuadrículas A y C.

bastante claras, se ha preparado además una representación gráfica de estos datos (Figura 19) para hacer aún más ilustrativo el caso.

Ahora se nota una tendencia general a que la concentración de huesos disminuya con el transcurrir del tiempo, desde niveles de alta concentración en las fases más antiguas de la ocupación del sitio hasta las fases más recientes. Pero esta disminución no es regular ni a una tasa más o menos constante, sino que se produce como una serie de debacles muy severas en los niveles $10,8,5$ y 2 , las que se

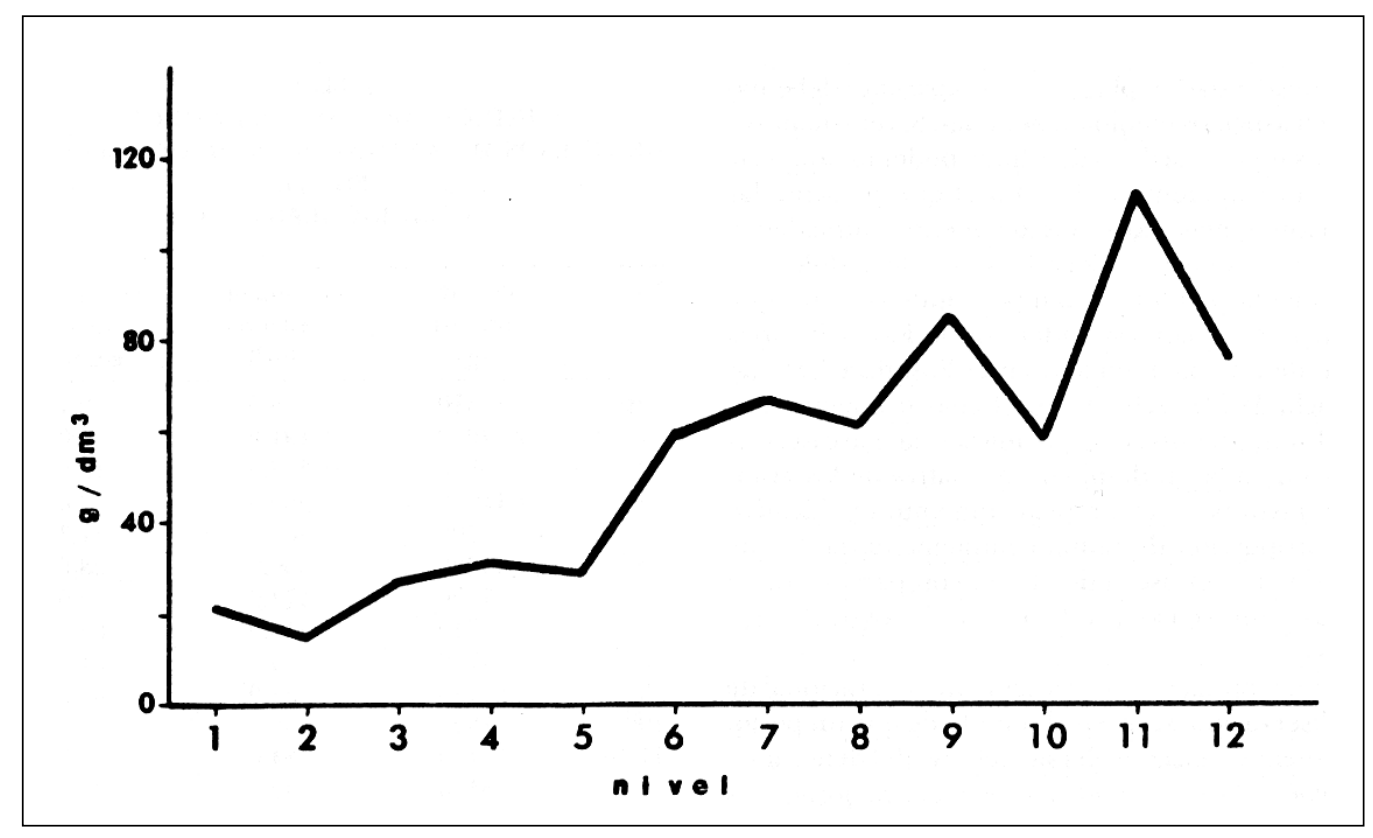

Figura 19. Concentración de huesos de animales en Piedras Gordas, por niveles. 
alternan con períodos de recuperación o estabilidad bastante relativas.

Al comparar esta curva con la del porcentaje de arcilla (Figura 6), se nota una clara correlación entre cada una de las crisis de concentración de huesos de animales con eventos climáticos extremos, los que seguramente afectaron severamente el equilibrio ecológico de la Puna. Significativamente, las dos primeras crisis, en los niveles 10 y 8 , coinciden con tiempos de frío, mientras que las crisis de los niveles 5 y 2 corresponden a períodos de mayores temperaturas y menor humedad.

Las connotaciones de estas correlaciones, agregadas a las que se perciben respecto de los índices de concentración de artefactos, indicadores de niveles de intensidad en el uso del sitio, están recién siendo notadas y descritas en forma muy superficial. Sin duda, se requiere de mayor investigación para lograr un percepción más profunda y completa.

Patrones de caza y aprovechamiento de animales

La observación de las variaciones intrínsecas en la distribución de cada tipo de fauna, así como la comparación de razones matemáticas entre animales adultos y subadultos y entre proporciones de diversas partes anatómicas, proveen indicios suficientes como para intentar reconstruir algunos aspectos sobre los patrones de caza, aprobechamiento de animales, uso del sitio y ciertas correlaciones con procesos medioambientales y culturales.
Una forma de examinar variaciones intrínsecas en la distribución de tipos de fauna es la de reunir la colección de huesos identificados dentro de tres categorías generales: camélidos, cérvidos y el resto de fauna o fauna complementaria. Esta última incluye mamíferos pequeños, aves y batracios (ver Tabla 8). Las curvas de variación de frecuencias relativas de estas tres categorías, por niveles (Figura 20), indican una situación bastante estable de predominio de camélidos, contribución secundaria de cérvidos y una menor presencia de fauna complementaria. La inversión de este patrón en el Nivel 1 no puede tenerse en cuenta por las razones que ya hemos expuesto.

La situación general, ya descrita, tiene características de variabilidad a través del tiempo, que es necesario puntualizar. Por ejemplo, existe una notoria correlación negativa $(\mathrm{r}=-0.96)$ entre los porcentajes de camélidos y cérvidos, de manera que puede asegurarse que estos dos tipos de fauna fueron altamente alternativos en la atención depredadora de los habitantes de Piedras Gordas. Esto es, a todo aumento relativo en la disponibilidad de camélidos, correspondía una disminución en la captura y aprovechamiento de cérvidos. La posibilidad de que esta interacción variable entre cazadores y sus presas tuviera correlación con procesos de variación del medio ambiente, es muy alta. Al parecer, situaciones de "deterioro" del ecosistema de Puna, debido a fluctuaciones excesivas de la temperatura medioambiental, habrían producido cierta escasez de cérvidos, por lo que los cazadores habrían tenido que

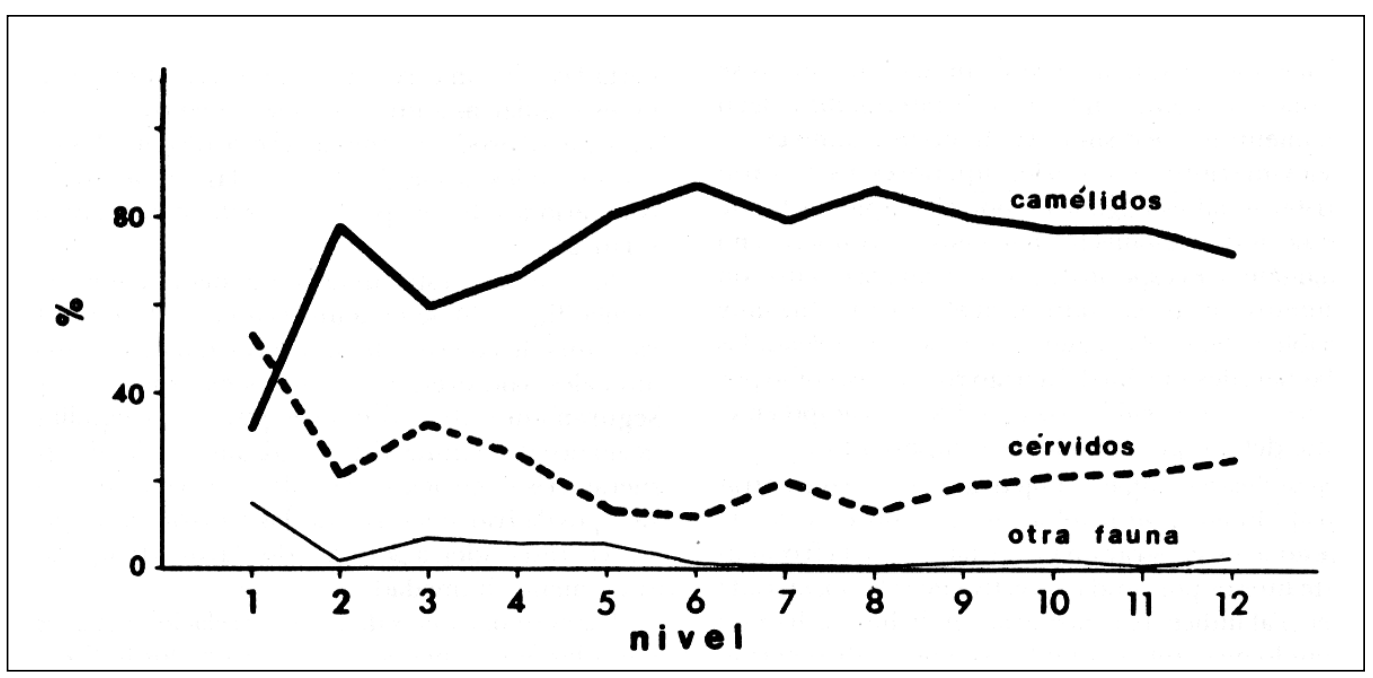

Figura 20. Variación de las frecuencias relativas de tipos de fauna en Piedras Gordas. 


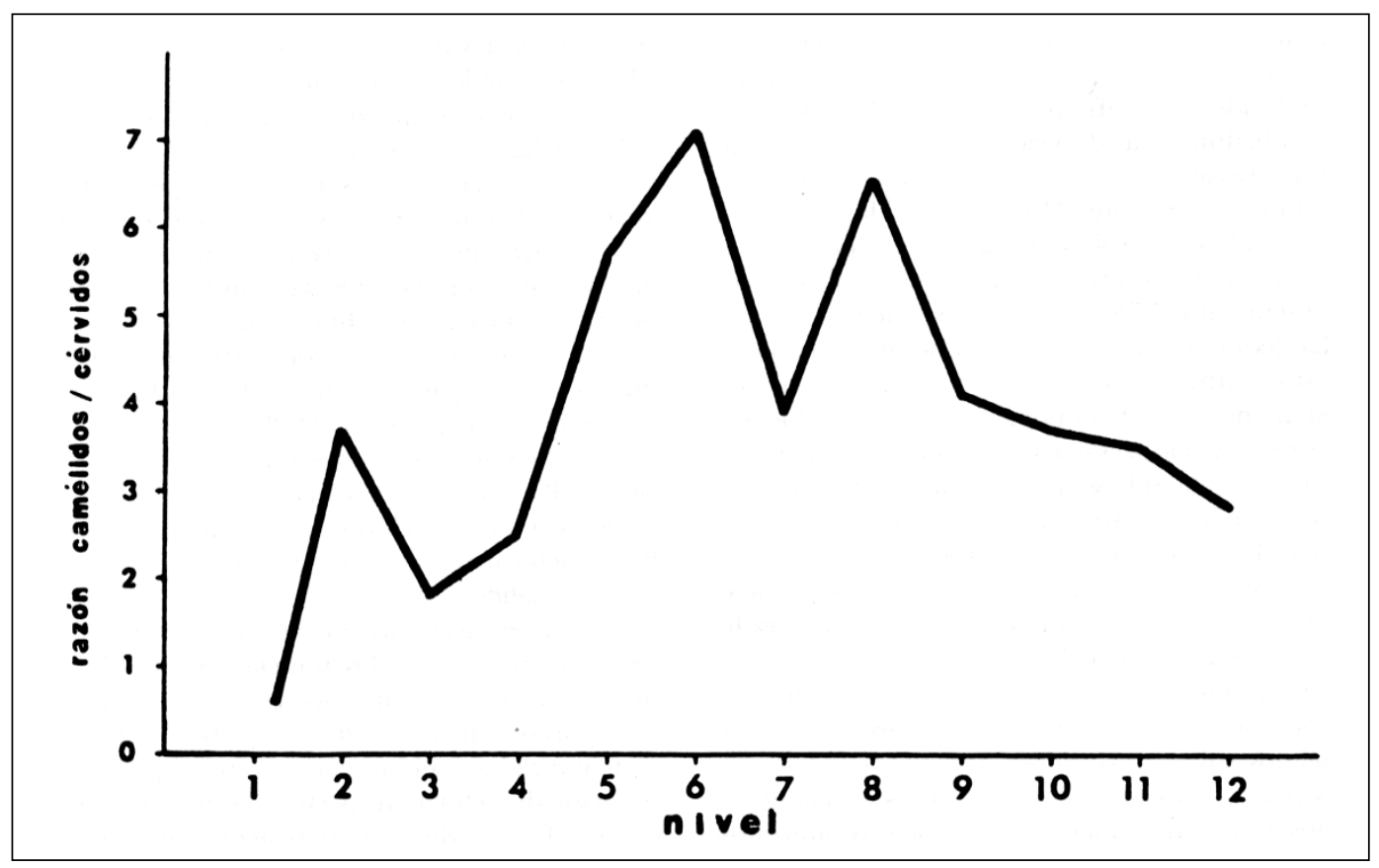

Figura 21. Variación por niveles de la razón matemática entre camélidos y cérvidos en Piedras Gordas.

tornar su interés, con mayor énfasis, en las diversas especies de camélidos andinos.

Esto es mucho más notorio cuando se observa la manera en que varía la razón matemática entre las frecuencias de camélidos y cérvidos, de nivel a nivel. La Figura 21 muestra estas variaciones, pudiendo verse una tendencia a que dicha razón aumente significativamente en aquellos niveles que se han establecido como representativos de las cuatro crisis medioambientales que se han detectado. En el nivel 10, donde el aumento es el menos notorio, éste representa el $32 \%$ de la cifra correspondiente al nivel 12. En todos los otros casos, tales aumentos son mucho mayores respecto de situaciones en niveles inmediatamente por debajo, siendo el caso extremo el del nivel 2, con un aumento de $106 \%$ respecto del nivel 3.

La complementariedad de los otros tipos de fauna también se muestra con rasgos que son dignos de ser anotados. La aparente irrelevancia porcentual de esta categoría, en los niveles inferiores del sitio, contrasta notoriamente con el aumento que se registra a partir del nivel 5, hasta el nivel 3 (ver Figura 20). Estos fueron tiempos en que la Puna experimentó un gran deterioro del medio ambiente y también del modo de vida fundamentado en la cacería, aparentemente llevado a extremos muy críticos por el aumento desproporcionado de la población humana. El retorno de la curva porcentual de la fauna complementaria, a niveles nuevamente insignificantes en el nivel 2, bien puede ser una consecuencia de la derivación de la base económica hacia la nueva modalidad del pastoralismo.

Otras deducciones acerca de los hábitos de caza de los pobladores de Piedras Gordas pueden hacerse a base de la observación de la variabilidad de las razones entre animales adultos y subadultos, representados en la colección analizada de huesos de animales. La Tabla 10 ofrece esta información para todos los niveles no disturbados de la excavación. La ausencia de datos para cérvidos en el nivel 9 responde al extravío involuntario de la ficha de laboratorio correspondiente.

Lo primero que se hace notorio en la Tabla 10 es la menor variabilidad en las razones correspondientes a camélidos, cuando se las compara con las de cérvidos. La desviación de razones respecto del promedio, entre camélidos, es significativa sólo en el caso del nivel 4, mientras que entre los cérvidos existe una variabilidad mucho mayor, con tres niveles $(6,7$ y 8$)$, excediendo significativamente el patrón normativo definido por la cifra promedio de 6.3 adultos por cada 


\begin{tabular}{|l|rcr|rrr|}
\hline \multirow{2}{*}{ Nivel } & \multicolumn{3}{|c|}{ Camélidos } & \multicolumn{3}{c|}{ Cérvidos } \\
\cline { 2 - 7 } & Adultos & Subadultos & $\begin{array}{c}\text { Razón } \\
\text { A/SA }\end{array}$ & Adultos & Subadultos & $\begin{array}{c}\text { Razón } \\
\text { A/SA }\end{array}$ \\
\hline 2 & 80 & 74 & 1.1 & 35 & 7 & 5.0 \\
3 & 123 & 80 & 1.5 & 76 & 33 & 2.3 \\
4 & 173 & 55 & 3.1 & 52 & 30 & 1.7 \\
5 & 460 & 269 & 1.7 & 98 & 29 & 3.4 \\
6 & 729 & 530 & 1.4 & 103 & 8 & 12.9 \\
7 & 1236 & 721 & 1.7 & 467 & 34 & 13.7 \\
8 & 1074 & 929 & 1.2 & 294 & 22 & 13.4 \\
9 & 564 & 337 & 1.7 & - & 31 & - \\
10 & 243 & 211 & 1.1 & 89 & 13 & 4.9 \\
11 & 136 & 97 & 1.4 & 54 & 21 & 3.9 \\
\hline 12 & 167 & 127 & 1.3 & 83 & & 6.33 \\
\hline Promedio: & & & 1.56 & & 4.92 \\
\hline
\end{tabular}

Tabla 10. Razones adultos/subadultos entre camélidos y cérvidos en Piedras Gordas (PG-1), cuadrícula C, por niveles.

subadulto. Las desviaciones estándar determinadas para cada una de estas distribuciones de datos son también elocuentes. Mientras entre los camélidos esta medida es de sólo 0.56 casos ( $36 \%$ del promedio), en cambio entre cérvidos es de casi cinco casos, representando el $78 \%$ del valor promedio.

La deducción más inmediata que se puede hacer de estos datos es que en general hubo una mayor presión en contra de la población de camélidos por parte de los cazadores que utilizaron Piedras Gordas. Esta presión no sólo se traducía en un mayor número de animales muertos, sino sobre todo en cuanto a la edad de la presa. La mayor incidencia sobre subadultos entre camélidos tiene que haber provocado una tasa mayor de atrición entre éstos, comparado con el caso de los cérvidos.

Las razones por las que los cérvidos subadultos no fueron objeto de caza, en la misma medida que los camélidos subadultos, deben ser diversas. Una de estas podría radicar en las diferencias en hábitos y modos de vida de cada tipo de fauna. Los camélidos son más gregarios que los cérvidos y el radio de acción de cada manada suele ser mucho más restringido que el que suele apreciar en el caso de los cérvidos. Por otro lado, con la sola excepción de la vicuña, los camélidos suelen ser de mayor tamaño que los cérvidos, de manera que incluso si el esfuerzo de caza fuera igual, resultaría de mayor provecho invertir esfuerzos en camélidos antes que en cérvidos.
Esta apreciación tiene por lo menos una línea de evidencia en los datos obtenidos de Piedras Gordas. Al cuantificar los huesos de pies y manos y de las patas y brazos de camélidos y cérvidos, por separado, se han hallado consistentemente mucho menos huesos de pies y manos de los que debía esperar, dada la anatomía de estos animales. Esta observación parecería ilustrar una subrepresentación de los pies y manos, si no fuera porque es ostensible la mayor tasa de fragmentación de los huesos de patas y brazos. En todo caso, puesto que la razón entre huesos de pie y huesos de pata para camélidos (4.0) es ligeramente mayor que para cérvidos (3.2), por lo que resulta significativo que las razones observadas en la colección de Piedras Gordas sean de 0.67 y 0.29 , respectivamente. Quiere decir que, en contra de lo esperado, hay mucho menos huesos de pie de cérvidos que de camélidos.

Esta diferencia tal vez corresponda a hábitos de aprovechamiento primario de los animales. Si consideramos una situación en la que los cazadores tienen que transportar el producto de la cacería, desde el lugar de matanza hasta el campamento principal, la maximización del retorno respecto del esfuerzo desplegado debe haber sido un motivo de preocupación. Mucho mayor provecho se debe haber obtenido incluso de los huesos de los pies de un camélido, que de los mucho más pequeños de un cérvido. Por lo tanto, deben haber sido mayores la probabilidades de que los extremos de las patas de los cérvidos se hayan descartado en el lugar de 
caza o en campamentos secundarios aledaños al lugar de matanza, antes que ser transportados hasta el campamento base.

Tal sistema de decisiones, que deben haber concernido también a otras partes del animal y no sólo a las extremidades, debe haber tenido visos más radicales todavía, a medida que aumentaba la distancia entre el lugar de caza y el campamento. Es casi seguro, dados los hábitos de vida de camélidos y cérvidos, que los primeros hayan sido encontrados y cazados generalmente en localidades más cercanas a los lugares de habitación humana, mientras que los cérvidos se habrían conseguido en áreas más apartadas, dada la inclinación de estos animales por eludir a la gente y sus rutas de tráfico.

\section{Resumen y conclusiones}

En las páginas anteriores se ha hecho una exposición detallada de la información generada por las exploraciones regionales en Junín y Cerro de Pasco y por las excavaciones realizadas en el sitio Piedras Gordas (PG-1), ubicado en la parte norte de la región estudiada. La revisión de esta información ha sido hecha en forma separada para cada uno de los aspectos cubiertos, por necesidad de organización descriptiva; pero resulta necesario que en esta sección se integren estos diversos aspectos, a fin de proveer una estructura secuencial que refleje la historia ocupacional del sitio, su definición en fases y la caracterización de estas, tanto cultural como medioambiental.

Paralelamente, se discuten las posibles correlaciones del sitio, con evidencia proveniente de otros sitios en el Area Andina, sobre todo para intentar una cronología local. Finalmente, se generan algunas conclusiones respecto de los patrones de uso del sitio, con la expectativa de que en alguna forma contribuyan al mejor entendimiento de los procesos humanos de la Sierra Central de Perú durante tiempos precerámicos.

\section{Historia ocupacional}

Una serie de líneas razonables de evidencia apunta hacia la posibilidad muy fuerte de que Piedras Gordas fuera utilizado por primera vez entre 8000 y 9000 $\mathrm{AC}$, ya en tiempos postpleistocénicos. Una fecha de radiocarbón (SI-4074) que indica una antigüedad de $7995 \pm 55$ para el nivel 11, no parece apoyar esta apreciación, pero su incongruencia puede ser explicada, como se verá más adelante, al discutir el problema de afiliación cronológica de cada fase ocupacional. La presencia de cerámica en los niveles superiores, cuyos tipos han sido identificados como propios del Período Formativo, marca el final de la ocupación del sitio por cazadores, alrededor de los años 1000 y $500 \mathrm{AC}$.

El examen del material cultural recuperado de 12 niveles en Piedras Gordas indica que durante todo este tiempo el sitio fue utilizado como campamento por cazadores, quienes dejaron tras de sí enormes cantidades de artefactos líticos, de hueso y asta, y restos de los animales depredados. La consistencia proporcional de los diversos tipos de artefactos en todos los niveles del sitio ha sugerido que éste poseyó y mantuvo una misma función económica durante los ocho o nueve milenios de su ocupación, incluyendo una fase reciente de tiempos ya cerámicos.

Esta función económica puede definirse como la actividad propia de un campamento base, o principal, en el cual se han realizado tareas de reducción secundaria de artefactos de piedra, aprovechamiento de animales, preparación y consumo de alimentos, procesamiento de pieles y otras actividades menos utilitarias como la elaboración de elementos decorativos personales, hechos en hueso.

A pesar de la regularidad funcional observada en el sitio, se ha podido comprobar una serie de instancias de variabilidad, que pueden ser interpretadas en términos de cambios culturales correlacionables con cambios en el medio ambiente. Examinadas en sus aspectos más superficiales, tales correlaciones representan formas de interrelación entre la gente y el medio ambiente, en un proceso constante de ajuste y readaptación, durante el cual las estrategias culturales humanas no parecen haber sido siempre las mismas ante estímulos medioambientales iguales.

En cuanto ha sido posible aislar episodios de cambio cultural y cambio medioambiental, se utilizan estos eventos para definir siete fases ocupacionales en el sitio, las que se pueden describir como sigue:

Fase I (9000-8000 AC). Representada por los niveles 12 y 11. Parece haber sido un episodio de clima bastante frío, propio de las últimas etapas del Pleistoceno Final, marcado por el retiro del avance Antarragá, coincidente con la Fase Janca 4 de Cardich (1964). El fechamiento tentativo de esta fase en el noveno milenio AC se prefiere en vez del aparentemente 
indicado por la fecha de radiocarbón obtenida a base de una muestra de hueso de camélido extraído del nivel 11 (7995 \pm 55 , SI-4074). Las razones por las que se hace esta decisión son diversas e incluyen consideraciones no sólo culturales, sino además medioambientales.

En primer lugar, al examinar patrones de distribución de diversos tipos de puntas de proyectil se nota que los tipos 1 y 2 (Figuras 12a y 12b) aparecen abruptamente y en proporciones significativas recién en el nivel 7 (Figura 11). Estos dos tipos, el "barbado" o "pentagonal" y el "Ayampitín", han sido definidos comúnmente como diagnósticos de los complejos Lauricocha I (Cardich 1964) y Jaiwa y Puente (McNeish 1971). Estos complejos, representados en sitios tanto al norte como al sur del Cerro de Pasco, han sido fechados con bastante nivel de confiabilidad entre el quinto y noveno milenios $\mathrm{AC}$ y no existiendo razones aparentes para pensar que la presencia de estos tipos de puntas pudieran haberse retrasado en Piedras Gordas, es posible deducir que el nivel 7 de este sitio no podría ser mucho más reciente que el complejo Jaiwa, ubicado en el sexto milenio AC. Por lo tanto, y dada la posición estratigráfica del nivel 11 , respecto del nivel 7 , se puede concluir en una mayor antigüedad para aquel nivel de la que indica la fecha de radiocarbón.

Otra consideración que ayuda a cuestionar la fecha indicada se basa en la curva de temperatura que se ha reconstruido para el sitio, en la cual el Altitermal, Postglacial Medio, o Fase Yunga, es claramente precedido por un episodio de frío muy marcado. Esta secuencia es correlacionable con la sucesión de fases establecidas por Cardich (1964), quien reporta la identificación de un avance del frío entre 7000 y 6000 AC, al que denominó "Sheguel-Huaman". La posición estratigráfica de este evento en el perfil de Piedras Gordas se ubica principalmente en el nivel 8 , debiendo ser, consecuentemente, el nivel 11 mucho más antiguo.

Aparte de las razones mencionadas, hay también otras que comprometen más directamente a la muestra utilizada para el cálculo de esta fecha de radiocarbón. Se trata de una muestra de hueso de camélido recogida de un medio extremadamente húmedo, consecuencia de fuertes filtraciones de agua desde lagunas ubicadas en áreas vecinas de mayor altitud que el sitio. No es posible determinar el grado de contaminación que esta situación podría haber suscitado, pero seguramente debe ser considerable. Desafortunadamente, las condiciones de humedad de los niveles de base en Piedras Gordas parecen haber contribuido a la ausencia notoria de restos de carbón, que son tan comunes en niveles intermedios y superiores, limitando las posibilidades de obtención de muestras para fechamiento por radiocarbón a los huesos de animales, con todos los inconvenientes que éstos significan.

Los niveles 11 y 12 registran grandes concentraciones de huesos de animales, sugiriendo una intensa actividad de caza. La baja densidad de artefactos líticos, sin embargo, podría interpretarse como indicador de una población humana bastante reducida, a pesar de la posibilidad de que los que utilizaron el abrigo rocoso en estos tiempos tuvieran cierta predilección por el uso del hueso y asta de animales en la elaboración de artefactos, tal como se deduciría de la concentración relativamente alta de éstos.

Por lo demás, esta fue una fase ocupacional bastante estable, en la que predominó la calcedonia como materia prima lítica. La industria en sí aparece como muy rudimentaria, centrada en el uso de lascas. Los raspadores corresponden a cuatro tipos, de los cuales tres son formas generalizadas que se usaron en todos los tiempos del lapso ocupacional del sitio. Un cuarto tipo de raspador, el tipo J, resulta más conspicuo por su gran popularidad en niveles inferiores. Se trata de una forma muy tosca, denticulada (Figura 14h).

La ausencia de puntas de piedra parece ser sólo un problema del tamaño de la muestra obtenida, pues se han reconocido preformas en etapas avanzadas de reducción que pueden identificarse como precursoras de eventuales puntas del tipo 3.

En estos tiempos, Piedras Gordas estaba definitivamente involucrada dentro del territorio del cuarzo y la calcedonia, esto es, la parte occidental de la región, pero esta situación habría de cambiar con el transcurso del tiempo, como veremos más adelante, a medida que nuevos grupos humanos se fueron agregando a los primeros ocupantes de esta fase en el uso del sitio y la explotación de los recursos naturales circundantes.

Fase II (8000-7500 AC). En esta fase debió culminar el proceso de retirada de los hielos hasta puntos y niveles comparables a los del presente; aunque sólo transitoriamente, tal situación climática supuso una configuración del ecosistema diferente a la que había venido existiendo en la fase anterior, lo que parece haber conllevado a un desequilibrio crítico entre la población humana y el medio ambiente, 
manifestándose en la forma de una drástica reducción en la productividad. A pesar de que la densidad de artefactos de piedra logra un ligero aumento, los restos de fauna más bien se reducen en $48 \%$ de los índices de concentración registrados para la Fase I.

El hecho de que tal reducción en la efectividad de los ocupantes de Piedras Gordas sea correlacionable con una disminución concomitante en la densidad de artefactos de hueso y en el uso de la calcedonia como materia prima, hace pensar que tal vez los grupos que enfatizaban el uso del hueso como materia prima resultaran desplazados por otra gente, la que en lo sucesivo preferirían la piedra. El factor que habría permitido tal reemplazo bien pudo ser un episodio de depredación excesiva, observable en la información del nivel 11, correspondiente a la fase anterior.

Los artefactos de piedra mismos proveen también indicios en este sentido. En el caso de las puntas, se puede decir por lo menos que quienes quedaron en el uso del sitio durante la Fase II fueron grupos representantes de dos tradiciones morfológicas. Las puntas "unifaciales" del tipo 3 y las puntas "avellanadas" del tipo 7 son tecnológicamente pobres, pudiéndose incluir este hecho entre las razones que explican la aparente ineficiencia de los pobladores de Piedras Gordas en estos tiempos. Por lo menos el tipo 3 de puntas parece tener antecedentes de su uso en la fase anterior, por lo que no se puede descartar la otra posibilidad, tal vez asociada, de un empobrecimiento de los recursos locales por efecto de la depredación en tiempos anteriores.

Esta última apreciación no deja de ser atractiva. Parece muy factible que los grupos de cazadores que en la Fase I utilizaban extensamente el hueso, antes que ser desplazados podrían haber dejado el área, al dejar ésta de ser adecuada a un modo de vida basado en la depredación excesiva, gracias al uso y aplicación de una tecnología de caza, tal vez establecida en el Pleistoceno, de la que no poseemos información. La hipótesis de depredación excesiva tiene por lo menos un indicio adicional al ya sugerido, en la disminución de la densidad de animales durante la Fase II, según lo indica el índice de densidad de huesos de animales en el nivel 10 de la excavación.

Tanto en este nivel como en los dos anteriores se ha podido observar que la presión humana sobre la fauna fue muy alta. Con la sola excepción de la Fase VI, en el tercer milenio AC, no hay otro episodio durante el cual se hayan dado razones matemáticas tan bajas entre camélidos y cérvidos. Más aún, es en estas fases cuando se ve que la presión más equivalente sobre camélidos y cérvidos se traduce además en mayor atención por los cérvidos subadultos, al punto de que las razones adulto/subadultos (ver Tabla 10) se redujeran hasta niveles casi iguales que las prevalecientes para el caso de los camélidos. Si consideramos que estas razones son bastante constantes entre camélidos, a lo largo de todo el lapso ocupacional del sitio, resulta que las variaciones en las mismas entre cérvidos deben ser tenidas muy en cuenta.

Al parecer, es factible percibir el proceso ocupacional de Piedras Gordas como una secuencia alternada de momentos de estabilidad relativa con una serie de crisis de interacción entre grupos humanos y el medio ambiente. De estas crisis, la primera, detectable sobre todo en la Fase II, sería la que liquidó un modo de vida que habría progresado en el Pleistoceno Final y cuyos rezagos parecen percibirse en los niveles adscritos a la Fase I. La consecuencia cultural de tal liquidación habría sido el establecimiento en las punas de un modo de vida identificable como propio del Arcaico del Area Andina. La última crisis, configurada en la Fase VI, habría obsoletizado el modo de vida fundamentado en la caza diversificada, propia del Arcaico, para dar lugar al advenimiento del Período Formativo, cuyas evidencias cerámicas han sido encontradas en los niveles superiores de Piedras Gordas.

Fase III (7500-7000 AC). La culminación del retroceso de los hielos parece haber sido seguida por un período "corto" de temperaturas algo más altas que las del presente, ante de enfriarse nuevamente como consecuencia del episodio "Sheguel-Huaman". En Piedras Gordas, este "corto" período se habría definido en el nivel 9 (ver Figura 6).

La Fase III experimentó un aumento muy marcado en productividad de caza, asociada con una alta inversión de actividad humana, según se desprende de los picos tan conspicuos en las curvas de concentración de huesos de animales y de densidad de artefactos de hueso y piedra (ver Figuras 8, 18, 19).

Aún se puede apreciar cierta preponderancia del uso de la calcedonia, pero se nota al mismo tiempo que el horsteno y otros tipos de piedra van adquiriendo importancia. La interpretación que se está adelantando, en el sentido de que el sitio fue transfiriendo su orientación hacia una situación de "frontera" hacia 
donde convergen cada vez mayor número de grupos humanos, con tradiciones culturales diferentes, parece reflejarse en la introducción, durante esta Fase III, del tipo 8 de puntas de proyectil y de los tipos I y E de raspadores (ver Figuras 11, 13).

Conjuntamente, este nuevo equipo cultural parece haber sido responsable de la mayor efectividad en la caza, durante la Fase III, aunque no parece haber mayor variación en hábitos de caza, respecto de la fase anterior. La razón matemática entre camélidos y cérvidos (Figura 21) es ligeramente mayor, siguiendo la tendencia ascendente ya observada desde el inicio de la ocupación del sitio. La falta de datos sobre la razón matemática entre adultos y subadultos cérvidos en el nivel 9 no permite ver si es que hubo variación en esta medida. Lo más probable es que no la hubiera, si es que la constancia de las otras curvas (ver Figura 21 y Tabla 10) puede tomarse como un indicador.

En resumen, lo que se desprende de la información disponible es que la presión depredadora ejercida sobre la fauna de la región debe haberse mantenido a niveles comparables con los de las fases anteriores. Esta consistencia en hábitos de caza permite concluir que el incremento observado en la concentración de huesos de animales en el sitio, como índice de productividad de los ocupantes de Piedras Gordas, debe haber sido el resultado no sólo del aparente mejoramiento de las condiciones medioambientales, sino además del efecto producido por la introducción de nuevos grupos humanos que contaban con un equipo cultural cualitativamente más refinado.

Fase IV (7000-5000 AC). Esta fase se caracterizó por un clima muy frío y húmedo, producido por un pulsamiento glacial que se reconoce como el avance "Sheguel-Huaman". Climáticamente, este episodio no parece haber afectado más que la primera mitad de la Fase IV, definida en el sitio en los niveles 8 y 7, pero dejó una secuela muy definida en el patrón cultural de los ocupantes de Piedras Gordas. Esta secuela posee características que son apreciables a lo largo de por lo menos otros 1000 años, después del final de "Sheguel-Huaman".

La productividad de las actividades de caza declinó ostensiblemente, según se desprende de la depresión en la curva de concentración de huesos de animales (ver Figura 19). Esta vez, el mejoramiento del clima, subsecuente al frío de "Sheguel-Huaman", no produjo un repunte significativo en el nivel de productividad.
Concomitantemente, la actividad humana experimentó una drástica reducción cuantitativa reflejada en la declinación sostenida de las curvas de densidad de artefactos líticos y de hueso. El ligero repunte de estos últimos en el nivel 7 (ver Figura 18) está correlacionado con la introducción al sitio de dos nuevos tipos de puntas. Estos nuevos tipos 1 y 2 (ver Figuras 11, $12 \mathrm{a}$ y $12 \mathrm{~b}$ ), junto con el aumento de algunos tipos de raspadores, especialmente el tipo $\mathrm{D}$, estuvieron asociados al inicio de nuevas modalidades de caza adecuadas aparentemente a patrones diferentes de disponibilidad de tipos de fauna.

Los fríos excesivos del séptimo milenio $\mathrm{AC}$ deben haber reducido la disponibilidad de cérvidos en la región inmediata a Piedras Gordas, obligando a una mayor presión sobre los camélidos. Aun cuando este patrón distributivo se reduce durante la segunda mitad de la Fase IV, no por esto deja de ser ostensible el hecho de que las razones adultos/subadultos, entre cérvidos, se mantengan en niveles excepcionalmente altos durante toda la fase. La escasez tan evidente de cérvidos subadultos debe haber sido una consecuencia del desplazamiento del hábitat de estos herbívoros hacia zonas más alejadas de Piedras Gordas.

Si esta interpretación es correcta, entonces resulta posible correlacionar el aumento relativo de cérvidos en la segunda mitad de la fase con la introducción de nuevos grupos humanos en Piedras Gordas. Una vez más, el mejor bagaje cultural de estos nuevos grupos, evidenciado por la perfección elaborativa de las puntas de tipos 1 y 2 habría contrarrestado, al menos parcialmente, la creciente escasez de fauna en la región de influencia del sitio provocada por el deterioro del ecosistema.

Fase V (5000-3000 AC). Los niveles 6 y 5 de Piedras Gordas están siendo asociados con la fase climática Yunga 1, de Cardich, coincidente con el período del Postglacial Medio, que suele reconocerse como el "óptimo climático". La ubicación cronológica de estos niveles, adjudicados a la Fase V del sitio, parece estar confirmada por tres fechas radiocar-

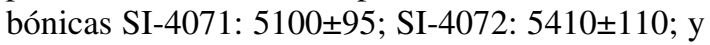
SI-4073: 5680 \pm 75 , distribuidas en los niveles 5 y 6 de la excavación.

Cronológicamente, la Fase V de Piedras Gordas es correlacionable con las fechas establecidas por los complejos Piki y Chihua, en Ayacucho, y Lauricocha II, en Huanuco. Culturamente, no parece haber mayores discrepancias, constituyendo la información 
del sitio, sólo detalle acerca de las características de la interrelación entre poblaciones humanas y el medio ambiente en estos tiempos.

La Fase $\mathrm{V}$ experimentó un gran aumento en el número de tipos de puntas y raspadores de piedra. Por lo menos cuatro nuevos tipos de puntas y tres nuevos tipos de raspadores son introducidos al sitio, con el consiguiente aumento en la actividad humana, según se deduce de las curvas de densidad de artefactos de piedra y hueso (ver Figuras 8, 18).

Este nuevo embate por parte de nuevos grupos humanos está relacionado con un uso mucho más generalizado del horsteno, como materia prima, desplazando definitivamente a la calcedonia de su posición predominante en fases anteriores. Por primera vez en la historia ocupacional del sitio se nota un caso de reemplazo de formas artefactuales, pudiendo interpretarse como el desplazamiento de algunos grupos humanos por otros. La aparición de los tipos de puntas 4, 9 y 10, entre otros, supone la evidente reducción y eventual desaparición de las puntas del tipo 3 (ver Figura 11). Es significativo que junto con estas puntas desaparezcan además los raspadores del tipo K (ver Figura 13), pudiendo ser el caso de que unas y otro pertenecieran al equipo cultural del grupo humano que resultó desplazado en esta Fase V.

Al contrario del reemplazo que se acaba de ilustrar, la actividad humana, lejos de restringirse, fue significativamente mayor, con un efecto negativo muy sostenido en la productividad de las actividades de caza. Una vez más, se nota una grave restricción en la disponibilidad de cérvidos, lo que impone una mayor presión sobre los camélidos. Por otro lado, es en esta fase que se retorna a la práctica de incluir el mayor número posible de subadultos entre los cérvidos que son objeto de caza. El hecho de que esta práctica indiscriminada sea asociable con un elevamiento de la proporción de otros tipos de fauna, en la segunda mitad de la Fase V, bien puede corresponder a cambios en los hábitos de caza tendientes a buscar alternativas a la creciente escasez de grandes herbívoros.

La otra posibilidad, es que algunos grupos humanos recién llegados a Piedras Gordas pudieron ser gentes más orientadas a técnicas de atrapamiento de animales pequeños, sobre todo vizcachas y ranas. Esta posibilidad parece tener respaldo en el hecho de que las nuevas puntas, introducidas al sitio durante esta fase, corresponden a formas y tipos bastante burdos, tal vez no tan efectivas, al menos en comparación con la calidad tecnológica y estética de las puntas de los tipos 1,2 y 8 , introducidas mucho antes.

Sea uno u otro el caso, lo que parece muy bien definido es que la Fase $V$ en Piedras Gordas fue una época de gran actividad humana, pero de retornos muy bajos en términos de productividad. Esta conclusión contradice la impresión generalizada de que el "óptimo climático" tendría que haber sido un tiempo bueno para el desarrollo de la sociedad y la cultura durante el Arcaico. Por lo menos en las punas de Junín y Cerro de Pasco la información apunta hacia otro lado.

Según parece, el elevamiento de la temperatura medioambiental en unos $5^{\circ} \mathrm{C}$ por encima de los niveles actuales, habría generado una crisis ecológica cuyas consecuencias inmediatas fueron la escasez de grandes herbívoros y el incremento de la presión humana en términos de un aumento significativo del número de grupos humanos que utilizaron Piedras Gordas en sus actividades de caza. Si es que cada tipo de puntas es asociable a grupos culturales diferentes, que habrían utilizado el sitio en forma casi simultánea, entonces se deduce que durante la Fase $\mathrm{V}$ por lo menos nueve grupos diferentes convergían en Piedras Gordas por estos tiempos, esto es, dos veces el nivel de presión humana experimentada en la Fase IV, tres veces más que la Fase III y cinco veces más que las fases primordiales del sitio.

Fase VI (3000-1500 AC). Esta fase, representada por los niveles 4 y 3 , no es más que la consecuencia lógica de la anterior. El clima, más moderado, no parece afectar en ningún modo positivo la tendencia crítica que se venía afianzando. El número de grupos humanos que utilizaban el sitio no sufrió mayor modificación, puesto que el tipo 3 de punta fue reemplazada por la introducción del tipo 6, una forma bastante bien elaborada. Sin embargo, resulta notorio el hecho de que la actividad misma sufrió una gran reducción, según se desprende de las crecientes declinaciones en las curvas de densidad de artefactos líticos y óseos. Paralelamente, la productividad, medida por la concentración de huesos de animales, sufrió aún mayores reducciones, aun cuando no tan traumáticas como la de la fase anterior.

La situación de "frontera" del sitio se establece definitivamente al imponerse el horsteno como la materia prima lítica más generalizada. Por otro 
lado, la persistencia de la crisis ecológica por que se iniciara en la Fase V, parece haber provocado un proceso de selección entre los grupos humanos que utilizaban el sitio. Tres tipos de raspadores, J, I, H, y por lo menos cinco tipos de puntas, habrían de desaparecer hacia el fin de la Fase VI.

Otro aspecto notable, es que los cérvidos vuelven a aparecer en proporciones importantes. Este repunte, sin embargo, no presupone un alivio en la presión sobre la fauna menor de la región, sino más bien parece ser una consecuencia de la creciente escasez de camélidos, los que habían venido sufriendo un gran impacto depredativo desde el principio de la ocupación de Piedras Gordas.

En esta fase, esta acción depredativa se torna más grave aún, sin embargo, según lo indican las razones matemáticas entre adultos y subadultos, tanto entre camélidos como entre cérvidos (ver Tabla 10). Una vez más, estas razones bajan hasta niveles que son "normales" entre camélidos, pero que entre cérvidos habían adquirido niveles mucho más altos en las fases IV y V.

Fase VII (1500-500 AC). La última fase ocupacional de Piedras Gordas está representada por el nivel 2, casi exclusivamente. El criterio más obvio de definición de esta fase ha sido la presencia de restos cerámicos en el depósito. Aun cuando éstos también aparecen en los niveles 1 y 3 , no se los incluye en el análisis, el primero por razones de disturbamiento y el otro por contar con tiestos sólo en su parte más inmediata con el nivel 2 , siendo muy pocos en número, como puede verse en la Tabla 7.

A pesar de la cerámica, elemento cultural que se suele asociar con la generalización de modos de vida basados en la domesticación de plantas y animales, en Piedras Gordas es ostensible que las actividades de caza continuaron todavía durante la Fase VII.

Estos parecen haber sido tiempos en que el clima se habría tornado un tanto más cálido que el de la fase anterior. Este mejoramiento relativo en las condiciones medioambientales no parece haber favorecido mayormente las actividades de caza. Junto con un declinamiento aún mayor en los niveles de actividad, según lo indican las curvas de densidad de artefactos (ver Figuras 8 y 18), la productividad también continuó decreciendo, tal como se deduce de la curva de concentración de huesos de animales en el depósito (ver Figura 19).
El ligero repunte en el uso de la calcedonia (Figura 10) parece ser un efecto de la eliminación de un número significativo de grupos humanos en el uso del sitio. Sólo cuatro tipos de punta (ver Figura 11), acompañados por siete tipos de raspadores (ver Figura 13), permanecieron en el sitio, durante la Fase VII. De éstos, sólo los raspadores tipos B, C y E mantienen proporciones comparables o mayores a las de fases anteriores.

Resulta interesante anotar que los tipos de puntas y raspadores que quedan como sobrevivientes en este nivel son, en general, de gran calidad técnica y estética, sugiriendo un proceso de selección muy bien definido, como resultado del cual sólo quedaron en Piedras Gordas, manteniendo labores de caza aquellos grupos humanos culturalmente mejor adaptados a las condiciones críticas en que se dejó la Puna después de varios milenios de explotación.

Con la disminución de la población, la presión sobre la fauna se alivió significativamente, reduciéndose la escasez de camélidos (ver Figura 21) y elevándose la razón adultos/subadultos entre los cérvidos (ver Tabla 10).

\section{Comentarios finales}

La evaluación de la información obtenida de Piedras Gordas y de la región de Junín y Cerro de Pasco provee una serie de líneas de evidencia sugerentes de un patrón de uso y explotación de la Puna, dentro de parámetros funcionales consistentemente regulares, en el sentido de que se trató de una cultura de cazadores y recolectores cuyas características la ubican confortablemente en el Período Arcaico de la secuencia cultural andina.

Esta consistencia, sin embargo, posee aspectos de variabilidad que, por lo general, han pasado desapercibidos como resultado de cierta preocupación por describir ensamblajes culturales, descuidando la observación de la información en términos de procesos socioculturales y de su interrelación con el medio ambiente.

En este estudio se ha buscado establecer formas de tratamiento de la información y análisis tendientes a lograr una mejor observación de estos procesos. Los resultados, a pesar de corresponder a etapas preliminares de un proyecto de investigación a largo plazo en las punas de la Sierra Central de Perú, aparecen como muy positivos y adecuados a las finalidades establecidas. 
Aun cuando pareciera todavía muy prematuro cualquier intento de confrontación de la evidencia lograda con aspectos teóricos sobre la configuración sociocultural de cazadores y recolectores, y el declinamiento de este modo de vida para dar paso a la llamada revolución neolítica, no resulta fácil resistir la tentación de avanzar algunas consideraciones, por lo menos en lo que respecta a ciertas ideas que han venido siendo expresadas por colegas respecto del Precerámico andino.

Por ejemplo, es conocido el debate informal que se ha venido suscitando respecto de la capacidad de sostenimiento del ecosistema Puna y de las posibilidades que podría haber ofrecido a un modo de vida sedentario en tiempos de cazadores (Rick 1977, 1977a), idea que pareciera estar hallando eco entre especialistas. Las áreas de información en que se basa esta hipótesis pueden ser encontradas en forma detallada en los informes de Rick, de manera que no las repetiremos aquí. Por el contrario, es posible exponer las que se han generado a través de las investigaciones en Junín y Cerro de Pasco, puesto que parecen contradecir la posibilidad de sedentarismo en las punas.

En primer lugar, la definición de la región en agrupamientos de sitios de diversa índole funcional, dentro de un patrón general propio de cazadores, que se han denominado subregiones, ocurre significativamente en la mayoría de los casos en zonas de Puna alrededor de sistemas lacustres que están ubicados en la cabecera de drenajes bastante independientes unos de otros. Esto es particularmente notorio en el sector oriental de la región, fuera de la cuenca del río Mantaro (ver Figura 1). Resulta interesante notar que es precisamente esta parte de la región la que se ha definido como un territorio diferente, en términos de los tipos de piedra que se utilizaron como materia prima. Más aún, éste es el denominado territorio de las lavas, un material que no es precisamente local, sino que parece haber sido traído desde fuera de la región.

Si es que se les puede asignar credibilidad y confianza a los datos de Piedras Gordas, aunque se trate de un solo sitio, pareciera que lo que ocurrió es que los pobladores originales postpleistocénicos eran más dependientes de los recursos líticos de la región que aquellos que fueron llegando con el transcurso de los tiempos. Las calcedonias son relativamente abundantes en los lechos de ríos de la región, mas no así los horstenos ni las lavas. Un examen de la
Figura 10 da una idea muy clara de la manera en que los recursos locales fueron siendo reemplazados por tipos de piedra foráneos, un proceso que estuvo asociado con la introducción en Piedras Gordas de cada vez mayor número de tipos morfológicos de puntas (ver Figura 11), lo que a su vez es interpretable como un aumento gradual del número de grupos humanos, premunidos de equipos culturales diferentes, que fueron agregándose a aquellos que ya venían utilizando el sitio.

Si es que cada tipo morfológico de punta representa por lo menos un grupo humano diferente, seguramente organizado en banda, la consistente contemporaneidad de diversos tipos de puntas en el relleno de Piedras Gordas (hasta por lo menos nueve en las fases V y VI) hace de la posibilidad de su uso habitacional sedentario un ejercicio imaginativo muy grande. Se trataría de unas 50 personas, compartiendo un área de no más de $200 \mathrm{~m}^{2}$. La experiencia entre bosquimanos ha sugerido que sólo una familia de seis personas requiere y usa un área de no menos de $12 \mathrm{~m}^{2}$, y considerando el factor de aglomeración que supone cualquier aumento de individuos en un grupo, ha sido posible establecer que 50 personas necesitarían un campamento cuya área no podría tener menos de $1000 \mathrm{~m}^{2}$ (Yellen 1977: 116; Wiessner 1979).

Es más probable que en Piedras Gordas hayan estado convergiendo todos estos grupos en diferentes meses del año, cada año, y que si cualquier grupo encontraba el sitio ocupado, simplemente se alojara en otro abrigo rocoso cercano. Esto explicaría el patrón observado de abrigos rocosos más o menos cercanos, pero que ofrecen evidencia de un uso menos enfático.

Nos confrontamos, pues, con un patrón ocupacional bastante particular, pues supone la utilización de un mismo sitio en la Puna por grupos diversos, en forma alternada, tal vez a lo largo de todo el año. Este patrón seguramente ha sido el responsable de la generación de una apreciación en el sentido de que los abrigos rocosos de las punas habrían estado habitados todo el año, sugiriendo alguna forma de sedentarismo. Ahora bien, estos grupos diferentes son identificables como tales gracias a la diversidad de sus equipos de artefactos, lo que se evidencia mejor en tipos de puntas y raspadores, lo que lleva a la conclusión conexa de que habrán venido de regiones diferentes, en donde los rasgos culturales habrían estado más definidos en términos de territorialidad. 
Consecuentemente, una de las tareas inmediatas de investigación debe ser la evaluación cultural precerámica de los valles interandinos que bajan hacia el norte, este y oeste, desde el altiplano de Junín y Cerro de Pasco. Obviamente, un indicio de lo que probablemente será determinado está ya dado por la definición en territorios de la región, a base de las distribuciones de materia prima lítica.

Otro punto que merece ser comentado con cierto énfasis en esta sección es el que se refiere a tipos morfológicos de artefactos líticos y sus correlaciones cronológicas. Es muy común en la literatura acerca del Precerámico andino que se fundamente la antigüiedad de ensamblajes culturales y sitios en función de una aparente correlación absoluta entre tipos de puntas y ciertos complejos culturales que se han venido definiendo. El concepto de tipos diagnósticos está ampliamente aceptado, según se puede apreciar en informes científicos, incluyendo tal vez el presente.

La información obtenida de Piedras Gordas, en donde tanto el control estratigráfico como la masividad del material cultural encontrado aseguraron un tratamiento estadístico de la variabilidad tipológica de artefactos, indica que el concepto de tipos diagnósticos debe ser modificado radicalmente, no sólo en sus connotaciones cronológicas, sino también en su aplicación en la identificación de ensamblajes y complejos culturales propios del Precerámico andino.

Para ilustrar el punto, basta con limitarnos al examen de la distribución cuantitativa de tipos de puntas en los diversos niveles de la excavación en Piedras Gordas (ver Figura 11). De primera intención, resulta notoria la persistencia temporal de casi todos los tipos de puntas. No hay tipo alguno que limite su presencia a una sola fase ocupacional, sino que, por el contrario, hay formas que se manifiestan en proporciones significativas a lo largo de varias de estas fases. Los tipos 7 y 8, por ejemplo, aparecen en cinco fases ocupacionales cada una, cubriendo cada tipo lapsos de por lo menos siete milenios. Más dramáticamente, el tipo 1 de punta, utilizado comúnmente como el tipo diagnóstico de complejos asociables con el Horizonte Lauricocha I, de Cardich, se da consistentemente desde el nivel 7 hasta el nivel 2 de la excavación, cubriendo cuatro fases ocupacionales relativamente tardías, desde el 6000 AC hasta el fin de la ocupación del sitio hacia más o menos el $500 \mathrm{AC}$.
Obviamente, no es posible racionalizar esta evidencia en forma de llegar a la conclusión de que todo este lapso ocupacional de Piedras Gordas pueda pertenecer al complejo Jaiwa, de Ayacucho, ni tan sólo siquiera al Horizonte Lauricocha I de Huanuco. Menos aún es posible adscribir todos estos niveles al lapso cronológico establecido para estos complejos. Al parecer, los tipos diagnósticos más podrían servir en Piedras Gordas, no tanto en términos de su simple presencia, sino más bien en cuanto al nivel en que aparecen por primera vez, la frecuencia con que aparecen en cada nivel y el tiempo en que dejan de aparecer definitivamente, siendo tal vez el primer aspecto el más útil y de mayor importancia interpretativa.

El tercer tema que se quiere cubrir en estas páginas finales, antes que intentar el rechazo de una hipótesis como la del sedentarismo en la Puna, o tratar de modificar un uso inadecuado de conceptos como el de tipos diagnósticos en morfología lítica, intenta la inclusión en la teoría antropológica acerca de procesos socioculturales en las punas andinas, de una nueva serie de consideraciones acerca de la interacción entre las poblaciones humanas y el medio ambiente.

$\mathrm{Si}$ es que se necesita expresar estos procesos, en términos de una frase identificatoria, se podría hablar de un patrón sostenido de depredación, que al cabo de varios milenios llevó a extremos insostenibles el deterioro del ecosistema de Puna, obligando a las poblaciones humanas a transferir su atención hacia actividades diferentes a las de caza y recolección, en favor de formas de domesticación de animales y plantas. Este proceso no fue, sin embargo, el resultado exclusivo de las actividades humanas, sino que se habrían conjugado éstas con una serie de modificaciones en el medio ambiente, producidas por cambios climáticos en el pasado, los que habrían afectado gravemente el equilibrio del ecosistema, tal como lo conocemos hoy en día.

La acción depredadora de los grupos humanos es notoria en la información disponible, en varias líneas. Primero, en la tendencia descendente de la productividad económica de los ocupantes de Piedras Gordas, según se puede ver en la curva de concentración de huesos de animales (ver Figura 19); pero también en las evidencias que se poseen acerca de una presión demográfica creciente, infligiendo cada vez mayor presión en los recursos disponibles de la Puna. 
La presión demográfica se manifiesta en el registro arqueológico bajo dos aspectos, por lo menos: uno, es la creciente inclusión de nuevos grupos humanos en Piedras Gordas, según se deduce del número cada vez mayor de diversos tipos de artefactos, especialmente puntas y raspadores; el otro, proviene de datos regionales acerca de la distribución de sitios y su periodificación relativa. Al parecer, la creciente presión sobre los sitios de acampamiento más adecuados, como el de Piedras Gordas, habría forzado a algunos grupos de cazadores, seguramente los menos sofisticados, a desplazarse hacia áreas marginales de la región. Estas áreas marginales se ubicaban por lo general a mayores altitudes que el piso del altiplano de Junín y sus alrededores. En una palabra, la creciente presión demográfica se tradujo no sólo en un mayor uso de sitios ya establecidos, sino por la expansión de las poblaciones humanas, en términos territoriales.

Los tres temas teóricos que se han tratado en estos comentarios finales han sido examinados a la luz de la información disponible hasta ahora. En este sentido, las conclusiones a que se ha arribado no debían ser tratadas como definitivas, sino que por necesidad tienen que esperar una mayor y mejor validación de parte de un grado mayor de coincidencia informativa, la que deberá ser lograda a medida que progresen las investigaciones en la región de Junín y Cerro de Pasco. Tal vez los mejores aportes de este estudio no son tanto teóricos como metodológicos, en cuanto han permitido generar formas cuantitativas de análisis que están produciendo resultados muy provechosos.
Su alto grado de objetividad y su posibilidad de comunicación inequívoca deben permitir la eventual comprobación de hipótesis, reduciendo tremendamente la subjetividad tan generalizada en estudios del Precerámico de los Andes Centrales.

Agradecimientos Los trabajos que aquí se reportan se han venido realizando desde 1975, con el auspicio económico de Smithsonian Institution de Washington D.C., en la forma de una serie de contratos de investigación. Es menester reconocer y agradecer las invalorables gestiones, recomendaciones y supervisión científica de los Dres. Clifford Evans, Betty Meggers y Dennis Stanford, del Departamento de Antropología de dicha institución. Las labores de campo en Perú se han realizado en parte dentro del Proyecto Junín de Estudios Arqueológicos, que dirige el Dr. Ramiro Matos, de la Universidad de San Marcos, Lima, y en parte dentro de la función del autor como Investigador Asociado del Museo Nacional de Antropología y Arqueología, Lima. Las temporadas de investigación más productivas fueron las de 1978 y 1979, cuando se ejecutaron trabajos de campo y laboratorio con la ayuda de profesores y estudiantes de las universidades del Centro y de San Marcos. El profesor Carlos Chahud, director del Museo Regional de la Universidad del Centro, Huancayo, merece una mención especial. Su ayuda se tradujo en diversas formas, resaltando su intervención en investigación y en su generoso ofrecimiento de espacio de laboratorio y almacenamiento en el local del Museo.

\section{REFERENCIAS CITADAS}

ALBAREDA, H., J. y A. HOYOS, 1961. Edafología, S.A.E.T.A., Madrid.

CARDICH, A., 1960. Investigaciones prehistóricas en los Andes peruanos. En Antiguo Perú, espacio y tiempo, pp. 89-118. Editorial Mejía Baca, Lima.

1964. Lauricocha. Fundamentos para una Prehistoria de los Andes Centrales. Studia Praehistorica III, Centro Argentino de Estudios Prehistóricos, Buenos Aires.

1975. Agricultura y pastores en Lauricocha y límites superiores de cultivo. Revista del Museo Nacional XLI: 11-36.

CUSTRED, G., 1977. Las punas de los Andes Centrales. En Pastores de Puna, J. Flores Ochoa (Ed.), pp. 55-85. Instituto de Estudios Peruanos, Lima.
CHAUD, C., 1979. Secuencia de la ocupación cerámica en la zona altina de la provincia de Huancayo, Perú. Actas del Congreso Peruano del Hombre y la Cultura Andina, Cusco.

FLORES ESPINOZA, I., 1960. Wichqana, sitio temprano en Ayacucho. En Antiguo Perú, espacio y tiempo, pp. 335-344. Editorial Mejía Baca, Lima.

FONSECA, C., 1976. Organización dual del sistema en las comunidades de Chaupiwaranga, Perú. Actas del XLI Congreso Internacional de Americanistas, vol. 3: 545-552. México D.F.

HARRISON, J. V., 1944. The geology of the Central Andes in part of the province of Junin, Perú. The Quarterly Journal of the Geological Society of London XCIX: 1-36. 
HOLDRIDGE, L. R., 1947. Determination of world plant formations from simple climatic data. Science 105: 367-368.

HURTADO DE MENDOZA, L., 1971. Industrias líticas del valle de Palcamayo. Actas y Memorias del XXXIX Congreso Internacional de Americanistas, vol. 3: 28-40. Lima.

1975 Ms. Report of the survey on Preceramic sites in the Cerro de Pasco-Junin region, Central Highlands of Perú. Department of Anthropology, Smithsonian Institution, Washington D.C.

-1976. Paleo-indian occupations at Junin, Perú. Actas y Memorias del XLI Congreso Internacional de Americanistas vol. 3, pp. 468-473. México D.F.

— 1977 Ms. Report of the second survey season on preceramic sites in the Cerro de Pasco-Junin región, Central Highlands of Perú. Department of Anthropology, Smithsonian Institution, Washington D.C.

1978 Ms. Excavations at Piedras Gordas, Perú. Progress Report of the 1978 Field Season in the Cerro de Pasco-Junín región. Department of Anthropology, Smithsonian Institution, Washington D.C.

— 1978a. Clasificación de sitios precerámicos en Junín y Cerro de Pasco. Actas del Primer Simposio Antropológico de la Sierra Central, Instituto Nacional de Cultura, Huancayo.

-1979. Puntas de proyectil en Piedras Gordas, Cerro de Pasco, Revista Ciencia Social 4.

-1979a. Inventario regional de sitios precerámicos en las punas de Huancayo. Informe final sobre el trabajo de campo y laboratorio realizado entre 1978 y 1979. Fundación Ford, Lima, e Instituto Nacional de Cultura. Lima.

HURTADODE MENDOZA, L. y C. CHAUD, 1978. Reconocimiento superficial y excavación en Piedras Gordas, Cerro de Pasco. Actas del Primer Simposio Antropológico de la Sierra Central, Instituto Nacional de Cultura, Huancayo.

IZUMI, S. y T. SONO, 1963. Andes 2: Excavations at Kotosh, Perú, 1960. Kadokawa Publishing Co., Tokio.

JENKS, W. F., 1961. Triassic to Tertiary stratigraphy near Cerro de Pasco, Perú. Bulletin of the Geological Society of America pp. 203-220.

LANDEO, L., 1979. Interacción económica regional en la comunidad de Santo Domingo de Cachi, Huancayo. Actas del $4^{\text {to }}$ Congreso Peruano del Hombre y la Cultura Andina, Cusco.

LAVALLEE, D. y M. JULIEN, 1975. El hábitat prehistórico en la zona de San Pedro de Cajas, Junín. Revista del Museo Nacional XLI: 81-119.

LYNCH, T., 1971. Preceramic transhumance in the Callejón de Huaylas, Perú. American Antiquity 36: 136-148.
MALAGA A., R. MATOS, J. WHEELER y E. PIRES FERREIRA, 1976. Sobre el laboratorio de paleoetnozoología. Programas Académicos de Arqueología y Medicina Veterinaria, Universidad de San Marcos, Lima.

MATOS, R., 1970 Ms. Datos para el estudio de la población lítica en las punas de Junín, Perú. Programa Académico de Antropología, Universidad Nacional del Centro, Huancayo.

-1972. Ataura: Un centro Chavín en el valle del Mantaro. Revista del Museo Nacional XXXVIII: 93:108.

- 1976. Estudios arqueológicos en Junín, Perú. Actas del XLI Congreso Internacional de Americanistas, vol. 3, pp. 553563. México D.F.

MAYER, E., 1971. Un carnero por un saco de papas: Aspectos del trueque en la zona de Chaupiwaranga, Pasco. Actas y Memorias del XXXIX Congreso Internacional de Americanistas, vol. 3 , pp. 184-196.

MCLAUGHLIN, D. H., 1924. Geology and physiography of the Peruvian Cordillera, Department of Junin and Lima. Bulletin of the Geological Society of America 35: 591-632.

MCNEISH, R. S., 1969. First Annual Report of the Ayacucho Archaeological-Botanical Project. Phillips Academy, Andover.

-1971. Early Man in the Andes. Scientific American 224: $34-46$

MCNEISH, R. S., A. NELKEN-TERNER y A. GARCIA COOK, 1970. Second Annual Report of the Ayacucho ArchaeologicalBotanical Project. Robert S., Peabody Foundation for Archaeology, Phillips Academy, Andover.

MEGARD, F., 1968. Geología del cuadrángulo de Huancayo. Servicio de Geología y Minería, Boletín 18.

MERCER, J. H., 1970. Variations of some Patagonian glaciers since the Late Glacial: II. American Journal of Science 269.

MURRA, J., 1972. El “control vertical” de un máximo de pisos ecológicos en la economía de las sociedades andinas. En Visita de la Provincia de León de Huánuco en 1562, Iñigo Ortiz de Zúñiga, pp. 427-476. Universidad Nacional Hermilio Valdizán, Huanuco.

RICK, J., 1976. Downslope movement and archaeological intrasite spatial analysis. American Antiquity 41: 133-148.

1977 Ms. Sedentary prehistoric hunters of the Peruvian Altiplano. Museum ot Anthropology, University of Michigan.

-1977a. Identifying prehistoric sedentism in hunter-gatherers: An example from Highland Peru. $76^{\text {th }}$. Annual Meetings of the American Anthropological Association, Houston.

RIOS S., 1978. Informe sobre el progreso del trabajo de campo en Piedras Gordas, Cerro de Pasco. Actas del Primer Simposio Antropológico de la Sierra Central. Instituto Nacional de Cultura, Huancayo. 
SZEKELY, T. S., L. T. GROSE, 1972. Stratigraphy of the carbonate, black shale, and phosphate of the Pucara Group (Upper Triassic-Lower Jurassic), Central Andes, Perú. Geological Society of America Bulletin 83: 407-428.

TOSI, J. A., 1960. Zonas de vida natural en el Perú. Instituto Interamericano de Ciencias Agrícolas de la OEA, Zona Andina, Proyecto 39, Programa de Cooperación Técnica. Boletín Técnico 5.

WHEELER, J., 1975. La fauna de Cuchimachay, Acomachay A., Acomachay B., Telarmachay y Utco I. Revista del Museo Nacional XLI: 120-127.

WHEELER, J., E. PIRES-FERREIRA, y P. KAULICKE, 1971. Preceramic animal utilization in the Central Peruvian Andes. Science 194: 483-490.
WIESSNER, 1979. Reply to Casteel (on a functional estimator of population from floor area). American Antiquity 44: 808-809.

WING, E., 1975. Informe preliminar acerca de los restos de fauna de la cueva de Pachamachay, en Junín, Perú, Revista del Museo Naciona XLI: 79-80.

-1977. Caza y pastoreo tradicionales en los Andes peruanos. En Pastores de Puna, J. Flores Ochoa (Ed.), pp. 121-130. Instituto de Estudios Peruanos, Lima.

WRIGHT, H. E. y P. J. BRADBURY, 1975. Historia ambiental del Cuaternario Tardío en el área de la planicie de Junín, Perú. Revista del Museo Nacional XLI: 75-76.

YELLEN, J. 1977. Archaeological approaches to the present. Academic Press, Nueva York. 
